\title{
Healing and wellness and the role of community colleges: A formative program evaluation
}

\author{
By Mary Wabano
}

A thesis submitted to the Faculty of Graduate and Postdoctoral Affairs in partial fulfillment of the requirements for the degree of

\author{
Master of Social Work \\ Degree \\ in Master of Social Work \\ Degree Program
}

Carleton University

Ottawa, Ontario

\author{
(C) 2014 \\ Mary Wabano
}




\begin{abstract}
:
Indigenous post-secondary college programs are relatively new in Ontario. A search for Indigenous specific programs on the Ontario Colleges website produced 39 Aboriginal or Indigenous specific programs (Colleges Ontario, 2013). Many of the programs describe Indigenous pedagogical approaches rooted within Indigenous epistemology as core to the design of the program. The Indigenous Wellness and Addictions Prevention program at Canadore College is one such program.

This formative program evaluation will discuss program strengths and weaknesses as it prepares graduates to work with Aboriginal populations in addictions treatment and prevention from an Indigenous healing and wellness paradigm. The purpose of this research is to evaluate how a community college can best situate an Indigenous college program within its academic framework without compromising both its academic integrity and its Indigenous foundation. The Indigenous Wellness and Addictions Prevention program is a two year college diploma program that grew out of a native drug and alcohol counsellor program.
\end{abstract}




\section{Acknowledgements:}

I would like to acknowledge the students and graduates of this program who participated in one of two sharing circles I hosted as part of this formative program evaluation. Their active participation in the circles and willingness to share their experiences in a good way helped shape this research. The key participants with their insight into the broader policy discussion and intimate knowledge of the program, its challenges and opportunities for improvement became the skeletal framework as the research unfolded. Miigwetch to the elders and traditional knowledge keepers who continue to challenge us to think outside of the familiar, encouraging us to look at programming from a different place. I also want to acknowledge Canadore College, its faculty, staff, students and leadership for providing this opportunity to critically review this program and to envision a learning environment that is not only respectful of Indigenous ways of knowing but have made great attempts at ensuring that Indigenous Knowledge systems have a meaningful place within an evolving academic landscape.

Gitchie Miigwetch to my Professors Dr. Allan Moscovitch PhD, my thesis supervisor, and Dr. Adje Van de Sande PhD of Carleton University's School of Social Work, who have both encouraged me to complete my degree requirements. Thank you for your guidance and your persistent checking in with me; Dr. Joyce Helmer who so graciously accepted the task of third and external reader; and finally, Miigwetch to my family who have encouraged me to continue on this learning journey, to my daughters Naawgiizigo-kwe and Waasayaabino-kwe, my inspiration and my hope for a better future for all Anishinabeg, for my nistess Brucie-buhn ${ }^{l}$ who never doubted me, to my parents and grandparents - my inspiration, my role models. Miigwetch.

\footnotetext{
${ }^{1}$ The suffix -buhn acknowledges the passing from the physical to the spiritual world
} 


\section{Table of Contents}

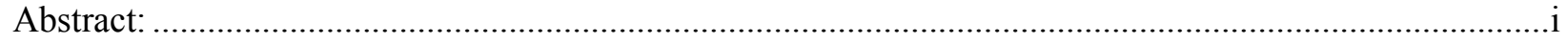

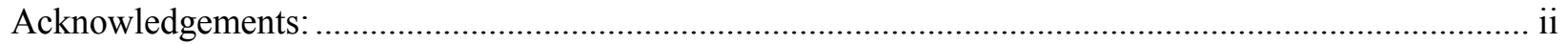

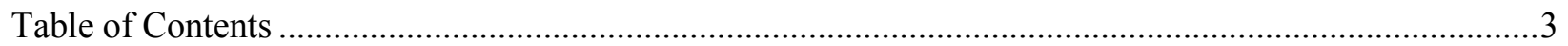

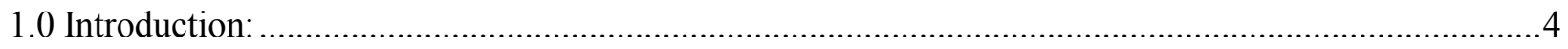

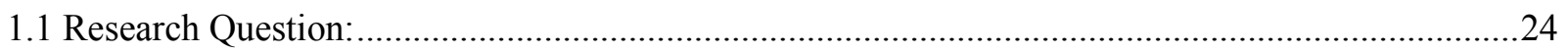

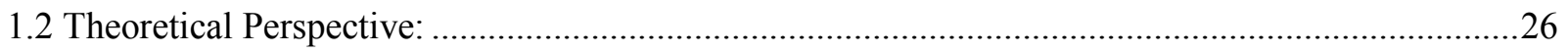

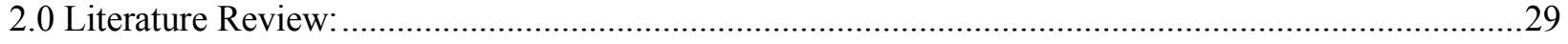

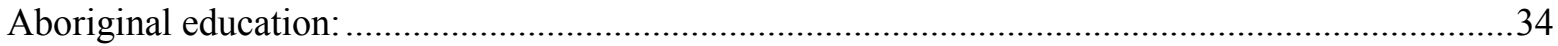

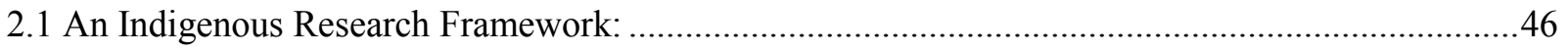

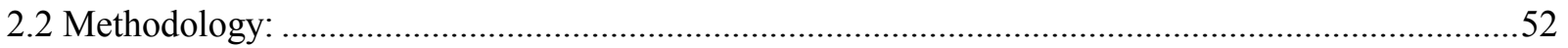

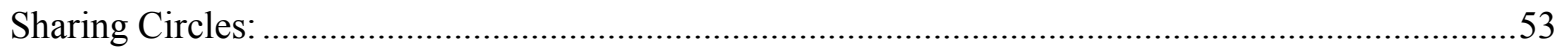

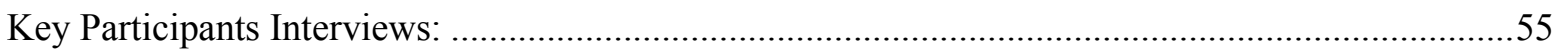

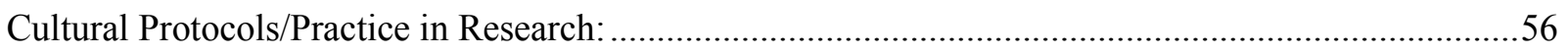

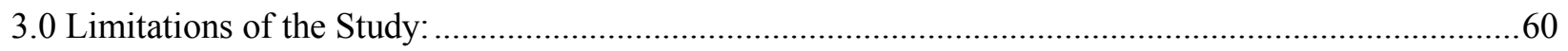

4.0 The Sharing Circles and the Key Participants Interviews ...............................................................61

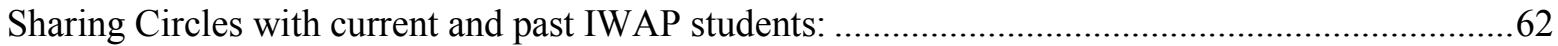

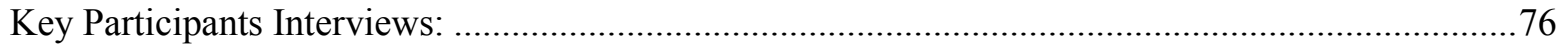

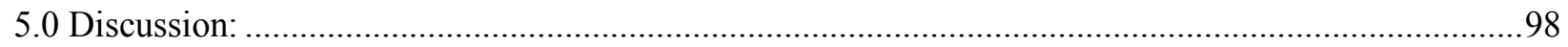

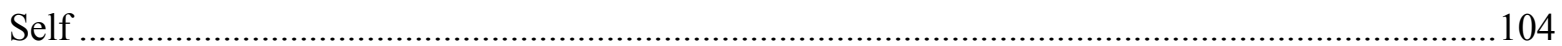

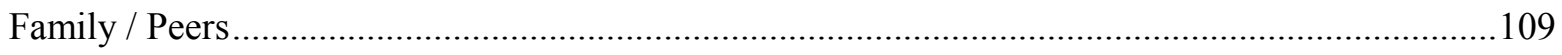

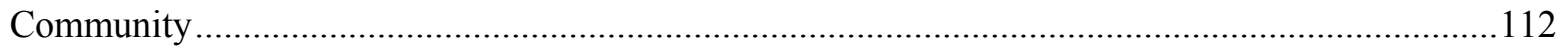

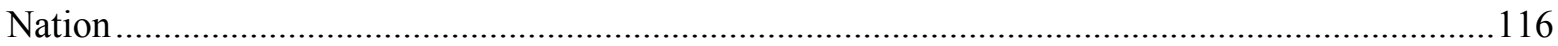

6.0 Conclusion:

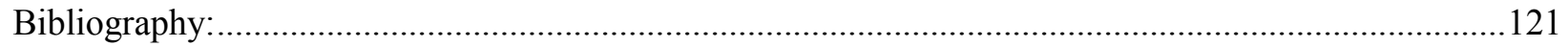

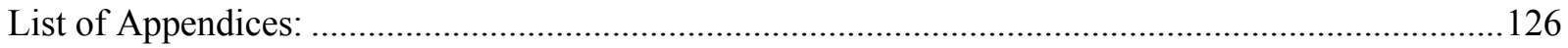

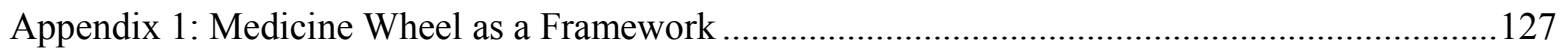

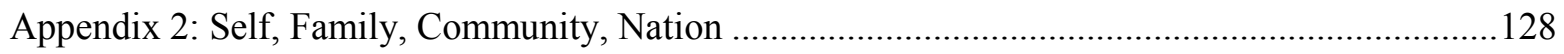

Appendix 3: Salient Themes on Medicine Wheel ........................................................................129

Appendix 4: Interview Protocol for Sharing Circle Past and Current IWAP Students ....................130

Appendix 5: Interview Protocol for Key Participants Interview ...................................................131

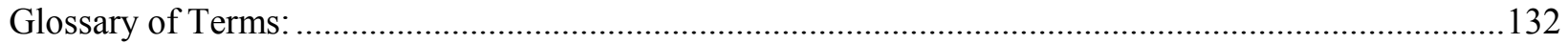




\subsection{Introduction:}

Canadore College is located in north eastern Ontario and hosts approximately 400 Aboriginal learners each year. The college sits on the traditional territory of the Nipissing Ojibwa. Canadore prides itself on the relationships it has established over the years with various First Nation and Aboriginal communities and its ability to respond to the education and training needs of its partners. Aboriginal programming has been developed and delivered by Canadore in a variety of areas including skills training such as carpentry, construction, and culinary training. In 1991, Canadore established a Native Drug and Alcohol Counsellor Certificate program in response to a request by Nipissing First Nation. The initial certificate program was delivered over forty weeks and was the only Native ${ }^{2}$ specific drug and alcohol counsellor program in Ontario. The unique culturally relevant program had two specific areas of focus: 1) Native culture and 2) substance abuse (Canadore College, 1999). The program outcomes were heavily influenced by a revitalization of positive self-identity in the First Nations community and a resurgence of traditional practices. The certificate program ran for eight years with a new cohort of students each fall.

In 1999, a program review recommended that the certificate program pursue an Ontario College diploma designation. The Indigenous Wellness and Addictions Prevention (IWAP) diploma program was approved by the Ministry of Training, Colleges and Universities that subsequent year. The IWAP program built on the former certificate and was delivered over four semesters. The curriculum was based in Anishinabe $e^{3}$ healing and wellness practices. Scheduled courses introduced learners to various traditional lodges such as sweat lodge, teaching lodge, women's lodge and various ceremonies including the use of traditional Anishinabe medicines. For many learners, this was their first experience with

\footnotetext{
${ }^{2}$ The term Native with a capital refers to the original inhabitants, and is used interchangeably throughout this document with Aboriginal, Indigenous, First Peoples', and Anishinabe

${ }^{3}$ Anishinabe is an Ojibwe translation to refer to the original people of the Americas otherwise known as Turtle Island.
} 
Anishinabe spirituality. The program focused heavily on applying traditional healing practices within their personal development to prepare graduates for work as addictions counsellors. The first year of the IWAP program was delivered in isolation from other programs and two faculty teaching positions taught in the program.

At the completion of year one, students had the option of exiting with a one year college certificate or continuing on to complete a two year diploma. The second year of the program "laddered into the first year of the Social Service Worker and Mental Health and Addictions Worker programs" (Canadore College, 2001, p. 1). In effect, students who had already completed a one year college level certificate moved into the first year of diploma program (the Social Service Worker and Mental Health Worker programs) in the second year of the IWAP program. The program remained unchanged for several years.

In 2010, the Aboriginal student services lead a review of Aboriginal student completion rates across academic schools. The review identified spikes in attrition of those students entering into the second year of the IWAP program. The review, as reported by Wabano (2012), identified several key findings:

The first year of the IWAP program was heavily focused on cultural helping methodologies and the learning environment was often land based. Oral instruction was the primary mode of delivery; Indigenous language was encouraged as students participated in experiential learning. There was a stark imbalance in the program competencies that had a heavy focus on Indigenous healing and wellness practices and was seen by the college faculty to lack the academic rigour of an addictions college level diploma program and students were not successful in the transition to the second year of the program as a result. (Wabano, 2012, p. 5)

A Program Advisory Committee (PAC) was established to review and make recommendations to the college to revitalize the IWAP program. Under the Ministry of Training, Colleges and Universities (MTCU) Binding Policy Directive, Program Advisory Committees are "established for each program of instruction or cluster of related programs offered at the college and are made up of a cross-section of 
persons external to the college who have a direct interest in and a diversity of experience and expertise related to the particular occupational area addressed by the program" (Ministry of Training, Colleges and Universities, 2010, p. 3). The PAC was made up of representatives from various Aboriginal organizations in the Nipissing/Parry Sound region that worked in the field of addictions and also included long standing members of the original IWAP PAC. All PAC members had an affiliation to addictions work from policy, counselling, intake, recovery, to prevention. Some were consumers from various Aboriginal communities.

The committee oversaw the development of the revitalization and program review over ten months. At the commencement of the 2012 program review (Wabano 2010), the PAC had made several recommendations including:

exit and dual diploma options be maintained; graduates be prepared to work in both Indigenous and mainstream populations dealing with concurrent disorders, prescription drugs and alcohol abuse; that a heavy emphasis on prevention planning along with community development be included in the program; that the program maintain its Anishinabe foundations with experiential and land based learning while ensuring the program was academically sound, meeting all accreditation standards. The Program Advisory Committee recommended that Indigenous faculty be recruited and hired to deliver the unique Anishinabe based curriculum. (Wabano, 2010, p. 9)

The new program incorporated each of the recommendations into the new program over four semesters.

\begin{tabular}{|c|c|c|}
\hline IWAP CERTIFICATE & IWAP DIPLOMA & MHAW DUAL DIPLOMA OPTION \\
\hline SEMESTER ONE & SEMIESTER THREE & SEMESTER FIVE \\
\hline TRADITIONAL HEALING, LEARNING AND TEACHING & INTERPROFESSIONAL EDUCATION \& PLACEMENT PREP & GROWTH AND DEVELOPMENT \\
\hline INTRODUCTION TO SUBSTANCE ABUSE COUNSELLING & GROUP WORK & FOUNDATIONS OF SOCIOLOGY \\
\hline $\begin{array}{l}\text { CONTEMPORARY CHALLENGES FACING ABORIGINAL } \\
\text { COMMUNITIES }\end{array}$ & PHARMACOLOGY FOR MH\&AW & GENERAL EDUCATION ELECTIVE \\
\hline COLLEGE COMMUNICATIONS I & METHODS II - RECOVERY STRATEGIES & \\
\hline INTRODUCTION TO CULTURE SPECIFIC HELPING & THE ACCOUNTABLE IWAPW & \\
\hline HISTORY AND PHILOSOPHY OF SW & EVALUATING INFORMATION & \\
\hline SEMESTER TWO & SEMESTER FOUR & SEMESTER SIX \\
\hline COLLEGE COMMUNICATIONS \| & METHODS III - RELAPSE PREVENTION & HUMAN SERVICE AND THE LAW \\
\hline CULTURAL SAFETY & THE LEGACY OF TRAUMA & MENTAL HEALTH ACROSS THE LIFESPAN \\
\hline $\begin{array}{l}\text { SUBSTANCE ABUSE IN NATIVE FAMILIES AND } \\
\text { COMMUNITIES }\end{array}$ & CONCURRENT DISORDERS & RELAPSE PREVENTION AND WELLNESS \\
\hline $\begin{array}{l}\text { METHODS - USING TRADITIONAL HEALING TO BREAK } \\
\text { THE CYCLE OF ABUSE }\end{array}$ & FIELD PLACEMENT ( 8 WK BLOCK) & COGNITIVE BEHAVIOR THERAPY \\
\hline INTRODUCTION TO COMMUNITY DEVELOPMENT & & \\
\hline FIELD PLACEMENT FOR IWAP ( 2 WEEK BLOCK) & & \\
\hline
\end{tabular}


The program course curriculum over four semesters is as follows:

\section{Semester 1}

Traditional Healing, Learning, Teaching: Students will begin to explore the importance of traditional medicine, the teaching circle, and the medicine wheel to personal growth, development, and healing and their value emphasized. Elements of traditional healing will be presented, discussed, and demonstrated. Group dynamics and group processes will be introduced through both a theoretical and experiential examination of topics such as leadership, conflict resolution, diversity, member roles and decision making. Learners will develop skills and knowledge to work effectively and co-operatively in group settings.

Introduction To Substance Abuse Counselling: Students will be introduced to the principles, methods and purposes of intentional interviewing as applied to human service counselling. Indigenous models of understanding the Healing Journey will be introduced and discussed as it relates to addictions counselling. Students will develop skills in assessment and referral and the role that administrative procedures have in the operation of various agencies. As part of this course, students will be introduced to the communication skills needed for accurate and comprehensive report writing.

Contemporary Challenges Facing Aboriginal Communities: Canada is a country of many Native and non-Native cultures. Comparative studies of these cultures will be conducted in order to create a deeper understanding of similarities and differences. Students will explore the varied belief systems, worldviews, values, and lifestyles of the main culture groups. As part of building an understanding the inter-relationship among different sectors of society, students will examine the influence that living in remote areas of Canada has on individuals, families, and communities. Students will explore the community dynamics, structure, and history and will examine contemporary issues influencing these communities and people, in particular, the causes of and the social problems that alcohol and drug abuse play in these communities. Solutions to social problems will be explored.

Introduction To Cultural Specific Helping: This course involves the students in first-hand experiences in preparing and participating in various cultural activities. Students will gain awareness and appreciation of the meaning and role of specific ceremonies, in particular the sweat lodge and the pipe ceremonies.

College Communications: This first-level post-secondary course will help students in all programs develop their ability to communicate effectively. The course requires students to meet first-year benchmarks for generic skills in researching, organizing, reframing, analyzing, and presenting information.

History And Philosophy Of Social Work: This course will provide students with an overview of the responses that the social work profession has made to various social and psychological problems. Emphasis will be placed on Canadian experiences with social policy regarding poverty, working conditions, Native issues, housing, and law and order. The role of the social service worker will be examined in terms of present issues and practices.

Cultural Safety For Health And Human Services: This experiential learning course is designed to help learners reflect on Aboriginal peoples' experiences of colonization and racism as these relate to health 
and human service care. Students will explore the concept of cultural safety as it relates to their practice. Students will be introduced to the livelihood of Canada's Aboriginal peoples in pre-contact history and discuss the effects on overall health and wellbeing in a contemporary paradigm. As practitioners in health and human care, students will learn to locate themselves in power imbalances that occur in practice and daily living.

\section{Semester 2}

Substance Abuse In Native Families And Communities: The experience of substance abuse in Native communities, including its historical causes and the social, economic and political forces that keep it alive is unique. Students begin to discuss common types of drugs and their effects on the users. Trends of abuse will be explored and reasons as to why people turn to substance abuse will be examined. Students will learn how substance abuse is a social issue and how it is connected to problems such as crime, violence, and other dysfunctional behaviours. For many individuals, the substance abuse occurs along with a mental health diagnosis. This concept of concurrent diagnoses will be discussed and students will learn how to deal with cases of dual diagnosis in a positive and professional manner. The course will emphasize the importance of collaboration and cooperation between healthcare and human service professionals when working with individuals who have dual diagnosis.

Methods-Using Traditional Healing To Break The Cycle Of Abuse: Students will examine codependency and will examine traditional methods of healing. Gender roles and addictions will be explored as learners analyze distinct patterns in gender and the impact on individuals and their families. This course will review the four stages model of addictions treatment and recovery as learners will develop skills and knowledge in Indigenous approaches in assessment, treatment approaches and partial recovery.

Introduction To Community Development: This course introduces basic concepts and theories of community development, including using an interdisciplinary, holistic approach. Students will be introduced to proposal writing and introductory community assessment as part of this course.

College Communications II: In this course, learners will apply the model of effective communication developed in earlier communications courses, will demonstrate the basics of informal report writing, and will focus on the organization of routine, informal situations so that they can communicate effectively in a vocational setting.

Field Placement: Students are given the opportunity for first-hand experience in a work environment. Field placements allow students to practice the skills learned in the classroom setting. Students have the opportunity to explore various employment options and to gain awareness on expectations and procedures in the workplace.

Methods II - Recovery Strategies: Relapse is a process, it's not an event. This course will introduce students to the stages of relapse. Relapse starts weeks or even months before physical relapse. Students will identify stages of relapse, behaviours and learn how to apply specific relapse prevention techniques within a helping relationship for each stage of relapse. 


\section{Semester 3}

The Accountable Indigenous Wellness And Addictions Prevention Worker: Students will discuss counselor behaviours and attitudes which promote recovery in the client. Included is the awareness of the legal aspects of clients' rights and allowing the student to wrestle with difficult questions of professional relationships.

Evaluating Information: This course will enable students to understand and appreciate the relevance of research findings to their daily work with clients. Students will learn to participate in evaluation of research findings in the field of human services.

Pharmacology For Mental Health And Addictions Workers: This course outlines some basic principles of pharmacology, including specific discussions of drugs and their origins according to classifications, mechanisms of drug action, pharmacokinetics, and toxicology. As well this course presents the various categories of drugs used to treat mental illness.

Group Work: An introduction to the dynamics and skills needed to work with different types of groups. Leadership responsibilities, group preparation, group development, and awareness of self as member / leader will be considered. As well, students will have an opportunity to design a group project and participate in various group exercises.

Inter-professional Education \& Placement Preparation: This course is an extension of HSP194/IWA 206 and continues to provide students with the opportunity to become familiar with the various human service agencies within the community. It provides the knowledge and skills required to secure and successfully complete a 12-week field placement. By exploring the relationship between human service agencies and the community, this course also prepares students for front-line positions in the field of human services.

\section{Semester 4}

Methods III - Relapse Prevention Programming: On the road to recovery and wellness, relapse prevention programming is an essential component on the continuum of wellness. Students will apply the principles of relapse prevention within a case study. Students will develop prevention programs designed to promote self-efficacy among their clients such as social skills, problem solving, conflict resolution, parenting, use of leisure time, feeding their spirit and acquiring self-management skills.

Field Placement ( 8 Week Block): This course gives the student an opportunity to practice the skills, knowledge and attitudes required to be an effective mental health and addiction worker by participating in an eight week block placement in a mental health and/or addiction services agency. The application of classroom theory in an agency setting provides the student with an experiential learning opportunity in preparation for the workplace.

The Legacy Of Trauma: This course presents a conceptual framework for understanding the experience of trauma and provides the student with the basic components of first stage trauma treatment as well as outlining specific tools and strategies used in treatment intervention. The role of gender and its connection to mental health issues provides a context to understand trauma and its impact. 
Concurrent Disorders: This course will assist in the development of diagnostic skills and language to support the treatment of concurrent disorders in treatment planning and aftercare support and referral. This course will assist in recognizing and addressing other signs and symptoms of addictive disorders with coexisting psychiatric disorder.

Nine program competencies were developed in collaboration with the program advisory committee:

1. Identify and demonstrate the use of various assessment techniques as it pertains to addictions counselling to identify client issues and needs in a helping relationship, including physiological and psychological effects on the human body and wellness.

2. Explain the effects chemical and alcohol dependence have on wellness (physical, emotional, mental and spiritual).

3. Examines and applies relevant addictions helping intervention strategies and techniques suitable for working with Native individuals, families and groups within a wellness paradigm including treatment planning, crises intervention and prevention services.

4. Apply effective written and oral communication skills in addictions counselling to communicate with clients, prepare reports, read and interpret public information documents, legislation or records as an integral part of the helping process.

5. Demonstrate professional ethics and integrity and the appropriate use of inter-professional education skills.

6. Apply basic principles, concepts and skills of group work and discusses considerations for group work within a First Nations context.

7. Demonstrate the appropriate use of traditional Native helping practices and culturally appropriate service approaches.

8. Analyze historical and post-colonial policies and their impacts on First Nations people in Canada.

9. Discusses addiction theory and conceptions and demonstrates practical application of theory in the helping process; analyzes implications within a Canadian First Nations context, including considerations for holistic community development models for social change. (Canadore College, 2012)

The program is delivered at Canadore College, full time and on campus. The program "provides

[learners] with the skills and knowledge need[ed] for employment in a variety of Indigenous settings.

This curriculum is based upon the teachings of the Medicine Wheel. Traditional teachings are intended

to guide [learners] through the physical, mental, social, cultural and spiritual elements of addiction as

they learn vital assessment, intervention and recovery techniques for individuals, families, and groups.

Traditional methods of healing include Sacred Circles, Teaching/Learning Circles, and the use of the

four sacred medicines - tobacco, cedar, sage and sweet grass. Graduates of the IWAP program are

eligible to become accredited Wellness and Addictions counsellors through the First Nations Wellness 
\& Addictions Counsellor Certification Board" (Canadore Colege, 2014, para. 1). As an Ontario College diploma, the course curriculum is delivered in 1328 instructional hours over four semesters. The first semester of the program has a total of 6 courses delivered over 294 hours. The second semester has 5 courses delivered over 342 hours. The third semester includes 5 courses over 308 hours. The final semester has 3 courses and includes an 8 week block field placement and a total of 384 hours. Scheduling software develops the program's class schedule along with the colleges other $60+$ programs. Classrooms are assigned by pre-determined constraints identified by faculty/Dean. Constraints may include whether or not the class requires technology, basic blackboard, whiteboard, lab, etc.

The majority of the IWA specific courses are constrained to a specific classroom equipped with a small exhaust fan that enables the use of smudge and is considered an electronic classroom. This room is the only room on the college campus that is equipped with an exhaust fan for smudging purposes. The IWA courses are core curriculum for the Indigenous Wellness and Addictions Prevention program. They are courses that are rooted in Anishinabe ontology and/or employ a bi-cultural epistemological approach. The courses include such titles as Traditional Healing, Learning, and Teaching, Introduction to Substance Abuse Counselling, Contemporary Challenges Facing Native Communities, Introduction to Culture Specific Helping, Substance in Native Families, Community Development, Evaluating Information, ethics and three methods courses that build on each other in Anishinabe approaches to addictions prevention, treatment and post-treatment. A designated classroom and tipi that sits adjacent to the college complex provides the learning and cultural spaces for the program and its Indigenous based courses.

Following the approval of the new IWAP modification in 2011, the College made an application to the First Nations Wellness and Addictions Counsellors Certification Board (FNWACCB) for accreditation of the IWAP program. This application was successful and the IWAP program received 
accreditation from FNWACCB in the spring of 2012. The new curriculum was subsequently launched in that same year. The First Nations Wellness/Addictions Counsellors Certification Board (2014) purports that it "represents a major historical turning point in establishing the official recognition of the special qualifications needed to work as an Addictions/wellness practitioner in Aboriginal communities" (FNWACCB, 2014, para. 4). At present, the IWAP program is the only Ontario College diploma program that has received accreditation from a professional body within the School of Human Services at Canadore College. The Indigenous Certified Addictions Worker is an entry level certification.

The college applied to the FNWACCB for recognition of the IWAP program based on the new curriculum that included a balance of both mainstream and Anishinabe based specific courses. Many of the Anishinabe based courses were modified to accommodate the introduction of new mainstream courses. The overall program hours remained within the Ministry's Ontario College diploma guidelines. The program advisory that oversaw the program modification had concerns about the program compromising its Anishinabe based learning. This formative program evaluation aims to address these concerns and to provide recommendations as to how to best maintain the program's unique vitality.

Ontario colleges are mandated by the Minister's Binding Policy directive to conduct systematic program reviews every five years. "Program Review is a means for an institution to ensure that programs being delivered are of high quality, relevant and current" (Canadore College, 2014). Currency and relevancy are measured against the needs of industry leading graduates to employment. The general systematic review involves program faculty, feedback from students, enrolment reports and projections, mapping evaluation strategies to learning outcomes, program costing relating to space, resources, delivery and includes a review of the programs specific data stemming from provincial Key Performance Indicators (KPI). 
"Key Performance Indicators (KPI) is a province-wide accountability tool to measure how well Ontario colleges meet the needs of students and the marketplace. KPI's are conducted annually by an independent body on behalf of the Ontario Ministry of Training, Colleges and Universities and the colleges' umbrella group, Colleges Ontario” (Colleges Ontario, 2013). KPI's determine the rates and levels of satisfaction among students, graduates, and employers of graduates through extensive surveying in the following five areas: graduate job placement, graduate satisfaction, employer satisfaction, student satisfaction, and graduation rates. "Demands for accountability, especially those directed toward publicly funded community colleges, suggest that program evaluation should be a routine activity of institutions" (Weissman, Bulakowski, \& Jumisko, 1997, p. 74). Institutions offering Indigenous based programs have an added accountability to Indigenous communities to ensure that Indigenous based programs are quality programs responsive to not only industry but are responsive to the unique needs of the Indigenous community. The current systematic review fails to investigate the extent or quality to which the program stands up to its claimed Indigenous based epistemology.

This formative evaluation of the IWAP program seeks to further the systematic review by discussing and analyzing how the program is both academically sound and maintaining its Anishinabe foundation; and how community colleges can better support Indigenous based programs in an evolving academic landscape.

\section{Indigenous Post-Secondary Programs in Ontario:}

Indigenous post-secondary college programs are relatively new in Ontario. "The Ontario public postsecondary system consists of 24 colleges ( 21 colleges of applied arts and technology and 3 college institutes of technology and advanced learning) and 19 universities. There are 2 colleges and 9 universities that offer programming in French or in both French and English...the colleges and university sectors in Ontario are quite distinct from one another" (Oldford \& Ungerleider, 2010, p. 20). 
A search for Indigenous specific programs on the Ontario Colleges (2013) website produced 39 Aboriginal or Indigenous specific programs. Many of the programs are described as being based in Indigenous understanding or world view and offer Indigenous based learning. The Indigenous Wellness and Addictions Prevention program at Canadore College is one such program.

In Anishinabe society, the transmission of knowledge occurs through relationships with all things. Traditional teaching practices within an Indigenous pedagogy are rooted in the oral transmission of knowledge and are relational. A universal and fundamental belief among Indigenous peoples is that we are all of Spirit and have within us individual gifts, one of which is free will. "Individualism is quite different from the mainstream concept of individualism, which focuses only on the self without much attention to others" (Hart M. A., 2014, p. 75). In Anishinabe ontology individuals are taught from the time they are born that mino-bmaadziwin (a good life) is a result of maintaining a healthy balance in life and in all relationships. Moreover, that family and community interdependence is the essence of life. The practice of non-interference is highly regarded and children are encouraged to explore their worlds as they seek out their life's ambitions.

Although the imposition of western systems has influenced how Anishinabe children are raised in contemporary society, these tenets remain very strong. In mainstream education systems, Anishinabe children are taught to conform to a Euro-western world view and are rewarded or punished accordingly. Lambe (2003) describes the contrast to mainstream pedagogy in education. "The structures of institutions of mainstream education in North America, whose influences extends into the academy, were designed to engender wide scale homogenization in an efficient and cost effective manner" (Lambe, 2003, p. 311). Homogenization of individual learning poses interesting challenges for institutions and faculty delivering programs rooted in Indigenous epistemology - if the goal is to maintain Indigenous foundations. 
Indigenous education and Western based education are very different. How Anishinabe finds his/her life vocation traditionally began to unfold with the giving of his/her Spirit name, his/her clan and within his/her family lineage. In today's world, many Anishinabe people will seek out and find their names and clan later in life due largely to the loss of practice in many Anishinabe communities as a result of oppressive forces such as the Indian Act, residential schools, forced religion, etc. However, a growing literature supports the critical need for learners to be prepared to work from multiple paradigms in the field of addictions and wellness (Anuik \& Gillies, 2012; Bojuwoye \& Sodi, 2010; Hart M. A., 2014; Wardman, 2014). The intent of this formative program evaluation is to add to the literature with respect to Indigenous based academic programs within Ontario colleges; and to discuss the challenges of hosting Indigenous programs within Western based institutions of higher learning.

Since the earliest contact with the settler society, Indigenous people have had adverse experience with mind altering substances; the impact of colonization has been the cause of social and family breakdown. The overwhelming sense of hopelessness is disempowering. As a member of my Anishinabe community, my family and indeed as an Indigenous person working within the Ontario community college system, I maintain a sense of hope that perhaps this research will influence how institutions understand Indigenous based programs. I have worked in the field of Indigenous education as an administrator, student counsellor, researcher and facilitator. Over the course of my interactions with Aboriginal post-secondary programs, I have come to realize that the majority of these programs have absolutely nothing to do with Aboriginal knowledge, understanding or empowerment. In fact, the only things Aboriginal about many Aboriginal post-secondary programs are the students sitting in the seats of these programs. Moreover, the curriculum and content found in many Aboriginal programs have been designed by non-Aboriginal educators who presume to have expert knowledge about what it is Aboriginal learners need to know. Additionally, colleges build support services that are reflective of the 
same ignorance. That is very concerning for a variety of reasons. It is my personal belief that education is a tool. When used properly, education has the ability to transform individuals, who in turn, transform systems. Indigenous programs have a place in the milieu of higher education. When given the proper supports, culturally based programs of instruction are transformative.

In the context of preparing graduates for work in mental health and addictions with Indigenous populations, the role of community colleges and their programs extends far beyond being responsive to industry needs. Indigenous communities have rich and diverse cultures and history continues to influence community wellness. Work within this paradigm is complex and requires educational programs that are balanced in both mainstream and Indigenous approaches to best prepare graduates for such work. I am able to conclude such thoughts because I have been directly impacted by all these factors in a very intimate way. I struggle with mainstream approaches to dealing with addictions, knowing full well that these approaches alone will not have an impact on my people. In a small way, I hope that my research will have a positive impact on the way individuals are trained to work with my people, from a place of understanding, respect and more importantly kindness.

\section{The Thesis:}

This thesis is presented over 6 chapters. By way of introduction, the first chapter introduces the IWAP program and presents the theoretical underpinnings of my research. Academic rigour and key considerations with respect to Indigenous programs are also presented.

The literature review in Chapter 2, discusses the history of colonization, and its continued impact on post-secondary education with respect to Aboriginal peoples, communities, programs and services. "Aboriginal people recognized long ago the need for fundamental changes to social work practices within Aboriginal cultures and have been calling for these changes for many years" (Hart M. A., 2002, p. 11). The literature review discusses how social work and schools of human services continue to 
uphold colonization through the very theories and practices they teach. These tenets are presented and discussed in light of the purpose of the program which is to prepare its graduates to work in the field of addictions treatment and prevention from an Indigenous healing and wellness paradigm. The literature discusses the critical need for emancipation from colonization and its structures for Indigenous people to move toward healing and wellness in Indigenous communities.

Education is also discussed in the Literature Review. It discusses how historically education was a means in which Indigenous people were stripped of their culture, identity, language and were subjected to gross acts of genocide. It presents a narrative from an Indigenous perspective how education can be a vehicle to transform individuals, communities and systems to support healing at micro, mezzo and macro scales.

The methodology section presents key elements of Indigenous research frameworks that center this qualitative research. Fundamental to the research design is the empowering effect IK frameworks has, not only on the research subject matter but on all those involved in the research process. This qualitative study engages current and past students and graduates in a sharing circle ceremony to share their individual experiences within the program. Additionally, key participant interviews with program advisory members, faculty, college administration and knowledge keepers balance the collection of intimate knowledge of the program as this research seeks to uncover how the Indigenous Wellness and Addictions Prevention program can ensure academic rigour while maintaining its Indigenous epistemological foundation. The methodology section describes the use of traditional medicines in the engagement of research participants as an important step in the research process.

These notions are further discussed as I present the findings of this research and respond to the research question. In the discussion chapter, structural supports, curricular content, policy and resources required to address the multi-dimensions identified by the research is presented from four major 
thematic levels. The final chapter presents considerations for future research with respect to Indigenous based post-secondary education programs as vehicles to transport individuals to deliver on the values, principles and goals of reconciliation.

The discourse on academic rigour within education systems is not new. In an age of new technologies that influence and transform business processes in a global economy, academic rigour has become a topic of much debate.

\section{What is academic rigour?}

Academic rigour is often regulated to quantifiable measures of success, including student grades, graduation and completion rates to the amount of homework assigned to students. For many, the term rigour assumes that the delivery of education must be daunting for both master and student and perhaps for many it is exactly that. According to the Glossary of Education Reform, rigour is a term that is widely used to describe "instruction, schoolwork, learning experiences, and educational expectations that are academically, intellectually, and personally challenging” (Great Schools Partnership, 2014). Blackburn and Williamson (2013) describes aspects of instructional rigour as having "high expectations, support and student learning, all supported by the climate of the school and classroom" (Blackburn \& Williamson, 2013, p. 9). Canadore College's Skilled Solution speaks to a safe learning environment for all its students and staff. The college's website also provides information on its various academic policies including the policy with respect to program review. Canadore (2014) reports that the program review applies to all programs of instruction, are directed to be carried out every five years regularly, the college commits to supporting an ongoing quality assurance and improvement process and builds on the annual curriculum review. This includes mapping program competencies to specific learning competencies to individual college courses (Canadore College, 2014). 
The Dean responsible for the program executes the review in accordance with the policy. The policy describes this process as collaborative involving professors, program support staff and the Dean. Detailed processes are provided in a program review handbook. An impartial program body audits the final program review report to ensure that all requirements of the process are completed and validity of the report (Canadore College, 2014). The quality assurance aspect although not specifically stated, would theoretically address aspects of academic rigour.

Academic rigour linked to the student learning experience, in relation to instruction, schoolwork, learning experiences, and educational expectations that are academically, intellectually, and personally challenging the program review falls short of assessing the student experience. Moreover, it also fails to address what the expectations of students are specific to the IWAP program and how the college supports student achievement within the sphere of a rigorous Indigenous academic program.

Within the landscape of Indigenous post-secondary programs, what constitutes academic rigour and does it differ from a Euro-Western perspective? The literature suggests that Indigenous based programs extend beyond traditional mainstream courses of study because they are rooted in a spiritual ontological world view with an understanding that knowledge is derived with relationships that include those with other than human beings. It is within this paradigm that this research discusses academic rigour and identifies critical supports to improve learning outcomes for learners and discusses necessary structural reform to support Indigenous programming within Ontario colleges.

Indigenous ways of knowing and their subsequent approaches to addressing colonization are critical to improving educational outcomes of Aboriginal learners and ultimately the ability to achieve a good life or mino-bmaadiziwin ${ }^{4}$. Hart (1999) describes this as, "the good life is the goal of healing, learning, and life in general...the central goal of life which the Ojibwa designated by the term

\footnotetext{
${ }^{4}$ Good Life - a literal translation to English from the Ojibwa language
} 
pimadaziwin, is to have life in the fullest sense, life in the sense of longevity, health and freedom from misfortune" (Hart, 1999, p. 96). I understand Mino-bmaadziwin or mino-pimadaziwin to be, living a good life.

In Ojibwa Anishinabe and Cree understanding to live a good life, you are blessed with having your needs met. The understanding connotes oneness with the universe both physical and non-physical. In that good life, you exercise faith in the knowledge that you are supported by the Great and Kind Spirit. This understanding, although seemingly simplistic, captures an unspoken connection to the Spirit; it is implicit in the knowledge. The Spirit is often overlooked or ignored altogether in Western knowledge based paradigms. "Spirituality has only recently become an important organizing feature of Aboriginal adult education programs" (Verwoord, Ashley, \& Jair, 2011, p. 51).

Indigenous Knowledge is often reduced to romantic notions based on Hollywood depictions of Indians. Kovach (2012) describes the on-going assault on IK as "being a part of our collective experience and a burden that our pre-contact ancestors did not have to shoulder. The relationship with the settler society impacts our world daily, in the supermarket, in neighbourhoods, and in educational institutions. In post-secondary education, Indigenous students experience the burn of colonial research on a consistent basis most evident in the suppression of Indigenous knowledges" (Kovach, 2012, p. 76). Indigenous knowledge and spirituality stem from an intricate relationship with the land such that the two are intimately linked. It is through this relationship that Indigenous people see themselves in relation to the rest of Creation. Belanger (2010) describes how this world view is the polar opposite to a Western world view:

The earth and Indians cannot be separated. Land in this case is the heart of Creation. Whereas Western depictions suggest that a god provided humans with the earth as a source of resources for their economic and social utilization, Indigenous scholars tend to present the land as the heart of Creation, a ream where humans are one among a vast array of creatures. (p. 7) 
It is through this understanding that we strive to maintain harmony and balance with the world around us. "When one is in harmony with nature, one is in harmony with the Creator, at peace with oneself...it involves the relationships of all the various powers, energies, and beings of the cosmos, and when everyone, human, animal, plant, and planet, fulfills their obligations and goes about their proper business, they are in harmony" (Hart M. A., 1999, p. 94). When we are not in harmony with our environment, we begin to fall out of balance. Our world and relationships begin to also fall out of balance. Antone and Hill (1992) describe this imbalance in relation to colonial processes and structures as an Aboriginal response to ethnostress.

\begin{abstract}
Ethnostress was to become the label for the confusion and disruption that people were experiencing inside of their world. For the purpose of definition, ethnostress, comes from two words; ethnicity which refers to the roots of our aboriginal identity and stress pertaining to the impact that the reality of our experience has on the development of the aboriginal person. In short, living within native communities, is a very stressful experience. But, to simply state this and not provide the bigger picture would not do the concept justice, we need to be able to relate the stress to the disruption of the aboriginal identity, and further, to understand the impact of this disruption on the individual and community itself. (p. 1)
\end{abstract}

A growing literature and indeed mounting evidence suggests that Aboriginal peoples suffer disproportionately as a direct result of historical and contemporary laws, structures and processes. Aboriginal people however, must be positioned to affect their life outcomes. "To change what is wrong is to begin liberating ourselves from the "wrongs" of having too many of our people hungry, drunk, on drugs, or committing suicide. If we acknowledge that we are all subject to, and acting out certain behaviors that flow from past oppressive experiences, the resulting dehumanizing trends that occur in our communities can be stopped" (Antone, Hill, \& Myers, 1986, p. 27).

The timing for trained and equipped Indigenous wellness and addictions workers cannot be more critical. The 2006 Census reported that Aboriginal youth are the fastest growing segment of the Canadian population. While only $2 \%$ of the Canadian population identify as Aboriginal, more than $48 \%$ of this population are under the age of 24 years old (Statistics Canada 2006). Socio-economic depictions 
of the Aboriginal population are bleak and have been for quite some time. The Canadian Council of Provincial Child and Youth Advocates (2010) reported that an Aboriginal youth is more likely to go to jail than complete high school. "In the area of criminogenic risk, which is related closely to safety, education and wellbeing, Aboriginal youth are grossly over-represented in the youth criminal justice system beginning at age 12 years. In Manitoba for example, Aboriginal youth represented 23 per cent of the provincial population aged 12 to 17 in 2006, but 84 per cent of youth in Sentenced Custody. For Aboriginal children and youth in Canada, there is a greater likelihood of involvement in the criminal justice system, including detention in a youth custody facility, than there is for high school graduation." (Canadian Council of Provincial Child and Youth Advocates, 2010, p. 6).

Aboriginal children are overrepresented in the country's child welfare system. Health and morbidity rates for Aboriginal people are at epidemic proportions. "The poverty experienced by Aboriginal peoples is the single greatest social injustice facing Canada. While Canada's child poverty rate is higher than many similarly developed countries, Aboriginal children disproportionately experience its impacts; poverty as a contemporary legacy of colonization undermines the ability of Aboriginal families to nurture and support their children" (Canadian Council of Provincial Child and Youth Advocates, 2010, p. 6).

The determinants of health are significant for Aboriginal peoples given historical pressures and contemporary situations. Poverty is a major determinant that continues to impact Aboriginal health. "Poverty is associated with increased substance use, which can lead to stressful family environments and diminished social support, which are linked to, among other things, depression. Physical environments such as crowded housing conditions have been associated with stress... youth substance over-use and violence as well as behaviour problems in children have been linked to over-crowded living conditions. (Reading \& Wien, 2009, pp. 3-4). 
The socio-economic conditions for a vast majority of Aboriginal people are marginal and present complex conditions. Graduates of the IWAP program must be prepared academically and professionally to work within this multifaceted field with individuals, families and within whole communities. The IWAP program must prepare its graduates with skills and knowledge to work within this milieu. 


\subsection{Research Question:}

This research is concerned with how Ontario colleges can best support Indigenous programs rooted in Indigenous ways of knowing while maintaining academic rigour. There is an often unspoken assumption that Indigenous programs lack academic rigour and are of lesser quality than similar mainstream programs. That sentiment was echoed by both Aboriginal and non-Aboriginal resondents in the 2010 program review. Perceptions are often shaped by history, cultural norms and institutional low expectations of marginalized groups. Performance, literacy and numercy levels of learners moved through both Canadian and US education systems are well documented and have influenced national and provincial policy. However, the challenges remain. Ignorance, bias, limited resources and the fact that the education gap continues to widen between Aboriginal learners and their mainstream counterparts are all evidence of this.

In spite of the great strides to have Indigneous based programs situated in mainstream insitutions, IK continues to be misunderstood at best or ignored altogether. Stonechild (2006) reported that "there are Native studies programs at almost every large unversity in Canada and many teacher institutes offering special programs to train Natives to be teachers. But their perspectives and ideologies are quite consistent with mainsteam courses... all of these courses indoctrinate Native students to conversative middle class ideologies." He further argues that "they are intended towards creating an Aboriginal bourgeoisie" (Stonechild, 2006, p. 118). Hart (2002) echoes these sentiments, "whether it is in the historial perspectives, values and beliefs that Amer-European individuals bring with them to the educational institutes; or the teaching methodologies followed in the lecture halls and classrooms; or the theories and practices that are taught in these institutions; or in the conversation between a professor and Aboriginal person, Amer-European colonialism remains present” (Hart M. A., 2002, p. 36). 
Battiste extends this even further as reported by Anuik and Gillies (2012) suggesting that "everyone has been marinated in Eurocentric thought, and every researcher/student has been a victim and beneficiary of the same educational system" (Anuik \& Gillies, 2012, p. 66). Colonization permeates the foundational institutions of this country that prepares us for life. Academic and institutional structures, nuances and overt processes continue to propogate a colonial agenda and in effect diminishes the capability to deliver a rigourous Indigenous programing as a result. Structural and policy considerations are critical if colleges are to better promote and situate Indigneous academic programs within their institutions as vehicles for decolonization.

The overarching question of this research is this: How can the Indigenous Wellness and Addictions Prevention program best provide an academically rigourous program rooted in Anishinabe epistemology and pedagogy? It was followed by five subsequent questions that were posed to research participants in sharing circles and in key participant interviews. These are the questions:

How do participants understand healing and wellness?

How will this program prepare graduates to work within Indigenous healing and wellness paradigms?

How can Indigenous based programs maintain their Indigenous foundations while meeting academic standards?

What are the perceived challenges in hosting an Indigenous based program in a community college (including policy considerations, funding challenges, operational considerations, program design, and faculty recruitment/retention)?

How can programming be improved?

Although there is a growing pool of Indigenous based programs in a wider range of schools of study across colleges and universities in Ontario, my research is concerned with the extent to which this 
program in particular is understood to have an academic place equal to similar programs rooted in Western paradigms. Kovach (2012) in her reference to the earlier works of Graham Smith states that "a decolonizing approach, built upon critical theory, is particularly effective in analysing power differences between groups; that it provides hope for transformation; that there is a role for both structural change and personal agency in resistance" (Kovach, 2012, p. 80). Amid a great number of publically funded community and privately owned colleges in Ontario, this program is poised to make great contributions to altering the way in which Indigenous based programs are birthed and advanced within Ontario colleges.

\subsection{Theoretical Perspective:}

Consistent with a wholistic ${ }^{5}$ epistemology, my theoretical framework is based in the Anishinabe understanding that that life is cyclical, relational and interdependent, and, that history continues to influence structures, policy, and academic frameworks which are rooted in Eurocentric ideologies. Those ideologies have long since viewed IK systems "as exotic objects that have nothing to do with science" (Battiste, 2012, p. 3). "There is growing evidence that social science research needs emancipation from hearing only the voices of Western Europe, emancipation from generations of silence, and emancipation from seeing the world in one color" (Chilisa, 2012, p. 3). I offer this research to provide an Indigenous review of an Indigenous program situated within a mainstream publically funded Ontario college, to assess how effectively the program can retain its Indigenous foundations while meeting academic standards within a mainstream academy. The parody of such an inquiry speaks to the far reaching effects colonization continues to impart on our daily lives.

\footnotetext{
${ }^{5}$ Wholistic refers to the whole, a whole item or whole body of a person or thing. The word defines the consideration of the entire structure or makeup, which includes the body, mind and the spirit in the case of a human being. (English Stack Exchange)
} 
Colonization is defined "as the subjugation of one group by another" (Chilisa, 2012, p. 9). In Canada, Indigenous peoples have been subject to subjugation through government imposition of laws, policies, and practices. The onslaught continues to the present through public policies such as education, child welfare, health and justice. The colonization of the mind has had the most detrimental effect on Indigenous peoples. There is a critical need to assert Indigenous knowledge and research frameworks as vehicles to the freeing of the mind and to shift the power imbalance within academia and the schools in which they preside.

To create an Indigenous research framework, I draw from decolonization theory, critical theory and transformative learning theory. I use this framework to discuss the role of post-secondary education in meeting the challenges of pursing healing and wellness in Aboriginal communities. Decolonization speaks to achieving freedom "rooted in spiritual, cultural and philosophical value" (Regan, 2005, p. 4). In that light, transformative theory lends to this work a vision that healing and wellness are obtainable and measureable within the epistemological underpinnings of mino-bmaadiziwin - a good life and identify the role post-secondary education has in supporting Aboriginal communities to achieve healing and wellness. Chilisa (2012) explains decolonization as a process of centering the concerns and worldviews of the colonized Other so that they understand themselves through their own assumptions and perspectives. She describes the process as having two distinct approaches:

Creating and consciously using various strategies to liberate the captive mind from oppressive conditions; and restoring and developing cultural practices, thinking patterns, beliefs, and values that were suppressed but are still relevant and necessary to the survival and birth of new ideas, thinking, techniques and lifestyles that continue to the advancement and empowerment of the historically oppressed and former colonized non-Western societies. (p. 14)

Herbert Marcuse "held that the goals of a critical approach to society are the emancipation of consciousness, the nurturing of a decentralized political movement and the reconciliation of humanity and nature" (Dirkx, 1998, p. 2). Through the lens of critical theory this research challenges the social 
and moral dichotomies that are evident in hosting an Indigenous based program within the confines of a Western institution. Paulo Freire articulated a theory of transformative learning which he referred to as conscientization or consciousness raising. "Critical consciousness refers to a process in which learners develop the ability to analyze, pose questions, and take action on the social, political, cultural and economic contexts that influence and shape their lives" (Dirkx, 1998, p. 2). Some educators who are informed more by a Freirian perspective stress "the significance of social structures and the need to change or transform these structures to realize a more just and equitable society" (Dirkx, 1998, p. 9).

Additionally, I draw from an Indigenous understanding that all of life is interconnected. This belief is universal among diverse Indigenous nations. I utilize the medicine wheel to visually depict the wholistic worldview of the Anishinabe and to also frame this research. "Although the concept of the medicine wheel has different meaning and expressions for different Aboriginal peoples, some of the principles are considered quite common" (Verwood, Mitchell, \& Machado, 2011, p. 50) such as the principles of inter-dependency, equality and balance in life. Academic rigour must be demonstrated in the classroom through instruction, application of learning, stated in student and faculty institutional expectations that are academically, intellectually, and personally challenging and supported by the climate of the school and classroom. 


\subsection{Literature Review:}

This literature review presents a discussion of historical and contemporary relationships that continue to influence Indigenous programs within education institutions and more specifically within academia and its structures. It presents a discussion of government imposition of assimilation policies, residential schools, internalized racism and education as a tool toward reconciliation.

Historically, education as an imposed system on Indigenous nations had a single goal assimilation. "The policy of aggressive assimilation was a radical experiment in social engineering. It was designed to quickly absorb Indians into the allegedly superior and more desirable British language and culture. By removing Indian children from their home environments and communities, in many cases for years at a stretch, the children were to become fully assimilated into white culture. Moreover, they were expected to be grateful for having been given the opportunity to receive such an education" (Stonechild, 2006, p. 19). Residential schools have left an indelible legacy in Canada's history and its relationship with Indigenous peoples that continue to influence Indigenous - settler relationships. "One of the main avenues for subjugating Indigenous peoples to colonial culture and governance has been through the imposition of education, most powerfully through the "Indian Residential Schools" program, that denies the legitimacy of thought, lifestyles, religions and languages of First Nations people" (Ball, 2004, p. 461).

Aboriginal ${ }^{6}$ and Canadian relations stem from a colonial history. This history is well documented from a Western perspective that describes Indigenous people as inferior and lacking the insight and impetus to improve their outcomes. This Euro-western narrative has formed the basis of historical and current relationships between non-Aboriginal and Aboriginal peoples. In Canada, Indigenous people

\footnotetext{
${ }^{6}$ The descendants of the original inhabitants of North America. The Canadian Constitution recognizes three groups of Aboriginal people - Indians, Métis and Inuit. These are three separate peoples with unique heritages, languages, cultural practices and spiritual beliefs. (Aboriginal Affairs and Northern Development Canada)
} 
have been subject to gross injustice through government imposition of laws, policies and practice. It is necessary to discuss the historical impacts this narrative has had and continues to have on educational programs as we seek to evaluate the effectiveness of Indigenous based programs with Aboriginal populations. It is not enough to assess student/teacher ratios, costs and resources without a solid understanding of the colonial relationships that continue to exist in Canadian post-secondary institutions in which these programs reside.

\section{Education and assimilation:}

As a matter of government policy, education was a direct and immediate means by which to strip away Aboriginal ways of life, identity, and language on a massive scale. Land was needed for settlement and Indians ${ }^{7}$ continued to live on the land as they had for millennia prior to contact. "Many thousands of Aboriginal children were taken from their homes and placed in the residential school system over the past 100 years. As recently as 1991 and more than a decade after most of the schools had closed their doors, 13 per cent of the country's population were residential school survivors” (Aboriginal Healing Foundation, 2003, p. 27). Children ripped from their homes and families suffered indecent acts of abuse and trauma inflicted by their caretakers. The Truth and Reconciliation Commission of Canada (2013) reports that,

More than 150,000 First Nations, Métis, and Inuit children were forced to attend these schools some of which were hundreds of miles from their home. The cumulative impact of residential schools is a legacy of unresolved trauma passed from generation to generation and has had a profound effect on the relationship between Aboriginal peoples and other Canadians.

Truth and Reconciliation Commission of Canada

\footnotetext{
${ }^{7}$ Indians persons identified under the Indian Act defines eligibility for Indian Status (i.e. Registered Indians). The Indian Register is the official record identifying all Status Indians in Canada (https://www.aadnc-aandc.gc.ca/DAM/DAM-INTERHO/STAGING/texte-text/br is elig 1315710514986 eng.pdf)
} 
According to Stonechild (2006), "the schools were very successful at destroying the cultural identity of the students, leaving a legacy that continues to damage First Nations communities to this very day" (Stonechild, 2006, p. 20).

Justice Murray Sinclair, Chair of the Truth and Reconciliation Commission of Canada describes the effects of residential schools and their continued impact on the relationship between non-Aboriginal and Aboriginal people,

\begin{abstract}
They were told that their languages and cultures were irrelevant. Their grandparents and ancestors were heathen and pagan and were told to give up their way of life for a different way of living. At the same time that was going on, non-Aboriginal children in non-Aboriginal schools in this country were also being told the same thing about Aboriginal people. So as a result, many generations of children including you and your parents, have been raised to think about things in a different way, in a wrong way. In a way that is negative when it comes to Aboriginal people. We need to change that. It was the educational system that contributed to this problem in this country, and it is the educational system that we believe that is going to help us to get away from that. We need to look at the way we educate children, we need to look at the way we educate ourselves, and we need to look at the way our textbooks say about Aboriginal people, we need to look at what Aboriginal people are allowed to say within the educational system about their own histories.
\end{abstract}

TRC, 2013

In spite of the far reaching and catastrophic impacts residential schools have had on such a grand scale, the existence of the schools and the laws that justified their existence are not widely known by everyday Canadians. This very important piece of Canadian history is rarely taught in history or social studies classes in Canadian schools. And relatively speaking, Native studies courses or the inclusion of Aboriginal peoples' as part of curriculum is only very recent. The overt omission of information works to maintain an ideology of imperialism and upholds tenets of Social Darwinism. Hart (2002) explains that,

For most Indigenous students in Eurocentric education, realizing their invisibility is like looking into a still lake and not seeing their reflections. They become alien in their own eyes, unable to recognize themselves in the reflections and shadows of the world. In the same way Eurocentric thought stripped their grandparents and parents of their wealth and dignity, this realization strips modern indigenous students of their heritage and identity. (p. 29) 
The colonization of the mind has had the most detrimental effect on Indigenous people. Chilisa (2012) describes imperialism as "the practice, theory and the attitudes of a dominating metropolitan centre ruling a distant territory...the theory, practice, and attitudes of the metropolitan created an idea about the West and the Other that explains the dominance of Euro-Western research paradigms and the empire of deficit literature on the formerly colonized and historically oppressed" (Chilisa, 2012, p. 8). It is this overarching perspective of history that continues to influence educational curricula across Canada from primary, secondary to post-secondary education.

"Colonization is driven by a worldview that embraces dominion, self-righteousness and greed. These ideas affect the relationship between the colonizers and the colonized...the effects occur on all levels" (Hart M. A., 2002, p. 24). At a micro level, the colonizer forcefully imposes these views and the colonized internalizes them. Learned and internalized racism wreaks havoc on the healthy development of the Indigenous mind, body and spirit. Indigenous programs must be designed to develop a healthy image of indigenous peoples. Hart (2002) argues that post-secondary education is often a destructive process whereby ontological and cognitive imperialism continues through the absence and nonvalidation of Indigenous knowledges. Indigenous based programs therefore must assert IK and build program competencies based on the underpinnings of IK. This validates and positions Indigenous programs within academic schools. The current practice appears to be that Indigenous based programs are aligned with similar mainstream programs and IK competencies then augment and round out the program. Whereas a decolonizing agenda challenges that the very fundamental design of an Indigenous based program should be based in IK. Hart (2002) furthers that, "survival for Indigenous peoples is more than just a physical existence; it is an issue of preserving Indigenous knowledge systems in the face of cognitive imperialism" (Hart M. A., 2002, p. 30). Aboriginal people have long insisted that returning to traditional Indigenous practices and beliefs would address healing, resurgence and 
reconciliation. Despite the extreme and oppressive force with which education was imposed on Aboriginal nations, it is the same vehicle that Aboriginal people see as moving the masses to reconciliation. Stonechild (2006) reports that just as education had been used in the past to destroy Aboriginal culture and language, education can now be used to build, restore, and revive Aboriginal culture, history, values, and beliefs through the schools which Aboriginal students attend (Stonechild, 2006).

This task is not without it challenges. The inter-generational effects of residential schools appear to be almost insurmountable. A legacy of very high rates of violence, suicide, addictions, and systemic and overt racism are all linked to the effects of colonization. The inter-generational burn of colonization is deeply rooted in systems, structures, policies, laws, and indeed mindsets of both the colonized and colonizer. Franz Fanon an Afro-French psychiatrist wrote extensively about the psychopathology of colonization. He describes the colonization process as an inferiority complex. "It is the outcome of a double process: — primarily, economic; — subsequently, the internalization-or, better, the epidermalization of this inferiority" (Fanon, 2008, p. 9). The inferiority complex unfolds as the colonized loses his/her own identity, knowledge, language and being, and is replaced by the language of the other; and that he/she learns to repulse the very essence of his/her being.

The collective Indigenous experience in Canada has been that of loss upon loss, legislated by this county's laws such as the Indian Act and enforced by civil servants and their agencies. The Truth and Reconciliation Commission of Canada mandated to collect and share the story of Canada's residential schools will soon publish its report on the residential school legacy in Canada. It shall not be a surprise to hear the personal stories of survivors and their heirs about how internalized racism continues to shape negative self-image and self-worth. 
Indigenous based programs are often viewed negatively as well among Aboriginal and nonAboriginal people. These programs are often seen as less than and are subsequently of lesser quality. As a result, Aboriginal learners opt to take a mainstream program over a similar Aboriginal program if available because of these assumptions. College personnel attempt to steer Aboriginal applicants toward Aboriginal programs without fully understanding why an Aboriginal program may be a better fit for learners in the first place. Faculty and other college personnel make judgement calls based on poor performance of Aboriginal learners citing they should be in the Aboriginal program suggesting that Aboriginal programs are not as academically demanding. While this research did not attempt to seek out why Aboriginal students were steered to Aboriginal programs, the underlying assumption is that the aforementioned beliefs are widely shared.

\section{Aboriginal education:}

Aboriginal student enrolment within post-secondary institutions has steadily increased since the late 1960's. In a 2004 review of Aboriginal peoples and post-secondary education, Malatest and Associates (2004) identified several barriers to Aboriginal post-secondary success. They report that "while socio-economic factors such as poverty and unemployment put them at an obvious disadvantage, Aboriginal students also face more subtle barriers such as discrimination, low self-concept and institution insensitivity to Aboriginal cultures....Combined with a history of forced assimilation through educational institutions, the barriers to Aboriginal participation in post-secondary education are formidable" (R.A. Malatest \& Associates Ltd., 2004, p. 1).

In the late 1980's Aboriginal student support services were introduced in Ontario colleges with the aim of increasing Aboriginal student enrolment, retention and graduation rates. Aboriginal programs were limited to those that would increase access by preparing Aboriginal students for entry into 
mainstream post-secondary education. Cultural supports, although limited, were designed to assist students in the transition to mainstream institutions.

Aboriginal learners were often viewed as requiring remedial training to meet entry requirements into programs. The education systems into which Aboriginal learners entered fell short of preparing learners for academic and skills programs. It is important to note the early introduction of Aboriginal specific programs in Ontario colleges as this history continues to influence how Aboriginal programs are perceived by both Aboriginal and non-Aboriginal peoples.

It is reported that Aboriginal education attainment levels lag far behind the mainstream. Aboriginal learners are reportedly less prepared for college level studies and statistics show that high school completion rates among Aboriginals are significantly lower than the rest of the Canadian population. Although the National Household Survey of 2011 reported that Aboriginals completing a college level diploma and trades certificate are comparable to their mainstream counterparts, high school and university completion rates continue to lag behind national averages (Statistics Canada, 2013).

With respect to First Nation schools, they are the responsibility of the federal government and do not have access to educational and pedagogical supports that provincial schools receive from school boards. Federally funded schools have a direct relationship with the federal government. The federal government lacks infrastructure in which to ensure proper funding and pedagogical and capital supports for Band Operated elementary and secondary schools, despite being in the business of education with respect to Aboriginal people since the early 1800's.

The Chiefs of Ontario (2013) report in a review of the Band Operated Funding Formula that [under] INAC's education program, First Nations students face a gap of twenty-three years to match the achievement of Canadian students due to severe under funding. Furthermore, it is not funding education systems, nor does the funding model appear to have any focus on other qualitative issues such as student 
achievement, culturally responsive curriculum and teaching, or parental and community empowerment (Chiefs of Ontario, 2013). With respect to Aboriginal post-secondary education, "the lines of jurisdictional responsibility between the federal and provincial and First Nations governments regarding First Nations higher education are fuzzy" (Stonechild, 2006, p. 2). Students attending post-secondary education (PSE) in Ontario, depending on whether they are Registered Indians within the meaning of the Indian Act or affiliated with an Aboriginal community may receive support to attend PSE. The monthly support amounts to little more than the monthly stipend paid to those living on government social assistance. The support is only available to students when they are attending full time. Students must overcome various barriers to attend post-secondary education programs that are often situated miles from their home communities. Compounding the stressors of even just attending PSE, Aboriginal students are often parents with school aged children, who must relocate to attend college, secure a family home, child care and all the necessary services required to maintain a healthy family and home life, while existing on a meagre budget.

Currently, Ontario colleges and universities receive special project funding for Aboriginal learners through the Ministry of Training, Colleges and Universities Post-Secondary Education and Training Fund for Aboriginal Learners (PEFAL). PEFAL funds are meant to help colleges/universities address the special supports Aboriginal students require when attending PSE. PEFAL funds are directed to provide culturally relevant student supports, retention activities, Aboriginal student counselling services, cultural supports including elder in residence programs and academic supports such as tutors and study groups. While the discussion of funding for Indigenous models of education are beyond the scope of this research, it is important to mention that the college receives these special project funds to support special curricular cultural activities within the IWAP program, along with other institutional 
wide initiatives for it's more than the reported $16 \%$ of the total Canadore student population represented by Aboriginal students.

In the mid-1980's funding through the Ministry of Training Colleges and Universities was made available to colleges demonstrating increasing enrolment of Aboriginal learners. One requirement for funding was that colleges had to establish Aboriginal advisory circles. The role of the advisory circles was to identify student supports to increase Aboriginal student enrolment and success. Many colleges in Ontario began to increase partnership and joint ventures with Aboriginal communities as a result of having direct relationships with Aboriginal communities through their advisory circles. Aboriginal programs vary across Ontario colleges and are a response to Aboriginal communities' requests for specific programming. The Indigenous Wellness and Addictions Prevention program was developed in response to the needs of a First Nation community.

The design of the program was a collaborative effort between the community and the college, with the college taking a lead role. The college's academic framework defined the programs vocational learning outcomes in conjunction with the community's identification of specific skill sets and the Ministry's program standards based on similar mainstream 'helping' programs. Content expertise to design the IWAP curriculum was not available within the college; as a result a consultant was hired to work with the college in this regard. Curricular and content expertise positions in the area of local IK and its contemporary applications is often absent in many mainstream community colleges unless the college has on its staff Indigenous employees. Even then, this work is highly specialized and requires a knowledge base and skill set that is reflective of both western based and Indigenous theory and practice. Some colleges are fortunate to have such individuals on staff and these individuals fulfil this role on a project by project basis. 
Despite an increasing number of Indigenous based programs in Ontario, there appears to be a dearth of literature with respect to how well Ontario colleges are delivering on Indigenous based programs. "Evaluation-whether formative or summative, or for accountability, development or knowledge-also has an important role to play in decision making at all levels of higher education" (Macdonald, 2006, p. 5). The meaningful inclusion of the Indigenous community in the evaluation of Indigenous programs, would not only identify factors and processes to improve the program's quality but would also demonstrate the institution's commitment to improving relations with Indigenous communities and ultimately increasing Aboriginal student success.

\section{Why Indigenous based programs?}

It is evident that "Indigenous worldviews are vastly different from the dominant cultural worldview in Western societies" (Hart, 2010, p. 4). And that our wold view shapes our perceptions, beliefs, values and behaviours. "Worldviews are cognitive, perceptual, and affective maps that people continuously use to make sense of the social landscape and to find their ways to whatever goals they seek. They are developed throughout a person's lifetime through socialization and social interaction. They are encompassing and pervasive in adherence and influence. Yet they are unconsciously and consciously taken for granted as the way things are" (Hart, 2010, p. 2). In the matter of preparing competent Ontario graduates, college programs are often built on Euro-western worldviews. However, to work within the milieu of Aboriginal healing and wellness, college programs must be reflective of the Indigenous population graduates will work with. Indigenous ontology therefore must be the basis of the program's theoretical underpinnings and its content reflective of Indigenous epistemology and its delivery demonstrate an Indigenous pedagogy. This requires a significant departure from current practice in Ontario colleges. 
It requires an acknowledgement and validation that Indigenous Knowledge and Indigenous based programs are valid, relevant and have a rightful place within the academic landscape. It requires an acknowledgement of white privilege and the existence of power imbalance. Kovach (2012) argues that "in critically analyzing the primacy of Western thought in research, a product of mainstream academic institutions, one quickly sees the politics of knowledge and inquiry - i.e., both epistemologies (our understanding about the world) and ideologies (what should count as knowledge and who gets to make that choice) - are used to maintain western privilege" (Kovach, 2012, p. 79).

The Canadian context challenges institutions of higher learning to lead in breaking new trails. As gatekeepers to professions such as social work and addictions counselling, Ontario colleges have a bridging role in responding to the needs of the communities which they serve while also maintaining professional standards. Hart (2010) argues that "the work with Indigenous peoples will often require us to act outside of the dominant worldview found in social work internally and particularly in fourth world territories" (Hart, 2010, p. 2). While Ontario colleges have made 'space' for such programs, the often token nature places their true value in rather marginalized and precarious positions within academic schools. "At best Canadian universities and educational systems teach [a] double consciousness to Indigenous students ... Canadian educational systems view Indigenous heritage, identity and thought as inferior to Eurocentric heritage identity and thought. Educators still know very little about how Indigenous students are raised and socialized in their homes and communities, and even less about how Indigenous heritage is traditionally transmitted" (Stonechild, 2006, p. 118). In schools of social work and human services, "colonialism is so discreet, as it hides behind its altruism and ignorance. Yet it is found in all aspects of the profession" (Hart M. A., 2002, p. 34). 


\section{Indigenous Worldview in Higher Education:}

Program currency, relevancy and responsiveness must be reflective of the community's ontological underpinnings within Indigenous based programs. Indigenous people understand the world and universe as inextricably linked, interdependent and share an understanding that all of life is interconnected. "Indigenous worldviews emerged as a result of the peoples' close relationship with the environment" (Hart, 2010, p. 2). This world view is understood to be interconnected at multi-levels. Coyhis and Simonelli (2008) refer to an understanding of a "seen and unseen world" (Coyhis \& Simonelli, 2008, p. 1932). Lavallee (2009) describes Indigenous epistemology as "accepting the nonphysical, one must accept that reality cannot always be quantified" (Lavallee, 2009, p. 23). Nabigon and Mawhiney (n.d.) introduced the use of the Cree medicine wheel to demonstrate a Cree approach to healing and the interconnectedness of all life. They describe the use of the wheel within a therapeutic treatment model. Many treatment facilities draw from Indigenous understanding of wellness in the development and delivery of services and employ a bi-cultural model. Graduates of post-secondary programs must be prepared to work within a bi-cultural services model and feel confident that the skills and knowledges they develop through post-secondary education prepares them for practice.

"There are more than a thousand Aboriginal Healing programs ongoing on reserves and in cities and towns across Canada and many more initiatives that consciously incorporate a healing component within other types of programs" (Aboriginal Healing Foundation, 2002, p. 11). Health Canada reports that the "National Native Alcohol and Drug Abuse (NNADAP) supports a national network of 52 residential treatment centres, with some 700 treatment beds" (Health Canada). NNADAP supports residential and non-residential primary, secondary and tertiary services located in First Nations. Off reserve services are funded by other federal or provincial ministries. With a growing Aboriginal population where more than half reside away from First Nation communities, it is imperative that 
alcohol and substance abuse treatment programs are reflective of the needs of this growing demographic. This requires education programs to prepare its graduates from Indigenous approaches that would prepare them to enter not only front line positions but take up program management and supervisory positions within these systems. Graduates of the IWAP program will find employment in either First Nation or urban communities. In many First Nation communities, they may be the only position in the community mandated to this work. First Nation communities by and large are often isolated or semi-isolated whether by physical proximity or by available services to the community. Community wellness workers are the front line, addressing critical and often fatal circumstances for whole communities including children, youth and adults.

This program and others like it are critical in preparing individuals for this work. Community wellness workers must be prepared to work in the front line dealing with all ages and genders with limited immediate access to primary, secondary and tertiary services. They must be prepared in crisis intervention, prevention programming, relapse prevention, community development, case management, assessment, counselling within an Indigenous reality that are often worlds apart from a mainstream experience, all while maintaining their own sense of wellness. Moreover, they must also be prepared to work within an inter-professional team often fulfilling a case management support role.

A rigorous program responds to and prepares graduates for this work within a wholistic pedagogy. "When a mainstream, standardized, one-size-fits-all curriculum is all that is offered, too often the result is a homogenizing, monocultural, colonizing approach to community and human service development that is inappropriate for the varied social ecologies of Indigenous children and families" (Ball, 2004, p. 457). The IWAP program then must prepare its graduates for work within Indigenous realities. 
The public health agency of Canada as reported in Canadian Best Practices Portal from the Government of Canada website states that "the social determinants of health influence the health of populations. They include income and social status; social support networks; education; employment/working conditions; social environments; physical environments; personal health practices and coping skills; healthy child development; gender; and culture" ( Public Health Agency of Canada, 2014). We know that the social determinants of health often influences the likelihood of those overcoming systemic and structural barriers to accessing post-secondary education. For Aboriginal peoples, the broader determinants of health also include "colonization, globalization, migration, cultural continuity, access, territory, poverty, self-determination" (National Aboriginal Health Association, 2014).

A collaborative national approach to address a growing epidemic of substance and alcohol related issues among First Nations has yielded the first ever national framework to support community driven approaches to healing and wellness. The Assembly of First Nations, National Native Addictions Partnership Foundation and the First Nations Indian Health Branch reports,

In response to increasingly complex needs: new drugs; more people reporting associated mental health issues; a rapidly growing First Nations youth population; and growing prescription drug abuse concerns in some regions and communities. These factors have dramatically changed the landscape upon which systems were designed. With diverse systems and increasingly complex needs, a challenge for communities, regions, and all levels of government is to coordinate a broad range of services and supports to ensure First Nations have access to a comprehensive client-centered continuum of care.

Assembly of First Nations \& National Native Addictions Partnership Foundation and Health Canada, 2011

Honouring our Strengths is the collective result of the work of the Assembly of First Nations,

NNAPF and FNIHB that looked at the need for a breadth of services to support Indigenous approaches

to healing in a wide range of areas including community development, early identification and intervention, aftercare, harm reduction, active treatment, and care facilitation. The authors cite that key components to work force development in this regard include "cultural knowledge and skills, recruitment, education and training, worker certification, worker retention, wages and benefits and 
personal wellness" (Assembly of First Nations, National Native Addictions Partnership Foundation and Health Canada, 2011). Whilst there is not a prescribed approach to best practice, the research undertaken can help guide the development of education programs whose goals are to help graduates find employment in these fields.

Two Ontario universities have taken affirmative steps to develop undergraduate and graduate social work degrees based in Indigenous epistemologies. Laurentian University launched the Native Human Service Honours Bachelor of Social Work program in 1988 in Sudbury, Ontario. "The School of Native Human Services Honours Bachelor of Social Work is a culturally-specific Native Social Work program that is recognized and accredited by the Canadian Association of Social Work Education (CASWE). The goal of the School of Native Human Services is to provide an accredited social work degree that offers knowledge, skills and experience to work effectively with Native and non-Native communities" (Laurentian University). In 2006, Wilfred Laurier University introduced "the first Master of Social Work program in Canada rooted in a wholistic Indigenous world view and contemporary social work practice. The goal is to develop social work practitioners who demonstrate an understanding of and respect for the history, traditions and culture of the Indigenous peoples of Canada. This unique program includes the use of Indigenous elders, a traditional circle process, and Indigenous ceremonies" (Wilfred Laurier University). Through education, Indigenous peoples are positioned to better influence policy, education and services for Indigenous peoples. Additionally, graduates of such programs are then adept to draw from both Indigenous Knowledge and western based paradigms to bring about a better reality not only for themselves but for those whose lives they will touch.

The literature reinforces that relational nature of Indigenous knowledges. They are rooted in spirituality and have much to teach us about our relationships with one another, the earth, our environment and with our Self; and that, the process of uncovering, validating and living IK is essential 
for emancipation from colonization. Education has a critical role in the decolonization of Canada. Aboriginal and non-Aboriginal people each have a responsibility to this end. Chilisa (2012) identifies several strategies for decolonization: deconstruction of the past, its myths and reconstruction of a new future, self-determination and social justice, ethics, language, internalization of indigenous experiences, history and critique (Chilisa, 2012). Educational institutions by their nature are best situated to test and launch these strategies within educational curricula, services and programs at all levels.

Indigenous based programs also have a critical role in that they prepare graduates for life beyond PSE. With respect to students in Indigenous based programs, we know that although they may meet admission eligibility requirements, not all students are prepared for college level study. Indigenous students are often marginalized for a number of reasons. Academically, we know that a huge percentage of Aboriginal learners are often adult mature learners who have been away from formal education and are returning to PSE later in life. While increasing Aboriginal participation in Ontario's PSE is promising, labour participation rates do not reflect the increasing number of Aboriginal graduates. Popovic (2012) reports that low literacy levels among Aboriginals are barriers to securing employment. She further reports that, "while a plethora of programs exist one of the most persistent issues preventing the attainment of a higher education is the lack of literacy in $\mathrm{FNMI}^{8}$ communities. This is especially worrisome as weak literacy skills are associated with poorer labour-force outcomes" (Popovic, 2012, p. 30). When evaluating Indigenous based programs, essential literacy and numeracy skills must also be assessed to ensure that graduates attain a level of proficiency.

Post-secondary institutions have an opportunity to take lead roles in debunking myths and laying the foundation for the reconstruction of the future. Indigenous faculty and programs can play vital roles in this regard; their authority and expertise must be recognized within the institution. Academic rigour

\footnotetext{
${ }^{8} \mathrm{FNMI}$ - acronym used to refer to First Nation, Metis, Inuit people
} 
then within Indigenous programs must reflect a specialized authority that is not found in Western based programs of instruction. Indigenous knowledge as stated earlier, is relational, often subjective, interpretative and highly personal. Yet it is a shared understanding of the universe amongst Indigenous Nations and IK is communally validated.

Academic rigour is best demonstrated in form and content; it is often reflected in stated measureable outcomes and validated through external review. Assessment tools reflective of the Indigenous epistemology and pedagogy employed by Indigenous programs aligned with stated outcomes are also evidence of rigour. Given the often experiential and wholistic nature of learning occurring in these programs, evidence of this learning to demonstrate rigour must be well thought out. Additionally, recognition and assessment of bi-cultural approaches being taught in Indigenous programs must also be demonstrated. This requires a different approach to evaluating and assessing program quality for Indigenous programs. A review that takes into consideration the vastly different approaches found within Indigenous programs would articulate that Indigenous based programs are in fact Ontario college programs plus. Such programs are enhanced programs that prepare its graduates for practice within mainstream systems and with Indigenous populations who have very unique and special circumstances.

In 1966, the Hawthorn Report investigated the social conditions of Aboriginal people and coined the phrase "citizens plus". The report described serious marginalization, poverty, lower life expectancy, increased morbidity and significant education attainment gaps between Canada's Indian population and the rest of Canada. The report recommended that rather than abolish Treaty Rights and special status of Canada's Indian population, the federal government should recognize Indian people as Citizens Plus with certain unalienable rights. The report stated that "Indians should be regarded as 'Citizens Plus'. In addition to the rights and duties of citizenship, Indians possess certain additional rights as charter members of the Canadian community” (Indian Affairs Branch, 2004). 
It highlighted the critical need to recognize cultural, linguistic and historical considerations in the education of Indian children. That by and large, education systems were failing Indian children. The report made several recommendations to improve educational outcomes for Indian children including increasing funding for education, housing and essential services to allow Indians to improve life circumstances. It was projected that Aboriginal people would represent a growing yet increasingly marginalized population and improving their situations would benefit Canada as whole. Education, the report recognized required different approaches that were responsive to the needs of Indian children. Indian children although marginalized, presented with different worldviews that when supported from strength based approach to learning, yielded improved outcomes for Indian children. Ontario colleges in demonstrating their moral and ethical commitment to Indigenous peoples must recognize Indigenous programs as programs plus in this same vein.

\subsection{An Indigenous Research Framework:}

While this research aims to identify the programs strengths and weaknesses, it also seeks to construct a decolonizing narrative throughout the evaluation process. That narrative is presented in this research through the voice of participants. The questions were designed in keeping with the tenets of the medicine wheel. Drawing from a wholistic Indigenous Knowledge base and through a decolonizing lens this research seeks to assess how can the Indigenous Wellness and Addictions Prevention program maintain academic rigour while maintaining its Indigenous foundation? Utilizing the medicine wheel teachings, five key questions framed this inquiry:

In the Eastern direction we are given the gift of vision, from this place we are asking what it is the Creator asks of me?

1. How do participants understand healing and wellness? 
In the South we are concerned with relationships and time, what needs to be in place and how much time will we require?

2. How does this program prepare graduates to work within Indigenous healing and wellness paradigms?

In the West, we are focused on reasoning, why are we doing things the way we are?

3. How can Indigenous based programs maintain their Indigenous foundations while meeting (nonIndigenous) academic standards?

And in the north, we are concerned with moving forward in a good way. The center of the wheel is what grounds us, that is our connection to the Spirit.

4. What are the perceived challenges in hosting an Indigenous based program in a community college (including policy considerations, funding challenges, operational considerations, program design, faculty recruitment/retention)

And with good hearts and minds, from the center we are concerned with our connection to Spirit (manitoog).

5. How can programming be improved?

\section{Medicine Wheel Framework:}

The medicine wheel as a framework is fluid, relational and interdependent. It reflects a wholistic view of life. In this research I utilize the medicine wheel to frame the discussions with participants in both sharing circles and in key participant interviews. The medicine wheel also guided the analysis of data. "The medicine wheel is both a symbol and a tool to understand phenomena. It is a circle divided into four quadrants, or segments, which are separate but interconnected. This state of separateness but interconnectedness is sometimes depicted visually" (Lavallee, 2009, p. 23). 
"In the context of education, a greater number of institutions are using the medicine wheel in their programs and curricula for varying purposes, some of which support the inclusion of spirituality" (Verwoord, Ashley, \& Jair, 2011, p. 51). I utilize the wheel from my personal reference having received several Anishinabe teachings and praxis of such in my own life. I credit the work of the Three Fires Midewewin Lodge for the opportunity to hear firsthand ancient knowledge passed from generations to generations within a sacred place. It is this learning and life experience that has fueled my desire to seek out ways in which to enrich the educational journeys of Anishinabe.

The wheel symbolizes Anishinabe understanding that life exists in a balance, that there are polarities within life, a light and dark. And the wheel depicts our understanding of life as whole. Coyhis and Simonelli describe an understanding "that conflict and struggle are a natural consequence of the polarity-based, interconnected system that we all share in our lives on planet earth. Everything in the universe grows and changes through a process of conflict and struggle. In order for anything to grow or change it must struggle to do so first" (Coyhis \& Simonelli, 2008, p. 1933). It is the working through the struggle that our understanding and growth occurs. Reagan (2005) argues that decolonization is a process that both Aboriginal and non-Aboriginal peoples must go through. "Our respective paths in this struggle are different, but the goal is the same - transforming the social and political landscape to enable us to co-exist peacefully" (Regan, 2005, p. 5).

My work has also been influenced by Herb Nabigon a Cree professor in the Native Human Services Program at Laurentian University, who often illustrated his understanding of the polarity of life utilizing the medicine wheel. It has been shaped by many other teachers who shared with me and many others, Anishinabe understanding of life based on the four directions that are directly connected to our collective knowing of how Creation unfolded. I acknowledge my teachers as Bawdwaywidaung Binaise, Onaubinasay, Paimasagai-buhn, Waabshki Mukwa, Medwayweeyosh and the many 
grandmothers who graciously shared their knowledge with me at various times throughout my journey. As I work from within an Indigenous research framework, it is important to acknowledge the many life teachers who have influenced the way in which I am able to see and understand the world around me. I have also been deeply influenced by many non-Indigenous teachers, not all of whom are academics. It is through this this bi-cultural lens that I attempted to remain true to my Anishinabe values, principles and ethics as I journeyed through this research.

In utilizing the medicine wheel as a framework, I credit Jim Dumont, Anishinabe Elder, $4^{\text {th }}$ degree Midewewin-Innini, knowledge keeper, philosopher and educator who as a Professor in the Native Human Services Program at Laurentian University in 1995, first introduced me to this wheel as a framework. From that first lecture, I have been able to apply its wholistic foundations to much of my work in both my professional and personal life. As mentioned previously, often our view of world is simply understood as the way things are, we seldom question its validity until we are challenged or forced to accept a new way of understanding. Being introduced to the medicine wheel in my undergraduate studies was empowering. Never before did any part of my formal educational journey have such a profound impact on my learning. That is the essence and the transformative power Indigenous based education has.

Today, the medicine wheel is used in many modern contexts, from program design and evaluation, individual client based assessments to treatment planning to name a few of its contemporary uses. Anishinabe understandings of the wholistic framework of the wheel however, remain firmly rooted in Anishinabe knowledge.

\section{The Wheel:}

Dividing the wheel into four parts we see our Self more fully (Appendix 1). Each quadrant is often referred to as a doorway, as each quadrant presents its own gift. The quadrants remind us of life's 
natural order. Hart (2010) describes ontology as our understanding of what exists is determined by how we see the world, that there are many views of being (Hart, 2010).

In Anishinabe ontology, we know that the source of all of life is of Spirit. The Spirit is what centers us, keeps us grounded. Everything has a Spirit. It is depicted in the center of the wheel and labeled Manitoog; it touches all aspects of our lives. We are dependent on the Spirit because we are of Spirit. I have taken the foundation of the medicine wheel framework from the works of Michael Anthony Hart (199), a Cree professor in the School of Social Work at the University of Manitoba. He presented the medicine wheel in Seeking Mino-Pimatisiwin. He refers to the circles within circles to depict a multi-level understanding from self, family, community to nation. This framework is slightly modified here to reflect its use in this research. I credit Michael Hart along with the aforementioned Anishinabe teachers who have presented and utilized the medicine wheel in scholarly work and have helped pave the way to Indigenous Knowledge inclusion within the academy.

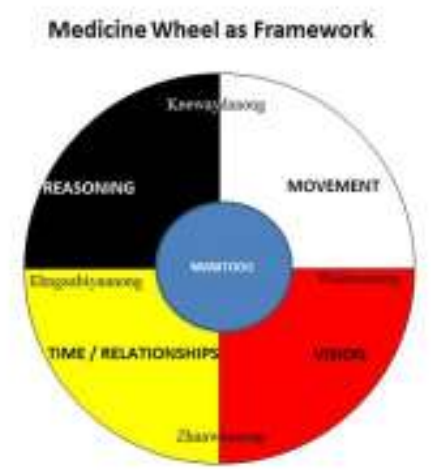

In the Eastern cardinal direction of the wheel we are given the gift of vision. This gift comes to us in the dawn, wabaanong. It is from this place that we ask, "What is it that the Spirit asks of me (us)?" In relation to this inquiry, what is my (our) understanding of healing, wellness, mino-bmaadziwin? 
In the southern cardinal direction, zhaawaanong, we are concerned with relationships and time. Who and how must we be concerned with in our quest for mino-bmaadziwin? From this place, we will discuss who and what needs to be in place to support Indigenous programming and epistemological approaches to learning in Ontario colleges.

In the western cardinal direction, ehngaabiyaanong, we seek to understand fully the work of the Spirit, we are concerned with truth. It is through this process that we are reminded of the gifts of the Seven Grandfather Teachings, “love, respect, honesty, truth, humility, bravery, and wisdom” (BentonBanai, 2010). From this place, we will make connections and begin to identify pillars that are needed to support such programming within Ontario colleges that are academically sound and rooted firmly in IK.

In the north, kewaydaanong, we are concerned with healing and moving forward in a good way, with kind hearts. It is from this place, we reflect on the journey we have made and are able to draw from the experience to move forward. This moving forward is best described as the process of decolonization, letting go of the learned behaviours and negative thought patterns that govern our lives and in this place, building and strengthening our own truth and understanding of life. It is these principles that frame the Anishinabe world view of relationships with all of Creation.

Marlow and Boone (2005) describe formative evaluation as "generally descriptive and provide detail about a programs strengths and weaknesses" (Marlow \& Boone, 2005, p. 87). However, the overarching goal of this research is to also to construct a decolonizing narrative throughout the evaluation process. In so doing, we can identify elements that would allow Indigenous based programs to grow within institutions that are influenced by colonial structures such as legislation, policies, funding regulations and indeed social work education itself. Moreover, that Indigenous based programs are merited with distinction based on demonstrated academic rigour, validated IK and measured Indigenous pedagogy. 


\subsection{Methodology:}

This qualitative research is situated within an Indigenous research framework and is informed by information acquired though engaging with current and past students of the Indigenous Wellness and Addiction Prevention program, and through engaging with key participants who were Ontario college faculty, administrators, program advisory members, and with Indigenous elders.

Cultural practice and protocols such as the offering of asemma (tobacco) requesting participation, prayer and use of sacred items such as medicines and an Eagle fan to open and close discussions were all important aspects of the research process (refer to the Glossary of Terms). The act acknowledges our interconnectedness to the Spirit and to one another. The reciprocal relationship between the researcher and participants is also acknowledged in the passing of the fan. I carry the eagle fan in my personal sacred bundle. It was gifted to me several years ago, to help guide me in my walk and my work as Anishinabe-Kwe (woman). The eagle fan connects us to the Spirit, when we hold the fan, we are honouring truth. When using the fan in ceremony, the carrier acts with utmost integrity, humility, truth, with good heart and good mind. The use of sacred items in ceremony acknowledges the reciprocal relationship between the researcher and participant and at once acknowledges and confirms the intent, integrity, confidentiality and ethical practice of the researcher. Through the use of ceremony, this relationship is sanctioned. However, given that Indigenous practice as such has yet to be acknowledged as demonstrated as consent by the academy, I opted to also request that each participant to indicate their consent with their signature in accordance with acceptable research practice.

The use of sharing circles and key participant interviews were selected to allow for participants to speak from their own personal experience. Inviting their free flow of thought in response to guiding questions is congruent with Anishinabe ethics and principles of free will. The reciprocity of sharing story within circle and within conversation emits an exchange of empowerment from both the sender 
and receiver of that exchange. In that exchange and understanding of the commitment to help one another, the researcher becomes as much a participant in this research journey. Wilson (2008) describes the active role of the researcher in Research is Ceremony, "it is also necessary to internalize the information that is presented. All this means is that you ring the ideas into the web of relationships that is you, rather than have the ideas stranded off on their own with only tenuous relations... only you can know how the information that is shared will fit into your context" (Wilson, 2008, p. 134). As researcher, you are charged with carrying the collective and sometimes individual voice of those who are otherwise silenced. Research from an Indigenous ontology, recognizes and upholds the special reciprocal relationships established between the researcher and researched.

\section{Sharing Circles:}

This inquiry gathered input from students and graduates of the program. These individuals have first-hand experience of the program and have a different perspective as to its strengths and perceived challenges. Current and former students and graduates were invited to participate in one of two sharing circles. Sharing circles allow for participants to share their stories in a safe and cultural environment as described by Macdonald (2006),

Evaluation practiced qualitatively is a narrative craft that involves the telling of stories-stories about individuals and groups of people in their own complex and dynamic communities, stories that enable understanding of what these communities share with others and what is unique to them, stories with an explicitly authorial signature...,and stories with the aim of understanding, and often action, as the improvement of practice or the reframing of the policy conversation, toward the appreciation of pluralism and complexity. (p. 11)

Notices of the research and an invitation to participate in the sharing circles were posted throughout the college.

The sharing circles were scheduled and hosted on campus at Canadore College. Notices explaining the purpose of the research and who should participate were posted in the classroom where 
the Indigenous programs were most likely to be scheduled, as well as in the Aboriginal student lounge and hallway leading to the First Peoples' Centre.

The first of two sharing circles had to be moved from the original classroom due to a scheduling conflict for the room. As students began to arrive, an announcement to move the circle to another location in the college was made. Five individuals participated in the first sharing circle. Of the five, one was a former student, two were second year students soon to be graduating from the two year program and the remaining two were completing their first year of the program. The second sharing circle was held two weeks later. By then the participants of the first sharing circle had spread the word of the research and encouraged other students to attend. Scheduling for the sharing circle was challenging as students were now preparing major final assignments or final exams. Five individuals participated in the second sharing circle. Of the five participants, 4 were first year students and 1 was a second year student.

At the commencement of the sharing circles, I explained the purpose research and the use of circle within the research framework. Participants were made aware that circle was scheduled over three hours and that I would be mindful of the time and would close the circle as we neared the end time. The elder in residence attended both sharing circles and opened and closed each circle with a prayer. Each participant was given time to speak to each of the five open ended questions posed to them (Appendix 4). An eagle fan was passed from each speaker, while that individual held the eagle fan, he/she was able to speak uninterrupted.

Participants from each of the sharing circles were able to speak to each of the five questions. The sharing circles were audio recorded and copious notes were taken by the primary researcher throughout the sharing circle to capture participant responses. 


\section{Key Participants Interviews:}

Key participants interviews were centered on understanding IK, and how Ontario colleges can better support Indigenous based programs within institutional academic frameworks. Key participants interviews were conducted with Ontario college administrators, faculty, support staff, community elders and program advisory committee members from a purposive sample.

Key Participants were contacted by email. A letter inviting their participation in the research was attached to an introductory email. The key informants were asked to confirm their interest in participating either by telephone or email. Subsequent interview times were scheduled with each key participant. Every research participant participated in key activities that employed traditional Anishinabe practices and use of traditional medicines and sacred items.

I proposed to conduct a total of 8 key participant interviews with a small purposive sample representative of key individuals involved with this, or similar Ontario college programs. A total of 7 key participants' interviews with administrators, teaching faculty and with members of the program advisory committee were held. Six of the key participant interviews were face to face and one was a telephone interview.

The interviews were conducted using a semi-structured interview guide. Five open ended questions were posed to each key participant. The length of the interviews varied from 60 minutes to 105 minutes long. When key participants were approached to invite their participation in the research, a follow up email was sent to them providing them a copy of the key participant consent form (Appendix 5). Prior to starting the interview, I reviewed their consent to participate and answered any questions. Key participants were asked for their further approval to have the interview audio recorded. All key participants consented to the audio recording; additionally copious notes were taken to capture responses. 
Assemma $^{9}$ (tobacco) was offered as a gift to key participants who participated in this study. Traditionally, the gift of tobacco was given by an Anishinabe so that he/she could ask for help in a good way. The gift of tobacco is represented in the East, it is the first medicine. When an Anishinabe person is asking for anything to help sustain his or her life, tobacco is offered to the Spirit, the animal, the earth, or other individuals in a good way as a gift and acknowledgement for the gift that is being asked for and received. The reciprocity of relationships is honoured in the giving and accepting of tobacco. The recipient determines for him or herself whether to accept the tobacco and ultimately the responsibility of honouring what is being asked. And with a good mind and kind heart, the recipient acknowledges that helping Spirit.

At the completion of the interview, notes were transcribed from the audio recording, each key participant received by email copies of their interview. They were asked to review the notes from their session and to return any changes or deletions back to me by a specified date. The notes were verbatim and included areas where there were pauses and / or laughter. Also included in the verbatim notes were comments that were made that key participant requested they be taken off the record. These statements were italicized and noted as 'off the record'. The off the record statements were not to be included in the final report. There were no requests for modifications to any of the key participant notes. Participants were again informed that the discussion would be presented within salient themes and no identifying information would be provided.

\section{Cultural Protocols/Practice in Research:}

As much as possible, I drew on traditional Anishinabe practice and cultural knowledge throughout the research. However, western research methodology was overarching and overpowering at various times throughout the research. My first dilemma was deciding how much indigenous knowledge

\footnotetext{
${ }^{9}$ Assemma - tobacco Anishinabe traditional medicine
} 
to share. There is a deep mistrust of Euro-western systems that is shared amongst Indigenous people around the world and with great reason. I struggled personally with determining what to share: how would it be received? How will it be used by others and am I right in sharing knowledge that is collective knowledge? With those questions looming, the urge to resort to Western research methodology was overpowering and could diminish the conflict I was having with myself. At the same time, doing so would do the research a great injustice.

In the void of a step by step Indigenous formative methodological framework and to simply satisfy the requirements of the academy, carrying forward this research within a Western paradigm may have been an easier road. That is not to say that the challenges of satisfying my degree requirements was by any means easy, the struggle to reflect the spirit and intent of the research from an Indigenous place requires the researcher to be at a spiritual and personal place that is grounded in all that is good, mino-bmaadziwin.

As I struggled with determining how best to sort and present rich qualitative data, I was challenged with asserting my own voice and the voices of who so eagerly and graciously participated in this research with the full knowledge that together, we speak to those who have gone before us and are creating a space for those who will come behind us. Lambe (2003) describes this experience... "is the conscious or unconscious assumption that European knowledge structures and values are universal and reflect the highest standards in terms of accuracy and validity, and other means of constructing knowledge or those outside the fold are not" (Lambe, 2003, p. 319). This Euro-centric imperialistic ideology is deeply ingrained in academic study. We are taught to strive for and to stay within its confines. What I have learned through this experience is that Indigenous research is creating new knowledge that requires a significant departure from the hallowed confines of Western based research. Indigenous based research paradigms and Indigenous Knowledge challenges the notion of validity in 
social science research and challenges the notion of accuracy and reliability. Western research has historically oppressed and silenced Indigenous voices. To codify participant voice and story would serve a great injustice to my research and in so doing would alienate and further silence the Indigenous voice in this research. Through ceremony and prayer and my commitment to the collective and individual voices of the participants, I was guided back to the wholistic teachings of the medicine wheel.

Chilsa (2012) describes the decolonization process within research as having five phases, rediscovery and recovery, mourning, dreaming, commitment and action (Chilisa, 2012). Through the telling of story in this research, participants were able to reconnect with their personal histories, collective histories and give voice to silenced generations. There was also a process of grieving past losses and acknowledging the gifts of our ancestors throughout this process with hopes and ambitions to improve the lives of Anishinabe. The subjective and personal journey of Indigenous research is absolutely necessary if Indigenous peoples are to lift themselves from the vice of colonization. "Indigenous thinkers have advocated for the recovery and promotion of Traditional Indigenous Knowledge (IK) systems as an important process in decolonizing Indigenous nations and their relationships with settler governments, whether those strategies are applied to political and legal systems, governance, health and wellness, education or the environment" (Simpson, 2004, p. 373).

In western based research, Wilson (2008) describes the "dominant system research paradigms is the concept of the individual as the source and owner of knowledge. These paradigms are built upon Eurocentric view of the world, in which the individual or object is the essential feature" (Wilson, 2008, p. 127). From my perspective as an Indigenous woman, this research belongs to the participants and the communities in which they come from. My role as researcher has been to facilitate and to give back to the people a little piece of myself in collaboration with their work, something that will bring good to all the people. Through this research, I have found that the departure from Western based research 
frameworks was most rewarding and resonated most with the goals to ensure the voices of the research participants were being heard. As the researcher, I could see myself reflected in the voices of all participants, both Aboriginal and non-Aboriginal. Five open ended questions were employed with the sharing circles and key participant interviews. The responses to the query and overarching research question are presented from these perspectives. The general findings sum up the research and the final chapter presents considerations for future research. 


\subsection{Limitations of the Study:}

This research included a review of literature, sharing circles with past and current students of the Indigenous Wellness and Addictions Prevention program and key participant interviews with individuals associated with this and other Indigenous based programs within the Ontario college system. Key participants were involved with the IWAP or similar programs in various capacities including teaching faculty, program advisory committee members, administrators, program Dean's, Vice Presidents or Directors, and/or community Elders.

Although each participant group was able to speak quite well to their individual experience within the program and within a college setting, very few spoke specifically to the program's content, learning outcomes and/or assessment strategies currently employed within the program. The research is limited to the qualitative responses provided by the participants groups. Quantitative program data would have provided a baseline data set with respect to program enrolment and completion rates, however would not address the question of academic rigour or maintaining IK with the program. The limitations of this study highlight the need for further research to establish such baseline data. 


\subsection{The Sharing Circles and the Key Participants' Interviews}

The findings are presented in the following section. Salient themes of the discussions held from both sharing circles and key participant interviews are presented visually on the medicine wheel framework and discussed within the participant group responses (Appendix 2). To ensure the integrity of perspectives and to ensure the spirit of each participant group was maintained, I opted to keep the responses by the two distinct participant groups separate.

Each group and indeed each participant offered great insight into the program and the needs of students, college staff, communities, institutionally and globally. The forward thinking amassed in the circles provides a wealth of knowledge, as did the conversations with key participants who were able to speak with earnestness and candour. As I began to sort through and bring together the rich qualitative responses that were shared with me throughout this study, I quickly realized that the impact of this Indigenous based program was multi-dimensional and although the overarching question of "how can the IWAP program maintain academic rigour while maintaining its Indigenous epistemology” guided this research, the ensuing discussion extended beyond classroom content and pedagogy, to identify institutional and social dichotomies that exist within Ontario colleges that impact Indigenous based programs, their faculties, administration, policy and ultimately how college's interact with students.

I was tasked with ensuring that the voices of each of the participants were reflected with the utmost respect and integrity and as much as possible in the spirit in which they were given. Salient themes were evident as I collected participant responses either through circle or key participants interviews. The personal and shared experiences by participants are illustrated on the medicine wheel as salient themes. 
Salient themes:

\section{Medicine Wheel (salient themes)}

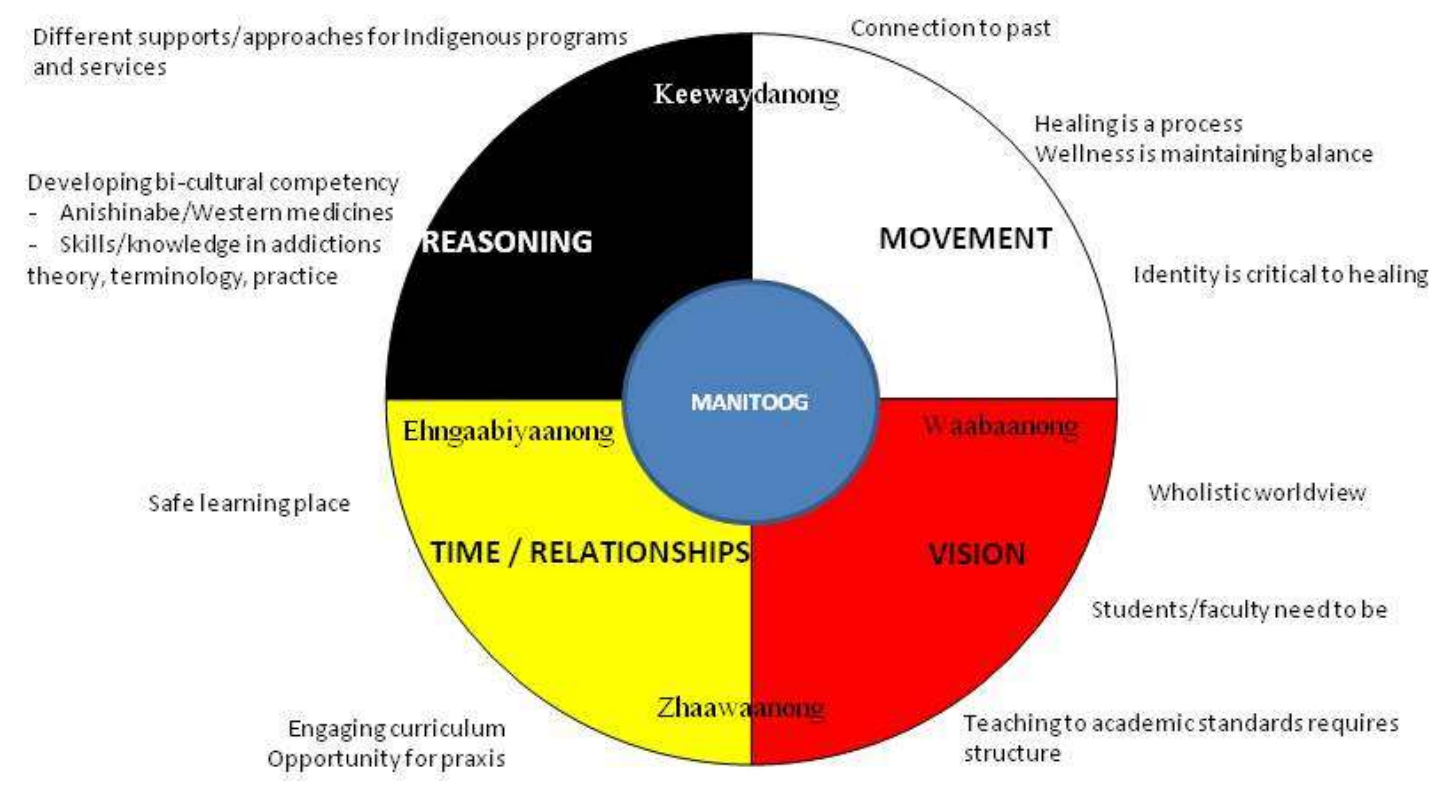

The salient themes are discussed further in the discussion section. What follows here are the qualitative discussions from the Sharing Circles and Key Participant Interviews.

\section{Sharing Circles with current and past IWAP students:}

\section{Wabaanong - what is my understanding of healing and wellness?}

Sharing circle participants describe healing as a process where one strives for balance in four areas of self: mental, emotional, physical and spiritual. Part of the healing process is coming to understand how imbalance affects your life as whole. "It's being able to come to terms with your past and that, and the things that others may have done to you". "It is about a mindset of moving forward, 
face the past and understand what is there and to know that it's okay to face that anger. Not to always have that survivalist attitude". The common thread in understanding healing was the act of letting go, and reaching far back into history, into the times of past generations. "Whether we got emotionally hurt or not, because our ancestors are still hurting from what happened to them, it's a long process at some point one of the generations has to stop that cycle. And it has to forgive the unforgiveable. Release those ancestors that were hurt; it takes a long time to do that, because we just keep acting out hurt and abuse that was taught to our generations coming down. It takes a long time to get there”. All participants spoke about their ancestors, their history and how that has had such a profound effect on their personal lives, identity and sense of responsibility. Each participant described healing as moving forward with a renewed sense, strongly connected to knowing their history and culture. In the field of addictions, mental health and wellness, intergenerational and unresolved trauma are often at the root of addiction issues.

"Spirituality is a really key point in healing because believing in a higher power than you; it could be anything, the son, spirit, God - that is spirituality. The Creator and stuff, they are spirits in our physical being; we all come in balance with one another and nature, because we are all related”. Through our relationships we are challenged to address those areas of our Self that are more difficult to face. One participant described it as this way: "You need to be fit, you need to be in a positive mental place, you need to be tending to your emotions that we may not always face, we think that they will just go away; the truth is we are going to have to face it". Participants echoed the sentiments of balance, nurturing and tending to your thoughts, ensuring that you maintain good positive thoughts. "It's one thing to be able to accept it, but another to understand what its purpose it was to you in understanding in your life and I think that is what healing and wellness is". 
Each participant described healing as a process or a personal journey where they were systematically addressing each part of themselves and striving for balance. Wellness on the other hand, was often described as a state of being that required as much work to maintain. One participant described his understanding of wellness as "a bunch of things; I think it is a bunch of little things done well that will lead to a bigger picture. I think it's about being centered with your Self - to be true to what is going on inside yourself, spiritually, mentally, emotionally. And I think that it's really working and striving toward, moving toward the person you know you are inside and who you really are, and working hard to not be that person that's what that means to me". Another participant summoned up his understanding of healing and wellness as, "It's something I want to work towards. Wellness is a balance of the mental and physical, spiritual and emotional. It's really helped me in this course to work on my mental side and my spiritual; I have to go do some more work on my emotional healing which I will do in ceremony. And physical is another area that I have to work on to get balance. That's my understanding of healing and wellness, to walk in a good way, to be peaceful and serene that is my goal in life today". Another participant added, "You have to know your past, or you will become spiritually lost".

The connection to the past each participant shared is essential in order to achieve a state of wellness. As Indigenous wellness workers in the field working amongst Aboriginal people, it is imperative that graduates of the program walk in a good in way. They are often closely observed by the community as they embark to establish rapport, trust and relationships with the community. Graduates will require knowledge of intergenerational trauma as it pertains to Aboriginal peoples, colonization and its effects and skills to develop self-efficacy and resilience. An academically rigorous program will demonstrate that these skills and knowledge base are aptly demonstrated throughout the program. Participant responses however indicate that teaching dispositions and teaching styles varied significantly 
and that some students did not feel like they were prepared academically for practice. In relation to understanding the principles of healing and wellness as a personal journey, participants were confident that the program was addressing this understanding. Some participants expressed that they preferred to focus solely on understanding Indigenous wellness and cultural practices.

\section{Zhaawaanong - who and what needs to be in place to support this program and prepare students for work in the field?}

When asked "how will or has this program prepared you to work within Indigenous healing and wellness models?" participants had mixed feelings and thoughts about how well they felt the program prepared them for employment in this field. Many of the first year students were very confident that the program was preparing them for work in this field. Many participants spoke about the various skills they were developing through their course work, readings and practical learning experiences. Other students, who were either former students or second year students, stressed that too much time was spent in circle and they felt that the sharing circles held in classroom were often too long and seemed to take on more of a healing circle atmosphere. "I understand traditional teaching and learning and that they are based on oral instruction, this forced me to be a good listener but I need to be engaged and feel like I am learning something". It was clear those students who were of the former curriculum felt as though the program could do better to prepare them for work in the field. It was evident that the teaching styles and demand on students were considerably different by the program professors in the two years of the program. Students in the first year of the program expressed confidence in their preparation for practice, while upper year students did not express the same confidence.

Another participant when reflecting on the program stated that "I strongly believe that as Aboriginal people we have to know our own history, we need to know where we come from to know where our ancestors come from, that is what I see as lacking in this program. There is a course on 
residential schools that gives a little bit of information, but it should dig deeper. We need to know where we have been in order to know where we are going". While other participants who reported being in their first year, commented that the three day culture camp held in the second semester of the program was a wonderful experience for them. Receiving traditional teachings and hearing the Anishinabe Creation Story was powerful. "The culture camp gave a good foundation of the teachings however, having a culture camp in the beginning of the year would have been better".

Participants spoke about how prior to coming to the program, they really didn't pay much attention to the teachings they received at home. Many spoke regretfully about not paying more attention to those teachings. One participant shared that she would have felt more prepared for this program had she paid more attention to the traditional and cultural teachings at home. She stated that she felt like she was not prepared to come into the program. "The cultural teachings have helped me in my personal life, especially in the outside world. I enjoyed the teachings, helped prepare me. The Helping the Helper course gives a lot of formal training, it has everything included in one course such as becoming a helper, drug \& alcohol abuse, residential schools, communication, was a variety, was good. Needs to add more about where our ancestors were at so that we can see how much everything has changed".

There was a shared sentiment among all the participants in both sharing circles that the IWAP program plays an important role in preparing students for work in this field. The program does prepare them to address historical trauma through both western and traditional approaches. "There is a belief that once an alcoholic always an alcoholic, people define us by our ancestors, we have the power to change. I speak from experience. I used to be an alcoholic. We have been using excuses for too long...my grandmother was abused, my mother was abused, and therefore I am the way I am. We have the power to change that cycle. That's important. That is why it is important to include classes on residential schools in the program". 
In that vein, learning on the land through traditional practices was felt to have the most impact on the students' learning and their confidence in working within this paradigm. "I believe that there are resources out there on the land that can speed up healing time and it may vary from person to person and is a slow process in my opinion". "You have to know your culture that was lacking in the first year. I am non-aboriginal myself, felt I knew more than those that are aboriginal. Before you can move forward, you need to know your past. On First Nation reserves it is all negative, substance abuse, mental health...they are sensitive topics and people do not enjoy talking about it because of the nature of it”.

All first year participants had very positive reactions to the teaching methods being employed in the program. Participants were eager to speak about the use of medicine wheel teachings as models for assessment and practical approaches to interviewing were quoted as being the most valuable skills they were able to develop.

\begin{abstract}
"The most important for me personally is a way that things are taught. It's more than just memorizing information but having ways in which to practice and not just recite definitions or being able to write long papers without truly understanding the material you're learning. So that when it comes time for us to be out in the field, we'll know what we're doing because each person we meet will be different and we'll be able to mix all of these different things that we've learned to best help the client because we have been open, instead of categorizing an $\mathrm{ABC}$ case and therefore having to do an $\mathrm{ABC}$ method".
\end{abstract}

The application of theory in the classroom learning environment is reinforced as students are able to develop an array of theory and helping practice from both mainstream and Indigenous helping methods.

While others were most impressed with learning about Anishinabe culture and traditional knowledge, "this program has helped me to work in this field for me it really was an introduction to the culture, for me I didn't have a chance to grow up in my community, I grew up in a lot of non-Aboriginal settings, so for me this program has really helped me understand where and how the current situation has come to be and to, in a sense, let go of some of the stigma that I had previously. That is not to say that I was disgraceful about it, but I could not understand why things are the way they are in the modern 
world. It has helped me to become familiar and to become attached to regaining my identity within the culture".

On a very practical level, participants felt very confident in the skills they have acquired in the course and through practice, are preparing them well for employment in this field.

\begin{abstract}
"This program has prepared me a great deal with showing me how we have to be able to record case notes, have to be able to write treatment plans and it has shown me a lot of different ways that we can do it. Myself I really enjoyed using the medicine wheel as a way of even assessing a client, even as I am looking at a treatment plan to handle all those four areas and to work on balance for the client. I don't even like that word client, but to work with people that we have to learn to be able to respect in the indigenous work, that we have to respect the persons wishes, if they don't want any traditional healing we have to respect what they want to do, a lot of our people follow religious ways".
\end{abstract}

Participants felt that although the program is based in Indigenous knowledge and practice, they are also taught to respect the views and beliefs of those they will work with. "We have to work with whatever the person that needs healing is accustomed to and respect the way they want to work introducing them into new stuff might be possible but you cannot force that on anybody". The use of cultural based assessment and treatment models for intervention and support are empowering, "for me the medicine wheel has been the biggest thing that you can use it with almost anything and the circle. Just the respect and encouragement that everyone gets in a circle that is the biggest thing I've learned here that everyone has a voice, no one is above anyone else we are equals and just how to help somebody find their inner fire and ignite it, that is what I've learned through this".

Participants were appreciative of learning both western and Anishinabe approaches in the helping relationship. One participant stated, "We learn Indigenous ways of healing, but we also study a lot of western ways of healing. I think both ways are good but me myself I would rather take the indigenous ways of healing because a lot of times, in the western way of healing you are prescribed pills or things that are specially for one area, and in healing most of the time you are looking at all four areas - emotional, physical, spiritual and mental, that's really important in healing because if you are only 
trying to heal one area, you lose focus on the other three. You lose balance, and when you learn how to work on four you learn how to bring that balance back to that area that's weak, so you become balanced". It is interesting to note that participants obviously feel more comfortable in learning Indigenous based helping methods and express frustration at the incongruence of Western approaches in some respects. An academically rigorous program would ensure that students although grounded in Anishinabe ideology with respect to wellness are also well versed in Western helping approaches and are able to decipher which approach is better suited in individual case planning as well as in community development practice.

The program based in the Anishinabe ontology that we are all related, appears to be reinforced through the course work and practical skills students report they are learning. "We learn to grow with each other. We need each other, when I am working as a counsellor, I am not healing them, I am helping them towards their healing, and they are healing themselves. I really respect if I can be helper in someone else's healing journey because we are all in need of each other and it gives us meaning in our life". The relational nature of Anishinabe ontology is evident as this participant speaks to the role of "helper" as more of a facilitator.

Participants spoke about the culture camp they had participated in during the winter semester. The camp was facilitated by elders and was held over three days. The participants all spoke about the camp as a very positive and empowering experience for them. "I love our teachings because I believe they are all true like our Creation story that we got to learn a bit of it at our culture camp, it has prepared me and given me more meaning to life - understanding of where we all come from and that we have a culture, just like all other races in the world. We all have culture that the Creator has given us. We all were given languages and its awesome, I realize that its prepared me a lot for a lot of things, being able to talk to people, communicating with people in a good way...And to learn to respect someone is a 
really good honour because it helps to bring out those emotions that we have about a lot of different things. A lot of us are stuck in the ways where we hide our emotions, we are not supposed to have emotions, but we all have emotions. We all get hurt, we all get frustrated, we all get happy, and when we're feeling happy it's a good feeling to have. And I think that healing is also working towards being happy, to have a full life, a healthy life. This program helps me to do a lot of it because it reminds me of how I can stay in balance; it reminds me of a lot of the teachings".

For some students, the topics on residential school, intergenerational trauma, history, colonization were all very informative, yet very sensitive. Some participants expressed that they had grown up in urban communities and knew little about First Nation reserves.

"Prior to this program I wasn't aware that Aboriginal people had such a rich spiritual history. I was aware of residential schools and the horror that people went through of the assimilation act and whatever, knowing all the history gives me a better understanding if I am in the helping field, if I am working with an Aboriginal person this would definitely give me a better understanding other than just a narrow minded point of view more or less. I think it is very important to not just Aboriginal people, you must know their background before you can help them heal. This program has helped me to work with Aboriginal people and within an indigenous wellness model”.

Another participant shared that he struggled with a negative self-concept, while others expressed sadness.

"When I said that there was some kind of stigma, it wasn't necessarily the judgment that was there but the frustration of not being able to understand the contrast between the community I lived in and my hometown. It was more of a sadness, sadness deep inside that I could not really express to someone who was not Aboriginal and come off as sounding judgmental or resentful. It was just the frustration of not being able to understand. But this program has helped me to understand, and to help other people understand the impact of intergenerational trauma and that understanding how trauma happens throughout the generations can be a step forward in a person's healing journey".

Participants expressed feelings of empowerment, feeling good and proud of their identity. They question their earlier experiences and seek to understand their personal experience as it relates to intergenerational trauma and how it continues to influence their lives. 


\section{Ehngaabiyaanong - pillars need to support programing that are academically sound and}

\section{rooted in IK}

When asked how Indigenous based programs can maintain their Indigenous foundations while meeting academic standards, the sharing circle participants who identified as being in year one of the current program indicated quite clearly that they had no question that the program was indeed meeting any and all academic standards. "As far as maintaining goes, it is maintaining right now. Just keep doing what it is doing. Not sure what the agenda is for the program, whether it is to expand or just keep what is there right now as a base. But as far as relationships the Indigenous programs and the school's academic standards, the school will always need a very solid relationship and communication and understanding from both sides. I think that ultimately that is what is has to be, open communication and understanding from both Canadore academic standards and Indigenous programs. I think what we want to learn [within Indigenous programs], is material that we would learn in other programs not just only for Indigenous people of Canada but counselling and psychology”.

Participants expressed that the skills they are developing are relevant, practical and are academically sound. The bi-cultural teaching and learning approach has helped to bridge diverse understandings of the helping process. The students who come to the IWAP program are a diverse group, some relocate to the city from First Nation reserve communities, others are Aboriginal students who have never resided in a First Nation community, living in an urban setting most if not all of their life, and others still, are non-Aboriginal with an interest in learning about Indigenous healing.

"When you are raised thinking in one way, you have a hard time understanding another person's point of view. But it's very important that the college understands that our professors might be giving a traditional teaching and that they are able to teach us how applies to the helping field. Its more holistic in the ways of our culture, you're not just looking at what you are learning but how to apply that and how it 
makes you feel, and accepting those emotions instead of just reading this definition as a long Latin word, it's more than just memorizing it. It's wholistic and it is very important that the college and all the faculty members are able to gather and understand and communicate, so that as more changes within the academic standards come along then there will still be this peaceful relationship within the college between the faculty and decision makers within the college".

While all participants were generally quite pleased with the program, students who were in the second year of the current program expressed a bit of frustration with what they saw as a lack of academic structure in their first year. They felt that while there should have been more opportunity for cultural hands on teaching and learning, too much time was spent in sharing circles. The transition into the second year, they stated has been a little challenging as they have had to adjust to a new professor in the program. The teaching styles of the professors, they stated are quite different. One participant stated that, "Whoever is coming to teach in this program, needs to have a good understanding of Aboriginal people, the hurt, the history and what is going on currently. There are huge changes from reserves to cities and change influences people. It is very important for professors who teach us, to have a good knowledge of Aboriginal culture".

Many of the sharing circle participants shared their personal healing journeys and each spoke to how the program has helped them to better understand their own healing process. Not all participants are abstainers; many participants shared having had conflict with the law and issues with alcohol and/or drugs and other substances. One participant shared, "I personally feel like I have a long way to go, to get back to the work field. It's been a few years since I've been in jail, I am going to get a pardon, and I am trying to behave. It helps a little to talk, but not as much as actually doing it. (laughs). I haven't really worked on myself within the culture. I am taking baby steps. I am helping my sister get her bundle together though. We recently got tobacco. I've been invited to go to a sweat lodge, if I feel like it I will 
go, but I haven't felt like it yet. I have been using for the past 2 years. I pray every day, today was the first time I laid my tobacco down. It is a slow process for me right now". While many participants expressed that they felt like the program should only be open to individuals who are on their healing journey, this participant felt quite safe in sharing her continued use.

\section{Keewaydaanong - overcoming challenges and moving forward}

Participants were asked to think about some of the challenges that they may have seen or experienced within the program and how the college might be able to address those challenges. The most prevalent issue and concern raised by each participant was the ability and space to smudge using traditional medicines such as sage or sweetgrass. The only place on campus that anyone is able to use medicines and smudge is in the IWAP designated classroom. However, the participants stated that when they do smudge in the classroom and have the exhaust fan turned on, there are always those who will complain or make derogatory comments. In reference to the use of smudge, one participant noted that "the class location might be a little strange as other participants said - that it kind of bothers other peer classes in the surrounding area, I don't think that it is something to be ashamed of; I think it's just something that they are unfamiliar with".

All participants also stated that they would get so much more from the learning experience if they could be out on the land a lot more. One participant explained that being on the land creates a sense of connection with Mother Earth who supports us in our lives, he explains that the Earth Mother reconnects us to life - grounds us, and when we are grounded we are less likely to fall apart. "If you are doing something outside on Mother Earth, people don't fall apart as much, because she's there, she's supporting us. The emotions come but they aren't as hard to take, you know, when you are outside on Mother Earth. That's what I would like to see improved [about the program]".

Participants in both sharing circles expressed concern for those individuals who come to the program from places of hurt, abuse, trauma and loss. They shared that the program touches on a lot of 
historical issues that will often trigger people. "It comes to be an emotional journey for students and other students. I think that it will just be to be mindful and to be receptive and be ready for those students who are going to have that kind of healing within the class". With respect to policies regarding a duty to report in situations of abuse or self-harm, students should be made aware of this.

"Some of the policies, should be mindful that a lot of the Indigenous students coming to this program come from those damages themselves, be it a history of drug abuse, history of sexual abuse, or a history of mental, physical abuse, and sometimes in this kind of setting such as the IWAP class, those issues can sometimes surface....I'm not thinking about anybody specifically, but they are not always considered, not always tended to, but it is a classroom setting and is not always a healing circle that is there for that purpose, but in my opinion the program needs to be more open and more receptive to students who chose to have that place to be to get those things out now that the understanding is there for them to be able to share those things. I think that it would be important too, to mention to students that staff does have a legal obligation to report any cases of someone who is speaking of hurting themselves or someone else within the class".

Participants further added that because of the extremely sensitive and potentially explosive content of the program, supports for students within the classroom and external to the classroom and college should be made available for students who will be triggered by the course content. That the classroom environment is not intended for "healing" per se, but that inevitably, many individuals if not all, will be affected by the material. They require adequate supports to help them work through those triggers. Some participants suggested that students should have healing circles away from the classes to help address "triggers" and provide support. "I think a healing circle is great place to do that. In a healing circle I guess there are policies too that you don't interrupt each other, you listen when someone else's is talking. That really means a lot to everyone when you are listened to. Our spirit feels good, I think our spirit really likes that when people listen to you, makes you feel good inside".

\section{Manitoog - what improvements can be made to the program?}

To improve the program, participants felt that extending the culture camp more than three days would give them more time to learn about foundational teachings such as the Creation Story. Students 
need to be encouraged to learn on their own as well, away from the classroom to seek out their own understanding of how the teachings apply in their own lives. Time spent on the land in a natural learning environment where the use of medicines could be done more often was another area that participants felt the program could improve on. In terms of challenges, one participant spoke about how other students in the college don't understand what goes on the IWAP classroom or what the program does on the land. And although there were invitations for anyone to come in and take part in the feast, other people did not come in. Participants stated that college decision makers should come in to the classroom or into the tipi to see what goes on. "It would be good for them to come to the classroom for a feast and to have some involvement to see that this isn't just a little powwow it's a ceremony and education mixed together in one and we're not trying to take advantage of them for any reason but to welcome them into our rooms and into our process and help other people understand".

All participants expressed a desire to help others understand the importance of culture as healing. “And especially I said before with the smudging, that's usually how we open up our classes, if somebody is having a hard time, we light that with our teachings. That's how we heal and help others, but I can understand at the same time how other students or how some other professors might complain and there's not really any right way to go about that because it's in our teachings, it's in our blood. But they may have a valid reason for their complaints. And they might also just not understand the importance of that". The participants expressed the need to find a viable solution that allows them the use of smudge while respecting the needs of others in the college.

\section{Miinwaa - final words}

To close the circle, participants were asked if there was anything further that they would like to add. Each participant expressed an appreciation for having the opportunity to be a part of the sharing circle and looked forward to hearing more about the final report. One participant stated, 
"I feel very lucky to have an opportunity to learn about my culture in an institution in a place with so many policies, rules, and codes and restrictions and departments, because it wasn't that long ago that all of these things were happening to our communities and it was within our professor's lifetime that things were occurring. And also we still see struggles today and it is such a huge opportunity to have this course offered to the public and it really shows a lot to be able to combine the Euro-Western way the policies with our culture and our traditions and our teachings, it is so huge and I am so grateful. Miigwetch".

\section{Key Participants' Interviews:}

Face to face interviews were conducted with six key participants one telephone interview was also conducted with one key participant. The key participants were given five open ended questions with respect to the IWAP program and/or with respect to Indigenous programs in general within Ontario Colleges. Key participants were selected from a purposive sample and included Ontario College administrators, faculty, elders and program advisory committee representatives.

\section{Waabaanong - what is my understanding of healing and wellness?}

Key participants were asked to describe their understanding of healing and wellness. Each participant described healing as personal journey with many starts and really no end. The process as described by many key participants, is a conscious act, we make up our minds about wanting or needing to be in a better place, mentally, emotionally, physically and spiritually. Healing was described as seeking balance. All key participants whether Aboriginal or non-Aboriginal described healing as addressing multi-dimensions of self over a continuum. While wellness, was focused on maintaining that balance. Wellness was described as walking in a balanced way, being in tune to your body, mind and spirit and tending to those needs. Wellness is described as something that we aspire to in our lives. Each participant spoke to being active, eating well and maintaining a positive outlook. While another participant described wellness as, "those periods in between that healing process where people feel well so that they can function in their emotional wellbeing, psychological wellbeing, in their families, communities, work and relationships". 


\section{One participant stated,}

"I look at your physical self as the vessel that the Creator has given us. I am the human being responsible to take care of that vessel. I have been given that skill by the Creator to learn how to take care of my physical self, that is my humanness, being in touch with my humanness and accepting that part of my Self'. It is taking care of your physical self, being mindful of what you are eating, and being active and exercising. With respect to addressing our physical self, one participant share "The physical part, seems to be much larger that a lot of people seem to understand because physical means a lot more than the health of my body, I think the physical is the house I live in, the job I have, the environment I am living in, is it healthy? All those things have some kind of impact on the physical, yeah the body is a part of that and sometimes you are impacted by those things in your environment, if you are not in a healthy environment your body is going to pay for that. If you don't have a job, eventually your body is going to pay for that and it's going to affect the way you think and feel. So that physical part is much bigger than wellness of a body or the health of the body. It's all the physical things we can see, it's all the tangible things that are there".

Spirituality explained one participant, is being in touch with your inner being, with the Creator and all that surrounds us. It is that relationship we have with our Self, with the Creator and all of

Creation. It is deeply personal and intimate. All participants spoke to a relationship with a higher power

- God, Spirit, or Creator as an important aspect of healing and wellness.

"Spiritually, I walk that red road, my spirituality is so important to me. I understand who my spirit is as Anishinabe-Kwe - as a woman, and the gifts I have been given as a woman. That's my spirituality - to recognize that and to accept that native spirituality in my life, and learn about it and work with it. That entails finding my name, my clan, going in to sweat lodge, working with sweat lodge, the teachings, working with the water, all those things that talk about native spirituality. Once I am able to do that, and I find that balance in all those things, then I can go and begin to work with the community".

One participant stated, "Healing for us as an individual, and as Indian people, is to tell that other story. And people have to listen to that other story and acknowledge that it's truth. Right now the way things are done, I always feel like we are just going through the motions”. Participants expressed a need to address historical oppression that continues to play out in systems, institutions, classrooms and relationships today. 
"Something has to happen at quite a bigger level. Will that day ever happen? Well you have to be optimistic that somewhere along the line that it will. Part of that change that is going to happen, I believe is by educating not just non-native people but native people as well. We have to tell our own story; many of us haven't heard that story at all. But we live it. We live with those pieces here and there. Some of us live under treaties, some of us have reserves, so we live with that stuff but we don't know where that came from. That other stuff is important to the story - the history of Canada needs to be told. So that's a part of a healing journey. A long ways around the question but that's what I think about healing \& wellness".

Many participants spoke about intergenerational and unresolved trauma in Aboriginal communities. The impact, it was shared, continues to influence how we see and feel about ourselves as Aboriginal people. One participant shared, "emotionally my healing progressed in that area where I started to feel again. I started to feel good about who I was. Prior to that when I was using, I never felt good about myself". Healing involves feeling good about who you are and to be able to do that, we learn how to nurture that part of our Self and letting go of those things that do not serve that purpose. Healing even as a personal journey requires us to reach out and seek out the help we need. "I started to search out people who were positive about life and who were also on a healing journey. All of this I had to figure out on my own and by talking to people who were already on their healing journey. To me that is what healing is" shared one participant.

With respect to caring for the emotional self, one participant explained, "The emotional part in wellness to me is when I am in touch with it every day and how I work through my emotions. That whoever I meet I am in touch with my emotions that I have, or the attitude that I have toward that person, that emotion and to accept that emotion and to learn how to work with it in a healthy way. Like if I have anger, its ok, but I have to learn how to work with that anger. Anger can motivate you to do something, to change a situation you are in or something”. Healing and wellness as described by each participant is within our personal power to achieve. 
With respect to addressing healing and wellness within Indigenous programs such as the IWAP program, participants spoke to empowering students by way of enlightening students with history, knowledge and experiential learning. In addressing history, participants noted that colonialism is not a nice story. It elicits reactions that are often startling or bewildering to all students who realize that they are affected by these historical events whether they want to admit to it or not. "We are talking about colonialism and I can never make that story nice. It just doesn't work. And when students hear that, they think that you are blaming them and they get angry and we end up apologizing for telling our story, but only because there'd be a line up at the Dean's office complaining about our course, because we are telling them our story".

Participants noted that programs such as the IWAP program have a role to play in providing a foundation for students to learn as part of the curriculum, about colonialism, the impact of residential schools, intergenerational trauma to both urban and rural families within a culturally safe learning environment. Not only do students need to feel culturally safe within the learning environment, but faculty as well must feel culturally safe and supported by the college as they do their work.

\section{Zhaawaanong - who and what needs to be place to support this program and preparing students for work in the field?}

From their understanding of healing and wellness, key participants were asked to comment on how they thought colleges and universities can prepare graduates from such programs for work in that field. Participants spoke to a wide range of considerations when posed this question. For many participants, the work in preparing graduates for future employment stems from preparing them as conscientious citizens.

From the basis of their understanding, key participants were asked to describe how colleges and/or universities can prepare its graduates for work in this field. All key participants spoke to the need 
for graduates to not only understand healing and wellness from a theoretical basis, but that they have had to have started to do their own personal work in their lives. All key participants expressed that graduates must have a solid foundation of the work involved in facilitating different concepts of "healing" as a process within their cultural contexts. That includes developing cultural competency and culturally safe practice. That foundation might include things like, demonstrated understanding of cultural safety competencies, understanding colonialism, the impact of residential schools not just on individuals but on intergenerational families whether urban or rural. "That foundation includes a context whereby they have an understanding of where to begin that healing process, so as to help facilitate the healing process in practice".

One key participant simply stated that colleges and universities need to stop doing what they always do. This statement echoed the collective sentiments captured in the responses of all key participants. Colleges and universities are typically designed and rooted in Euro-western epistemology, the majority of classes are scheduled within an 8:00 - 4:00 work day, classes kick off in the fall and end in spring. Although institutions have more recently introduced various delivery modalities, the majority of programs continue to function in this manner. Student support services are often designed to respond to a student in crisis, with few resources aimed at proactive approaches to empowering students to help themselves. "Not that long ago, I can remember that pretty well everybody sent you to a counselor if you seemed a little bit off, whether you were an Aboriginal student or not. If you were stressed out about money, your career, everything was sent to a counselor. That by and large is the push and pull of a student services model and for some it works, but it doesn't actually take care of the whole person. It doesn't teach about spirituality, it doesn't teach about healthy eating, it doesn't' teach other students to talk to each other; it doesn't embed what they are actually going to be learning in the curriculum”. Upon graduation, students must have a demonstrated ability and knowledge base to apply what they have 
learned first in their own lives to be effective and competent workers in the field. This sentiment was echoed by all key participants interestingly, the application to one's own life is not something that is expected of similar mainstream helping programs.

The college as a whole must adjust its services as well as academic programs to help prepare graduates to becoming self-aware with greater self-efficacy and skills to match. Key participants described this personal development as having attained a level of personal wellness. One key participant described this as a spiritual awakening.

"The student starts to become comfortable with their own spirit...their mind starts to become open to seeing other ways of how to learn. And once that happens, the student begins to grow in leaps and bounds. To me that is the beginning of the healing journey. I know that it was said to me a number of times where the college is not a place for healing; it's a place where you are supposed to learn and get out there in the world and start working and making money. But there is a lot more to it than that, even for us as Aboriginal people, one of the things that has really impacted us as a nation, comes from our history where residential school plays a big role in our way of living".

Graduates of this program must have mastered the understanding that people are different and they see the world differently; that tenet was echoed by all key participants. Aboriginal people have been accused as being less engaged, dismissive, uncommitted and so on, due largely to cultural traits and behavior in the educational environment. Aboriginal people are not often recognized as the first to speak in class, raise their hands or not quick to engage in discussion because they are often listening respectfully to the viewpoints of others. In their silence, they are gathering information that will help to form an opinion. As graduates and future professionals destined to work with Aboriginal populations, our graduates must be prepared to work with cultural competency. "I think preparing our students to other world views and how those world views affect the way you participate with others. They always say that native people are close to nature. That's because we see ourselves as a part of creation, we are not creation we are a part of it". Professionals who work with people must be cognizant of cultural norms and expectations, with that there is a need for training to develop cultural competencies in 
working with people. One participant shared an experience he had with a former student. "I had a student come see me and she's from another country. She failed her placement because she was doing what they call inappropriate things; she told me that she didn't know she was doing anything wrong. So this whole thing jumps at me, well we failed her". There is an assumption made by mainstream that people, their behaviours and systems operate within the same Euro-western ideology, we assume that the world operates from this vantage point. When we simply do not fit the mould and conform to these expectations, we are deficient.

One key participant expressed that this social conditioning starts early in the schooling of Aboriginal children. "I was asked to help a young woman who worked for the school board. She was putting together kits for teachers to learn about Aboriginal people. My idea about our babies in kindergarten is they are using most of their senses, smells, feelings,... if we went there with a piece of hide, moose hide where they can feel it, touch it, smell it. The first thing they [the school] would say is, nope you can't do that, because somebody might get sick from it. So what does that say to us? It's similar to where we are in college, same thing. You can't light the smudge; people are going to get sick. We are stopped from kindergarten to college. They have to look at that. We have to speak up about it".

The inclusion of Aboriginal world views in the curriculum across all program areas was another shared response by key participants. With that, professional development training for college faculty and staff are critical. There needs to be a buy-in by staff that will be required to also develop cultural competency in their work with students, with course content with Aboriginal staff and faculty and with the community at large. This would demonstrate the institution's commitment to Aboriginal education which is not always evident. "Yeah they let us have our native studies here and there but they don't really believe it's necessary. At least that's the feeling I get, I am not reading that from something somebody has told me, I am reading that from where my classes are scheduled, and how they are 
scheduled. I am confused too, in ways that they tell us that we have to teach it this way so that our students don't get angry". Aboriginal faculty are challenged in many ways and often feel unsupported as they grapple with the delivery of sensitive course content and white guilt experienced and expressed by students. This sentiment was echoed by all key participants.

Colleges and universities need to be educated on Aboriginal history to better support Aboriginal students and their faculty. Within traditional post-secondary institutions, spirituality has no place.

Institutions are designed to develop only one aspect of an individual - the mind. For Aboriginal people, learning, personal growth and balance as shared throughout both sharing circles and from key participants is a wholistic process.

\begin{abstract}
"Today as a helper, to be an effective helper you are going to have to think about what kind of skills do I need to be able to help these people. And you have to be able to understand the world that they came from, ask why do they think that? Why are they feeling that way? And often times the answer is going to be attached to that physical world. I don't have a job, I don't have housing, medical and all those things like that and the spirit is confused at this point, because if it wasn't confused, we wouldn't have the problems that we have. That's the indicator that things are not in balance. Right now all the indicators we got are all out of whack here".
\end{abstract}

Colleges and universities that have Indigenous programs need to practice what they teach. They are in a position to realign programs and services within their institutions to better serve all of their students. This would include letting go of outdated methods that no longer serve their purpose and being open to new approaches within the learning environment and allowing students to live in a realm in which they are going to work, so that when they graduate, they will be better prepared for real life experience.

One key participant when referring to the role of colleges and universities stated, "I'll be very blunt, racism and discrimination is a daily fact of our lives working in aboriginal education within the college system. A lot of times I find it is the big white elephant in the room. Because of course nobody wants to be accused of being discriminatory or racist, however we're running into situations now where it's become so systemic that is just become just a natural part of doing business. 
It's quite common to hear, well if you are doing this for the native students, what about the Italian students or the Chinese students or this particular demographic. So having that understanding at the senior leadership level has a trickledown effect to the rest of your team within the institution itself, hypothetically you are hoping that is going to be the case. We do get some push back. One of the things that make me very concerned is when people say, well I am color blind, and I don't see any differences in people. That's very concerning because we are very different. We come from a different history, a different world view and a different history and perspective, and just because it's different do not make it wrong. And for me cultural competence means recognizing that yes, there's differences in who we are as people, our languages our culture and how we approach the world, just because it's different doesn't mean it's wrong, doesn't mean that I have to agree to embrace everything within your culture, but it means recognizing yes there are differences there, but how do we work with those difference and gain an understanding".

\section{Ehngaabiyaanong - pillars need to support programing that are academically sound and}

\section{rooted in IK}

Institutions of higher learning have some rigid academic standards; key participants were asked their opinion on how Indigenous based programs can maintain their Indigenous foundations while meeting these academic standards. All key participants agreed that academic standards are necessary as they demonstrate program quality, validity and rigour. Graduates and employers both need to be confident that the latter are prepared to do the job. Several key participants commented that Indigenous programs are often viewed as not being as academically rigorous as mainstream programs.

"I know there is a perception out there that Indigenous curriculum doesn't always hold the necessary academic rigour as other non-Indigenous programs do. And I remember it was the same argument for Francophone education. And when you do research or academic standing for Francophone educated students, it is above the Anglophone average in the world. So all that says to me is that culture context is essential when you are delivering curriculum".

Indigenous curriculum and programs can learn from the processes experienced by those who struggled to have Francophone education recognized and supported. All key participants noted that support for Indigenous programs with respect to adequately funding the systems it requires developing Indigenous specific curriculum, learning resources, spaces and processes are lacking in the province. Educational supports are critical for Aboriginal learners from pre-school through to post-secondary if we are to 
address education disparities. Those supports are different from what the mainstream typically provides. Supports for Aboriginal students must include elders, cultural knowledge, in addition to educational supports. Again training for school administrators, teachers and other staff is essential. One key participant noted that, "Racism and discrimination is inherent. We have dealt with it here, and at another college".

One key participant suggested that academic standards and rigour are obtainable and measureable and can be accomplished by employing principles of universal instructional design.

\begin{abstract}
"Universal course design, using that pedagogy in terms of curriculum development and delivery because it takes into account differences, depending on how you set up assignments, how you grade assignments, it can take into account Aboriginal perspectives and foundations without compromising the academic standards of the program, and it is by far, absolutely possible. One of the things again feel very strongly about is setting the bar high for our students because they will reach the bar, but they need that support, they need that boost in self-esteem and they need that confidence building, and if you provide the tools and the learning environment to do that they will meet it and exceed it. So definitely, there's course design following that kind of model would be a perfect fit, without having to compromise any of the academic standards".
\end{abstract}

However, key participants also discussed how colleges and universities have determined the length of time a student requires in order to master a subject area. For many learners, a sixteen week semester is not enough time. Student success is relative. We measure enrolment, retention, attrition and graduation rates in a vacuum. We rarely report the obstacles that many of our learners have to overcome just to get to school.

"Because of the experiences within the education systems that we've had in the past and what we are experiencing right now. When you talk about rigid academic standards, that has been a really big barrier in some ways...the CAAT ${ }^{10}$ test trying to get students into school, who may have lots of experience but don't have that academic experience, doesn't mean that they are not capable - it just means that they need more programming supports in place for them. I know for a fact that we've had cases where people had failed CAAT tests and went on to successfully complete programming. I definitely see that there are barriers in

\footnotetext{
${ }^{10}$ Canadian Adult Achievement Test (CAAT) is a standardized assessment tool used by colleges to assess an applicant's educational comprehension level in basic communication, literary, numeracy, critical thinking and science in determining whether a mature student (non-direct entrant) meets admission requirements into a college level program
} 
accessing education, I definitely recognize that there needs to be a standard set, because you don't want to set students up for failure when they do come but at the same time I think that it needs to be a CAAT test and a more holistic approach in looking at what has been your life experience, what has been your work experience, how have they contributed to the learning path you are going on right now? At the end of the day, having competent faculty, and administrators that can oversee this and advocate is a really strong part I think, because at times Native specific programming is viewed as "less than". It's really challenging where my stance is, no you are getting added value, because you're having this perspective that is very unique incorporated and the sad reality is, especially when you look at social services, we have a high number of Aboriginal people accessing services and accessing the system, so being able to effectively service them and work with them, it critical that its incorporated in to your system. I don't' see any issue with maintaining academic standards with Indigenous based programs at all”.

Key participants spoke to the need for institutions to teach to the needs of the communities and to work with them to identify what their needs are and to develop collaborative strategies to address them. Canadore, some key participants stated, seems to be on that path but still has a ways to go in extending those supports.

Key participants also talked about how communities must do better at preparing their students for post-secondary studies. Often students arrive at college or university without a firm understanding of what is expected of them. There needs to be an orientation for many Aboriginal students to learn about the academic expectations, rules and that attendance is critical. One key participant described education as a tool to prepare graduate for active participation in the world. Many Aboriginal students struggle when they first arrive. Faculty must make the time to engage individually with those students who appear to be struggling. "Many of our institutions have large classes and students are lost in the crowd". Key participants spoke to the need to have processes and systems in place that would help to identify Aboriginal students earlier so that targeted supports can be employed to help them be successful in their studies. "We need to be able to identify that struggle earlier. Perhaps a screening process, or an assessment level, in university, we used to have to write a story, and from that they would evaluate your 
writing skills and recommend the courses you had to take. Can we do that here, kind of like a precollege assessment?"

Key participants were also quick to point out that Aboriginal students do fairly well. In postsecondary education, graduation rates are improving albeit at a slow pace, but they are improving. There are many Aboriginal students who do very well, but the discussion always tends to be focused on the ones who do not do so well. One respondent noted, "We always hear about those ones who struggle, we will always have those ones that struggle. But, I am not sure where that fits into institutions, when it comes to Aboriginal initiatives, we are down on the list. It comes down to this notion that we need help. I've been around long enough to know those Native students programs have been the last to be introduced and the first to go".

In terms of academic standards, key participants spoke about the need to ensure that Aboriginal content being developed and taught in programs are a true reflection of Indigenous Knowledge. Curriculum and educational resources need to be developed in community by Indigenous people. We cannot have institutions developing such content away and apart from the Indigenous communities. "In terms of that quality piece, when you are teaching about cultural norms, teaching or knowledge, you need to hire experts on it. It is not acceptable to hire a white person put them in a class to talk about Aboriginal history - maybe half the class because that's half the perspective and half the story, but not the whole side. Quality wise, hiring practices need to change too".

Colleges and universities can ensure content is appropriate and valid by working with Aboriginal communities and hiring Aboriginal researchers, curriculum writers, and faculty and by having oversight committees of Aboriginal experts. One respondent, when referring to her work with a local school board, talked about how schools and education systems would prefer to take something that is not necessarily relevant to the local community and introduce that as Aboriginal studies. Another respondent 
talked about how institutions recruit and hire Aboriginal folks from another part of the country and expect them to be able to develop and design programs or services appropriate for the local community. One participant stated that colleges need to "ensure that programs such as the IWAP program are built on teachings so that we are not making dream catchers and things...we have to have elders or those with traditional knowledge to oversee the whole program...an elders advisory (group) instead of having a (general) advisory (group), so they can give direction and have some pull on how the program is set up, so that they can give advice to the professors and to the teachers, and we can give advice to the Dean or whoever". The current structure relies solely on program advisory committees to oversee the program, there does not appear to be any engagement with IK keepers beyond the role of the PAC'S. Key participants expressed concern for what appears to be a lack of process and opportunity for local community engagement with respect to validating IK in the classroom.

Indigenous Ontario college staff participating in the research expressed feelings of frustration, apathy and concern to excitement at the prospect of having Indigenous based programs and courses in the college system; that in spite of the many challenges they have had to overcome, they each expressed an appreciation for the work. The historical legacies of residential schools, the 60's scoop to name a few, influence and shape how Indigenous people see education and in effect, how they teach. It is apparent that within this program, competing priorities of maintaining the cultural integrity of the program over academic rigour occurs. While not explicitly expressed, participants struggle with balancing the two which suggests that IK requires a setting of specific learning objectives measured against stated academic expectations, teaching methods and assessment. The current practice is left to individual faculty to determine how each corresponds to the other.

\section{Keewaydaanong - overcoming challenges and moving forward}

The Participantss were asked to identify and discuss some of the challenges in having an Indigenous based program in a community college like Canadore. Some areas for consideration 
suggested included policy considerations, funding challenges, operational considerations, program design, and faculty recruitment/retention. With respect to policy, many key participants commented that colleges and universities could do a lot better in developing policies with respect to Aboriginal people. This would include working with Aboriginal people to design policies and procedures that would better support them within the institution. One respondent shared "I've never been asked to participate in that. Because we don't do that...like Indian Affairs it is presented as, we have a plan for your guys. The Indian keeps saying, well you didn't ask us. You didn't include us, just like this new educational act. It might be a very good act, but you didn't ask us. All of a sudden you have this thing ready to go here but you didn't consult enough of us. You only consulted with one person". When developing policies, institutions should aim to include wider representation from the Aboriginal community. The college has made some good movement toward increasing Aboriginal participation in the development of policy and funding to support the First Peoples' Centre, community partnerships and other initiatives. One key participant shared, "we may have made strides at Canadore, it has become that function that energy, that participation, can become a bigger part of who we are, because of the approach taken by our Aboriginal Circle on Education, our faculty members and the First Peoples' Centre and others because our Aboriginal students have vibrancy, partnerships have depth. Whether it's doing things for the right reasons or strictly in a business sense, we've used the opportunity to come forward and influence policy".

At provincial and even national levels Aboriginal teaching and learning initiatives are still seen as "special projects". One participant commented that, "we have had to push to overcome expectations that is special project, policy consideration by and large continue to reflect that. Even as recently as the Association of Canadian Community Colleges with the Indigenous protocol. It still looks at Aboriginal teaching / learning as a special project. I can understand the province in doing special project, people 
and institutions need to move from being a special project or special policy and make sure that it is inherent in everything". This would address funding parity with other services and programs targeted to special populations such as First Generation learners, second career learners, Francophone, etc.

\section{Manitoog - what improvements can be made to the program?}

Key participants were asked to provide their perspectives on how to improve curriculum, reposition standards, overall program quality and ultimately student success. All key participants talked about how far colleges have come and specially Canadore with the Indigenous Wellness \& Addictions Prevention program. Prior to the introduction of the program in 1990, traditional Anishinabe medicines were never seen or used anywhere on campus. The program is continuing to evolve and institutions have begun to make a shift in offering more Aboriginal specific programs. Participants had three key views with respect to curriculum.

1. All participants spoke to the need to have on-going community consultation on the curriculum to ensure its relevance, and to ensure that it addresses changes happening in the field, in the community and globally. One participant stated that "relative to other colleges we are engaged with $\mathrm{ACE}^{11}$. They have a view from the outside looking in, on how we are delivering our programs, how we are delivering our services and the challenges their students are facing, but we have not engaged them in our academic realm by and large. We do give them academic updates, they have informed some of our directions in our strategic plan but when we are looking at learning outcomes and some of those things we haven't really engaged them to the extent I think we can. That's one of those biases I think academically we are going to have to overcome in order to get there". Other processes designed to review, assess and subsequently modify programs must also be looked at to ensure that they are

\footnotetext{
${ }^{11}$ ACE - Aboriginal Circle on Education are mandated by the Ministry of Training, Colleges and Universities to those colleges/universities receiving Aboriginal specific funding to support an Aboriginal advisory circle responsible to oversee college programs and services geared to Aboriginal learners, this includes student support services, counselling, academic programs and other initiatives
} 
inclusive. "Colleges need to ensure that some of the mechanisms such as PLAR" ${ }^{12}$, annual curriculum review or five year program revitalization deep dives or student success metrics are applicable to this type of program. Because it may or may not be the case that process or procedure reflects the type of approach we are taking to delivery. That if process or procedures don't reflect it, frankly on the back end the metrics are going to be left in the dark because it is not going to fit into that norm, it's not going to fit into what people want to see. So when we are designing those, and there's lots of work to be done, we got to make sure that there's ability for the metrics to reflect that when somebody takes a different direction to getting there”.

2. Hire Aboriginal faculty, not just in this program but across the college. Institutions must actively recruit Aboriginal teaching faculty and support staff positions if they are to make good on the strategic directives they espouse. Remuneration for such positions must be at minimum at par, but must also acknowledge the special and unique knowledge and skill set Aboriginal faculty bring with them. Indigenous Knowledge is acquired throughout a lifespan and is not something learned in a book. Indigenous elders, knowledge keepers and faculty bring with them unique perspectives that cannot be facilitated by anyone other than Indigenous peoples.

3. Colleges need to invest in appropriate spaces that allow for the use of alternative teaching methodologies such as the use of traditional teaching lodges, sweat lodges, use of smudge and tobacco when having pipe and other special ceremonies. There needs to be protected space on the land where our structures can stand without worrying about vandalism or having them destroyed when unattended. The use of medicines in smudge and ceremony should be accepted as common practice in the college. Indigenous people should not have to worry about being behind closed doors

\footnotetext{
12 PLAR - Prior Learning Assessment and Recognitionis a means of evaluating skills and knowledge acquired either through continuing education, or outside the classroom, through work experience, volunteering, life experience and many other avenues. The assessment results can be applied toward academic credit for those who are upgrading, retraining or pursuing education in Ontario's colleges after being in the workforce (Colleges Ontario, 2014).
} 
and ventilation. The college as an institution has a ways to go yet in creating sacred place for

Indigenous programs. We have started but not without our daily struggle. Racism and discrimination

are daily occurrences, even if ever so slight.

One Participant shared this story:

"we do live with a foot in both worlds. I can still be a Native person but I can still be a professional at the same time. I can still keep who I am and my culture but I can still do the work that meets mainstream expectations and needs, but it has to be a two way street. And that's sometimes where it gets challenging. We talk about things like white privilege and cultural competence and I was trying to explain to somebody, you will be having a conversation and somebody will say something and in that split second in your head you think, was that racist or discriminatory? Or was that something in my mind that I perceived incorrectly? So you kinda' have this internal debate in your head, so then you gotta' make this determination in your head, well do I call this person on what they said and if I decide to call them on it, I have to make sure that I am strong, that I am not going to blow my stack, that I can address it in a manner that is going to address the concern, or do I say no, I am going to just let it go. I am not going to say anything, and if you let it go, are you really letting it go? So this is all happening within a space of two seconds when you come across these experiences that in itself is really challenging".

It is an experience that each of the Aboriginal key participants shared in varying degrees throughout this research.

Finally, key participants were asked if there was anything else they would like to add to our conversation.

\section{Miinwaa - final words}

This was an opportunity for each key participant to speak freely. One key participant had this to share,

"One thing over the years now, I just got so used to it, its continuous bickering about our use of our culture in the walls of this college. I don't know what we do to change that and I know that you have made attempts from your level to put on different awareness presentations and maybe it has done some good for people I think that is still pretty raw here. I always wondered about bringing the indigenous side of our teachings out in the college, I always wondered whether it was better outside and not bringing it into the college system, I always wondered about that. And then what came to me was that, it has to be for the students, that is what I came to understand. The students are the most important. All those other things that go on here, well they can be left where it is, we need to move ahead and do what we need to do, and let them stay where they are at. We have 
come a long way just in the years that I have been here. I never saw medicines until I got here. I see a lot of artifacts but that's about it. I never smelled medicines in our hallways until the IWAP program came here. So I always feel good about that. I am not sorry that, I feel proud actually that it's still happening here for the benefit of the students, that's what it's all about. Miigwetch".

\section{Indigenous Knowledge has a lot to offer, many more programs can be learning from this IWAP}

program. Why are we not looking at having IK in Ecotourism, Rec Leadership, Nursing? There are lots

of opportunities that we have not explored.

"I think we need to stand up for who we are; we need to do more of that. I think that if more of us did more of that, then more would be done. It might be very stressful for the front line people. It might be very stressful for people who manage or who are caregivers, I mean you have to work with them. You have to be with them every day. Our teachers or professors work in this environment everyday ... how they are seen among their peers who don't understand spirit, who don't see spirit. Who complain about smudge... The ones that fall down and they wonder why they are falling down. When they fall down all the work that they've done is going with them. So how do we support those ones, how do we support one another? We still have that or those who are not in touch with their spirit and who are still living just like mainstream, they know how to do it just like mainstream, they know how to oppress. They know how to pull policy and how to talk...they know how to do that. So we have to be strong. We really have to be strong, not in fear, in fear of somebody going to knock me down like mainstream, that's how mainstream is; somebody is going to knock me off this ladder. And we have to say well you knock me off, so what, it's not my life. It's not my life to be knocked off this ladder, I have this life. There's other things that I can work on there's other things I can do. I get up..."

"I think the challenge around developing different policies for Aboriginal people, you are under the microscope. The reigning Anglophones are always making sure you are not watering down policies to make it easier, policies have to be different, I would be reluctant to use the word, flexible, and they have to be different while meeting the same rigour. I am interested to see what will come out of it."

"Cultural safety is something I would like to see adopt team teaching. Because when I look at a college like ours, or when I look at one of the big ones in Toronto, whether its straight on discrimination or reverse discrimination, it exists whether we want to believe it or not.... And sending an Aboriginal faculty member alone when faced with some of that stuff and to bear the burden of changing minds sets alone to me in some cases it's like we are setting them up. I think that cultural safety, whether it's called that or not, should be happening in every program here. Because our electricians are just as likely to cross the threshold of a First Nation just as one of our health care graduates will and the team teaching concept and I've wrestled with some of the challenges we've had here at Canadore, is one that I would like to see, it doesn't cost us anymore, it doesn't diminish the outcomes".

"The reality is institutions need to put their money where their mouth is. If you say that you support Aboriginal education you believe in Aboriginal education, then you better be hiring Aboriginal staff, you better be providing that financial support to programs and services because we cannot do it by ourselves, because unfortunately the money is not there and you can only be so creative, so you need that buy in from the rest of the institution. And from a financial perspective, that is a very strong speaking point, so if the college is going to be offsetting current staffing positions, are they going to pay $50 \%$ of the positions currently in place? Are they going to be hiring more Aboriginal staff both support and faculty to work across the college? Are you providing additional dollars for student services things like that? It's like the money talk and BS walks. Coming back to the realization we are 
working under very tight budgets, everyone has their challenges. If this is a priority, well if XX is a priority you find money to pay for that, if this is a priority then you better find money. But its delicate you don't want to come across as this fist pounding person".

\section{In summary:}

With respect to the key research question, how can the Indigenous Wellness and Addictions Prevention program best provide an academically rigorous program rooted in Anishinabe knowledge and teaching? What can be gleaned from this review is that Indigenous based programs when measured against standard program review are meeting quality assurance processes. They are demonstrated through standardized metrics linking program outcomes to specific course competencies and through the submission of teaching plans. What the research has identified however is that these standard assessments fail to reflect the experiential and relational nature of the learning occurring within this program. Moreover, that faculty are challenged with providing learning experiences that maintain a balance between what constitutes academic rigour while delivering IK practice and theory. The research also pointed out that some faculty were quite adept at providing a stimulating learning environment that is both challenging, personally fulfilling and students expressed that the program was preparing them quite well for practice. Key participants were much more versed in academic program design, evaluation, assessment, policy and had extensive experience within these domains and their responses spoke directly to how best the program can maintain academic rigour while maintaining its Indigenous foundations.

\section{Academic rigour:}

In terms of academic rigour the two participant groups shared the following sentiments:

\section{Content relevancy and currency:}

Both participant groups stated that the programs content must be relevant and current to assure that students were prepared academically and professionally to enter into the field of wellness and addictions 
work within Indigenous and mainstream communities. The program's learning outcomes as identified by the College and its Program Advisory Committee (PAC) have established these benchmarks:

1. Identify and demonstrate the use of various assessment techniques as it pertains to addictions counselling to identify client issues and needs in a helping relationship, including physiological and psychological effects on the human body and wellness.

2. Explain the effects chemical and alcohol dependence have on wellness (physical, emotional, mental and spiritual).

3. Examines and applies relevant addictions helping intervention strategies and techniques suitable for working with Native individuals, families and groups within a wellness paradigm including treatment planning, crises intervention and prevention services.

4. Apply effective written and oral communication skills in addictions counselling to communicate with clients, prepare reports, read and interpret public information documents, legislation or records as an integral part of the helping process.

5. Demonstrate professional ethics and integrity and the appropriate use of inter-professional education skills. (Canadore College, 2012)

In terms of how the college derives the content, both participants spoke to the need to maintain relationships with the Indigenous community as well as mainstream service providers. The program would demonstrate its rigour through the acquisition of addictions and wellness theory from both Indigenous and mainstream therapeutic models from prevention, treatment, aftercare and relapse. Indigenous experts - to ensure validity of IK and rigour in the application of appropriate helping strategies, Indigenous content experts should be intimately involved in the program's oversight, including curriculum and instructional design, evaluation methodology and the development of assessment rubrics. A council of elders and Indigenous Knowledge experts were cited as ways in which the college could ensure a rigorous IK base. In addition to overseeing the development of assessment rubrics for the above outcomes, the following outcomes would also require the establishment of assessment rubrics for the following IK based outcomes:

6. Apply basic principles, concepts and skills of group work and discusses considerations for group work within a First Nations context.

7. Demonstrate the appropriate use of traditional Native helping practices and culturally appropriate service approaches.

8. Analyze historical and post-colonial policies and their impacts on First Nations people in Canada. 
9. Discusses addiction theory and conceptions and demonstrates practical application of theory in the helping process; analyzes implications within a Canadian First Nations context, including considerations for holistic community development models for social change. (Canadore College, 2012)

Additionally, both participant groups spoke to being academically prepared when they are confident that the skills they are developing and perfecting are transferrable and demonstrated. These skills are identified as "Essential employability skills (EES) - are skills that, regardless of a student's program or discipline, are critical for success in the workplace, in day-to-day living, and for lifelong learning, and include communication, numeracy, critical thinking and problem solving, information management, interpersonal and personal skills" (Canadore Colege, 2014). Although each of these areas was not specifically named as such, the collective responses touched on each skill set to a degree. The student groups identified interpersonal and communication skills specifically when asked how the program could maintain its academic rigour and whether they felt that the program was preparing them for work in the field. Key participants favored communication skills such as reading comprehension, problem solving and critical thinking as demonstrating a more academically rigorous program. Student communication skills were an identified concern at the 2011 review of the program. When asked about some of the academic challenges, students cited that next to personal issues, communications and language barriers were the most pressing concerns.

Students who identified being in the first year of the program, spoke about how they have been challenged to produce academic papers, drawing on a variety sources and presenting information in a formal paper. While students in either second year or who were in the program $2+$ years, stated that they felt that they were not prepared for the field and that they felt that too much time was spent in circle. It is clear that while healing practices within the program ensures the program retains its Indigenous foundation, there is a critical need to balance these approaches with essential employability skills along with the nine identified program competencies. 
The following discussion chapter highlights significant factors drawn from both the literature and participant responses that defines academic rigour and identifies necessary structural supports to implement and evaluate systemically. 


\subsection{Discussion:}

This chapter discusses academic rigour with respect to the Indigenous Wellness and Addictions Prevention program and presents a discussion of the structural supports required to effectively address rigour in content and form. Indigenous knowledge paradigms have much to offer institutions of higher learning from pedagogy, instructional design, experiential and applied learning to supports for students, staff and community engagement. Post-secondary education has a considerable role to fulfil in this paradigm shift.

To make good on the principles, values and goals of reconciliation in this country, the way in which we see post-secondary education (PSE) must make a shift. "Counselling services in Canada and United States of America are based almost exclusively on Western paradigm of health that contrasts with those of Indigenous peoples' worldview" (Bojuwoye \& Sodi, 2010, p. 284). Wholistic and inclusive practices are cornerstones of Aboriginal ontology and are tenets that many institutions espouse but are challenged when trying to operationalize them. From the time before we are born into the physical world, we exist first as Spirit. In Anishinabe ontology, we are always learning and absorbing the world around us.

For Anishinabe children, we learn from the earliest time that, we are but a small part of creation. Traditionally, relationships were reinforced at critical times throughout the lifespan. Today, Aboriginal learners are schooled in mainstream education systems that do very little to acknowledge and celebrate their heritage and identity. This research reinforced an appreciation that education can be so much more enriching should institutions dare to approach Indigenous programs from an Indigenous center. The decolonizing nature of telling our stories and sharing our truths is fundamental in that process. Both key participants and students alike spoke to the need and space to be able to speak their truths. This approach to learning and centering of self is a vast departure from traditional mainstream pedagogy. In 
adult education, transformative learning theory appears to be most congruent to a wholistic Indigenous worldview and offers a theoretical base in which to draw from in the design of Indigenous programs such as the IWAP. Transformative learning theory was first articulated by Paulo Freire as “conscientization or consciousness raising" (Dirkx, 1998, p. 2).

"Critical consciousness refers to a process in which learners develop the ability to analyze, pose questions, and take action on the social, political, cultural and economic contexts that influence their lives. Through dialogue and problem-posing, learners develop awareness of structures within their society that may be contributing to the inequality and oppression" (Dirkx, 1998, p. 3). Other adult education theorists have furthered Friere's work and have presented key considerations with respect to a more wholistic and transformative educational journey. These key congruencies with Indigenous worldviews are discussed further with respect to this research, and addresses the structural changes needed to ensure that the Indigenous Wellness and Addictions Prevention program is indeed meeting and in many respects, exceeding academic rigour, while maintaining as its core Anishinabe ontological and pedagogical underpinnings.

Haig-Brown, Hodgson-Smith, Regnier, \& Archibald (1997), in an in-depth study of the Joe Duquette high school in Saskatoon describe this school's commitment to Aboriginal spirituality as the guiding principle for curriculum and human relations within the school. "The objectives of the school...indicate the high priority given to a balanced approach to education. Reiterating the focus on healing, the first objective calls for an environment that encourages and develops feelings of "worthwhileness, increased self-esteem, and a stronger Indian identity" (Haig-Brown, Hodgson-Smith, Regnier, \& Archibald, 1997, p. 49). The school serves as a model in Indigenous education that in all accounts is a stark contrast to the historical and even contemporary educational systems in which Indigenous students attend from primary, secondary to post-secondary levels. The school's philosophy is 
based in Indigenous understanding of the interrelatedness of all things. The use of circle, medicine and ceremony in conjunction with stated educational outcomes make up this school's pedagogical design. While the school is a high school geared to adolescent aged youth to teens, the school's philosophy and approach to bridging traditional and educational programming present important considerations in Indigenous based learning within a mainstream environment.

The supports, curricular content, policy and resources required to address the multi-dimensions identified by the research is presented from four major thematic levels (see Appendix 3).

Vision, Relationships, Reasoning and Movement as they relate to:

- Self - Family/peers - Community - Nation

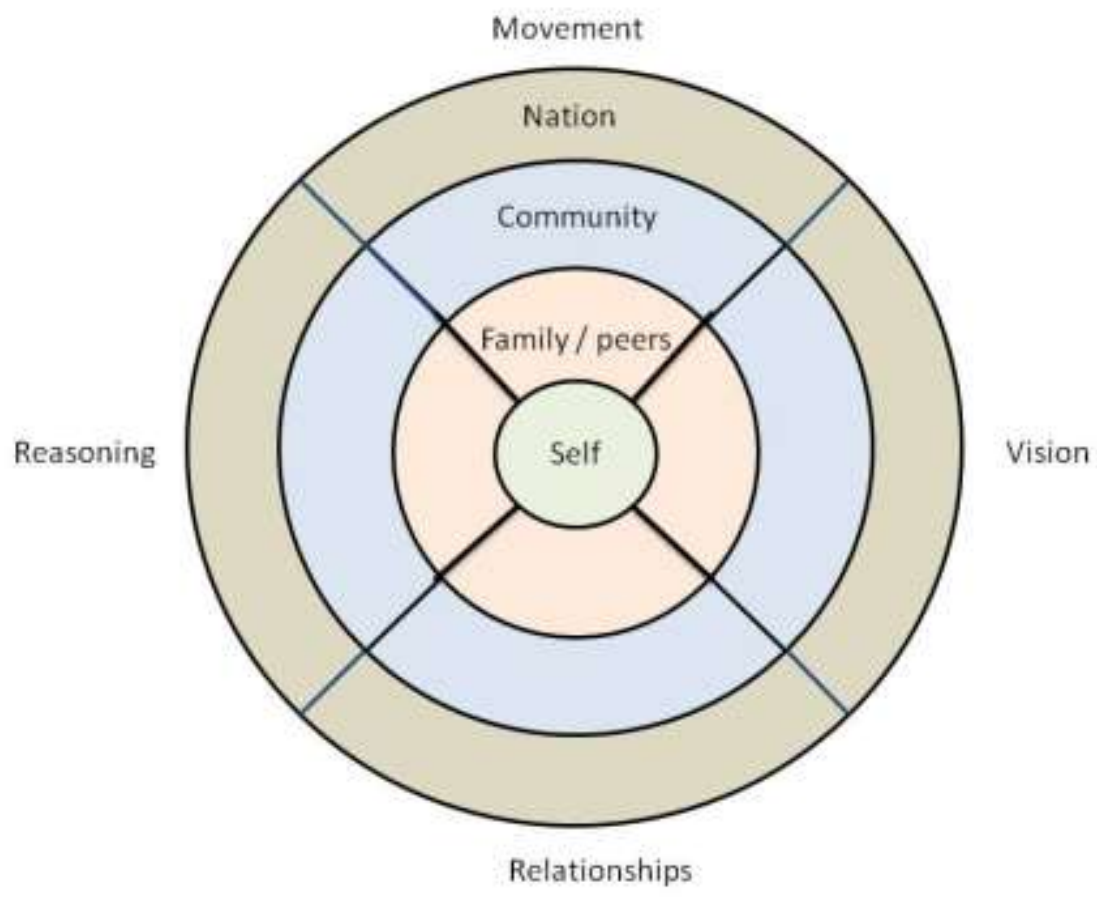

Learners, who come to the IWAP program, do so for many reasons - ultimately though they seek to become addictions counsellors and helpers in this field. The preparation they require to become effective addictions workers and helpers can be seen from these four levels. Additionally, faculty and 
those associated with the program have an affinity to mental health, addiction, healing and wellness at various capacities. The IWAP program was designed to address the gap of available Indigenous based helping programs in the field of addictions treatment within post-secondary education. While the vision for the program has not been clearly stated, it is assumed by the key participants that the program will continue to evolve. As programs go within colleges in Ontario, a program's vitality is often measured by its continued enrolment.

As the literature illustrates, a growing Aboriginal population, declining high school completion rates and increased reported incidents of mental illness, mental health disorders and substance abuse in Aboriginal populations (Health Canada, 1998; King \& King, 2014; Aboriginal Healing Foundation, 2003; Assembly of First Nations, National Native Addictions Partnership Foundation and Health Canada, 2011), enrolment into programs such as the IWAP could be expected to increase over the next several years.

The National Native Drug and Alcohol Prevention program review that was conducted in 1998, reported that in spite of having available to the many addictions workers employed within NNADAP programs nationally, much of the training received at that time was not recognized by educational institutions, nor were they accredited by a professional body. While that has changed with the advent of the First Nations Wellness Addictions Counsellors Certification Board, recognized training continues to be a challenge for northern and remote communities. In the 1998 review, “diploma programs, recognition by a professional body, and recognition by First Nations/Inuit ranked high in importance for elements of training" (Health Canada, 1998). Coupled with this, is a critical need for academic training that prepares individuals for work within the addictions spectrum.

Bojuwoye and Sodi (2010), reports criticisms by western-oriented healthcare practitioners toward traditional healing view such practices as "exotic, primitive, demonic, sorcery, magic and 
witchcraft...these criticisms are due largely to ignorance and misinformation or complete lack of information about traditional healing and traditional healers. Moreover, there is a tendency of Western critics to over-concentrate on risk and worst case scenarios or worst outcomes of certain traditional healing practices" (Bojuwoye \& Sodi, 2010, p. 288). Adding fuel to the fire, new age sects that claim to possess Indigenous Knowledge and its rites, do little to validate IK as an appropriate and effective treatment. To address the issue of mistrust, validity and competency, the college must demonstrate its commitment to the program, and to its internal and external proponents. A comprehensive collaborative review of the program's vision and long-term planning would serve the college and its community partner's well, by clearly defining roles and responsibilities of all program partners. The college could demonstrate its continued commitment to the program by identifying clear responsibilities of all partners and delineating lines of communication and oversight.

Establishing baseline criterion for standardized program assessments for the Indigenous programs at the college would address questions specific to program academic accreditation standards, learning outcomes, competencies and ensuring cultural appropriateness of such metrics. Indigenous academics should lead this development and work in collaboration with the institution's academic and research areas. A collaborative approach in the program's design and assessment would help to ameliorate the known disrespect for traditional healing practices amongst Western healthcare practitioners and the academic institutions that prepare them for their work. "Awareness of or knowledge of traditional perspectives on health and ill-health should assist in modifying Western healthcare practitioners attitude of disrespect towards that of respect for traditional healers" (Bojuwoye \& Sodi, 2010, p. 289).

Forming and maintaining positive collaborative relationships are essential to a programs relevancy, currency and responsiveness to evolving community needs. Internal relationships within the 
institution are critical for student success, faculty engagement and support, as well as administration's oversight of the college's strategic directives. Moreover, relationships external to the college with community based partners including treatment facilities, mental health service providers, healing and wellness workers in both mainstream and Aboriginal organizations are essential to create dynamic program advisory committees charged with overseeing curriculum and program responsiveness to employers.

Relationships with Indigenous knowledge keepers, elders and cultural support workers would ensure a true reflection of the diversity that exists among Indigenous nations. Moreover, such expertise made available at all points of review and delivery of the program speaks to cultural relevancy and validity. The Royal Commission on Aboriginal Peoples (1996) reported quite extensively the negative and severe impact exclusion of traditional practices and imposition of Western based helping has had on Indigenous peoples. Although Indigenous peoples of the world are undoubtedly the most researched, they have had very little to do with the research being conducted on them, about them or to them. Bojuwoye and Sodi (2010) further reported that "researching and documenting traditional healing practices would meet with challenges because indigenous ways of healing (including songs, dances, ceremonies, sacred medicines and traditional language servicing as vehicles and tools of traditional healers) are living texts" (Bojuwoye \& Sodi, 2010, p. 290). They cite that a major challenge would be to have a traditional healer share their knowledge and that is to be expected given the deeply entrenched mistrust, and rightly so, Indigenous peoples have toward their oppressors. Through this research, the questions of just how much IK to share is evidence of the deeply entrenched mistrust Indigenous practitioners continue to grapple with.

There are many reasons for the college to engage with its community regarding Indigenous based education. Given that the college sits on the traditional territory of the Nipissing Anishinabe, and is in 
close proximity to Dokis First Nation and the 7 First Nations situated in the Parry Sound corridor, the college potentially has available to them a rich breadth of expertise in Indigenous systems, knowledge and practice that could augment existing programs and present opportunity to explore new programs and services.

Community partnerships open the possibility for in-service learning opportunities, co-operative education and applied research, all of which help to build both institutional and community capacities. Canadore has already positioned itself a leader in many respects to increasing access to PSE and student success. Strategic alliances within the college with the institution's research department, the School of Indigenous Studies and its faculty could yield opportunities not yet explored.

A plan to move toward a more strategic agenda with key players and identified measureable objectives would bring together key pieces of information to better inform academic rigour and consequently enhanced institutional direction in Indigenous education. Linking with employers, content experts, Indigenous communities and Indigenous knowledge keepers to help identify required resources and responsive programming are all elements of such a plan. The potential for this college to be the next best practice are promising.

How can the Indigenous Wellness and Addictions Prevention program can best provide an academically rigourous program rooted in Anishinabe epistemology and pedagogy? How the program can address academic rigour while rooted in Anishinabe epistemology and pedagogy are discussed in detail in relation to self, families/peers, community and nation.

\section{$\underline{\text { Self }}$}

We have heard from the research participants that students must be prepared for college level study and be made aware of the program's sensitive content. The literature points out that that Indigenous people have been subjected to gross historical and contemporary injustice that continue to 
impact their lives daily. Students and Indigenous faculty also, bring with them the effects of intergenerational trauma that affect their ability to engage with the program curriculum without first having opportunity to become centered and focused. The IWAP program, in its unique design employs tenets of decolonization through the use of IK based practice, content and opportunity for students to engage in ceremony and other experiential learning.

Participants spoke to the need for students to have opportunity to address the triggers that are inevitable as a result of course content. One sharing circle participant stated that "some of the policies, should be mindful that a lot of the Indigenous students coming to this program come from those damages themselves, be it a history of drug abuse, history of sexual abuse, or a history of mental, physical abuse, and sometimes in this kind of setting such as the IWAP class, those issues can sometimes surface". It is important that students and faculty alike have opportunity to become centered, grounded and together establish rules and processes to proactively address potential setbacks. Developing and promoting student self-efficacy builds on the transformative education agenda. Staff designated to provide student support and faculty linked to the program should be oriented to processes and procedures encouraging greater self-reliance and praxis of content learned in the program.

Additionally, applicants to the program ought to be informed of the unsettling potential of the program content, and the policies and procedures with respect to a safe learning environment. Equally if not more important, is that Indigenous faculty have also been subjected to the same history, they too must be prepared to teach sensitive course materials and maintain a sense of objectivity, sensitivity and leadership. Their roles are critical in the learning process. Faculty engagement is discussed further in the following section. 


\section{Program recruitment:}

Much of the literature with respect to Aboriginal student engagement with PSE speaks to Aboriginal learners being unprepared academically and/or challenged due to systemic educational barriers experienced by many Aboriginal learners. The unpreparedness of Aboriginal learners is not specific to the IWAP program. Aboriginal students who meet admission requirements continue to struggle both academically and personally when arriving at college. Supports for students in the first year of study are critical.

During the recruitment stages of the program, applicants should be encouraged to undertake a self-reflection to help prepare them for this program of study. A program brochure and informational package to help interested applicants prepare for entering the program would mitigate much of the personal struggles currently faced, i.e. abstinence from alcohol and other substances. As part of the informational package, applicants must be informed of the college's duty to ensure a safe learning environment which includes policies regarding safety and duty to report.

Additionally, support services available to applicants and registered students should be identified and made available to applicants. Stonechild (2006) suggests that "institutions should be safe places where students can learn about, become empowered over, and resolve to rise above not only the personal, but also collective, trauma of colonialism" (Stonechild, 2006, p. 134).

\section{Learning pathways:}

Student advisors should be available to assist applicants with the application process. For those applicants who may not be ready for the IWAP program, a preparatory program should be made available to them with an identified pathway into the IWAP program. Where possible, opportunities to have these students integrate with the IWAP class in one course would be incentive for them to maintain good academic standing and personal wellness as they aspire to this program. This would also present 
opportunity for these students to determine whether the IWAP program is what they really want to pursue after all.

A concerted focus on language and communication skills would serve Aboriginal college bound students well. A pre-cursor communications course with emphasis on creative writing, self-expression and critical thinking would assist learners in the transition to college studies. Raising the academic bar and challenging students to meet the bar were identified as being a requisite to Indigenous programs. The supports required by students to do so are imperative. Supports from the first point of contact with applicants and throughout the life of the student are essential. This includes the use of educational resources such as specialized software for second language English speakers, peer lead study groups, tutoring, personal supports including counselling, access to elders, ceremony, medicines, and traditional foods.

\section{Experiential and land based learning:}

Access to land based learning and traditional wellness regimes would not only assist students with praxis of the course content and Indigenous healing practices, but would also address their own personal wellness and self-efficacy needs. "Indigenous helping processes based on our ways of being in, experiencing and understanding the world intertwine the personal experience within community and spiritual interactions...people do not make personal journeys in isolation” (Hart M. A., 2014, p. 77). This speaks to the need for program assessments and evaluation rubrics to reflect this very unique approach to classroom/lab learning.

Rybak and Decker-Fitts (2009) report that "wellness from a Native American perspective considers the communal context for individuals as well as they seek a balance of mental, spiritual, and physical aspects of living. The inclusion of the non-material as essential in the healing process distinguishes Native American medicines from western medicine...this view focuses in on the type of 
energies that exist in the relationships between people, their spiritual connections, and their connections with the earth...[and] includes a sense that each and every part of the cosmos is imbued with spirit, not only people, but everything including animals, rocks, rivers and so on" (Rybak \& Decker-Fitts, 2009, p. $335)$.

The elders in residence program would be helpful in facilitating such ceremony for students wishing to participate. The elder's traditional role is one of Spiritual teacher and mentor. Having these ceremonies facilitated by an elder in residence serves two purposes. 1) Students are able to participate in ceremony unguarded, cultural protocols take precedence within the spiritual practice, and 2) Faculty members are not put into client/helper positions - maintaining healthy boundaries in the student/teacher relationship.

\section{Transformative learning:}

In keeping with transformative learning, students would then have an avenue in which to situate themselves within structural and societal forces that continue their oppression and learn new skills and knowledge that would allow them praxis of program content. "Transformative learning aims at identifying these forces and freeing us from their coercive influence through reflection, dialogue,

critical, discernment, imagination and action. Adults are understood to be active, engaged participants in the learning process, co-creating or constructing what it is they are learning as they learn" (Dirkx, 1998, p. 9). Being able to situate themselves within the curriculum, students are active participants in the learning process. "Through environments that are both supportive and challenging, learners work together with each other and with the educator to construct visions that are more meaningful and holistic, that lead them to deeper engagements with themselves and the world. Through connectedness with community transformative learning leads paradoxically to a deeper sense of one's self as a person" (Dirkx, 1998, p. 10). Professional development and teacher training in transformative learning theory 
would help to guide faculty in course design, evaluative frameworks, classroom engagement/management and pedagogy. As presented throughout the research, we have all been through the same educational processes and schooled much in same in the manner. To ensure effective employment of transformative education theory, faculty and institutions need to be immersed in the principles of transformative education and structural supports to develop and implement strategies deployed.

\section{Family / Peers}

The very nature of this program forces learners to look at intergenerational trauma from both objective and subjective perspectives. In order to effectively work in this milieu, learners must be willing and supported to work through their personal issues. It is important that extensive student support mechanisms work in tandem with the program faculty, elders and support staff in the delivery of the program. Resources to address crisis intervention, access to traditional helpers and cultural supports such as ceremony are essential.

\section{Faculty supports:}

For the teaching faculty of the program, they must be supported in the work that they do. Their highly specialized training and expertise in their fields must be honoured and properly acknowledged not only through remuneration, but by having them lead institutional and departmental strategies to address the inclusion of IK within the institution. That while merely filling a position with an Aboriginal person who does not espouse to IK theory or pedagogy is counterproductive, it is important that the college and its Indigenous partners develop strategies to recruit individuals who will inevitably take lead roles in these processes. "In order to include Indigenous pedagogy into a Native studies program, it is important to balance individual, dispositions, interests, and expressions with methods of teaching and evaluation and academic and institutional needs, expectations and requirements" (Lambe, 
2003, p. 314). Their expertise in the establishment of consultative processes with community and interprofessionally, would serve the institution's mandate in making Aboriginal education a priority as identified in The Skilled Solution (Canadore College) - the college's strategic plan. Moreover, this would demonstrate the institution's confidence and esteem of their Aboriginal faculty. Dirkx suggests that the best way to lead is to lead by example. "The best teachers of transformative learning are ourselves - our own lives in community with others. If we want to learn about fostering transformation among our learners, the most important way to begin the work is with this particular, common, and sacred life one has been given. It is a simple and humble, yet incredibly profound, place to begin" (Dirkx, 1998, pp. 11-12).

Peer lead inter-departmental faculty meetings to explore how IK might be introduced into other programs and or courses would yield new knowledge and promote group think and collaboration. To do so however, the college must address cultural safety across all programs, services and departments. Aboriginal faculty teaching such courses must be supported by college policy, practice and have identified procedures to address classroom management, conflict resolution, and opportunity to debrief with peers on a regular basis.

We have heard through this research that Aboriginal faculty do not feel supported and question their cultural safety. "Cultural safety goes beyond cultural competence by analyzing power imbalances in society. In a health care context, cultural safety acknowledges the power differential inherent in the relationship between the health care provider and client and impact of privilege on health and relationships" (King \& King, 2014, p. 415). In PSE in Ontario, students wield a sense of power and have influence on institutional priorities, direction and situational responses. In the absence of clear policy and accompanying procedures, faculty expressed a sense of vulnerability. This sentiment was echoed in the research conducted by Cherubini, Niemczyk, Hodson, \& McGean (2010) regarding new 
Aboriginal teacher's perceptions in Ontario schools. "New Aboriginal teacher participants shared their feelings of vulnerability due to the fact that they did not have the same academic credentials as the majority of their mainstream teacher colleagues. They suggested that mainstream teachers did not accept them as a teacher and instead were often distinguished as an 'Indian teacher'. In many instances, this feeling of vulnerability emanated from their own experiences as students when they perceived themselves as marginalized by educators who did not recognize their cultural uniqueness" (Cherubini, Niemczyk, Hodson, \& McGean, 2010, p. 549). A recent report on First Nation, Metis and Inuit education in Ontario reported that 'there is a widespread knowledge gap in most teachers' and students' understanding of the history of Aboriginal peoples, the impact of colonialism, and the relationship between Aboriginal peoples and other Canadians" (People for Education, 2013, p. 3). To address issues of cultural safety, education equity and student success, this issue must be addressed globally.

\section{Institutional cultural safety engagement:}

Fanon describes this as a psychological inferiority complex rooted firmly within colonization. "Thus the problem of colonialism includes not only the interrelations of objective historical conditions but also human attitudes toward these conditions" (Fanon, 2008, p. 62). We also heard through key participant interviews that faculty continue to experience the expressions of colonization in their classrooms with the students they teach, the reaction and response to the curriculum and content and with their relationships with their peers and authorities. It is critical to not only the program's efficacy but to the institution that such perceived disregard for faculty and student safety is addressed.

Institutional wide cultural safety training for all college employees and governing boards, would demonstrate the college's commitment under no uncertain terms, to a safe learning environment and its commitment to Aboriginal inclusion in the institutions overall direction. Moreover, the college must make every opportunity to engage with its Indigenous faculties and other college staff including support 
staff and administrators in meaningful and participatory forums, whereby Indigenous staff are able to restructure the relationship between the college and the worldviews of Indigenous peoples. This can be achieved through the inclusion of Indigenous knowledge across college curriculum, pedagogy, service models, faculty supports, intra-professional collaboration, professional development, access and work release to attend cultural ceremony and teachings to name a few.

\section{Structural tenets and practices:}

The college can support this renewed relationship by making available learning engagement opportunities for its employees with Indigenous teachers, acknowledging the colonial history and contemporary structures that continue colonial oppression. Engaging Indigenous staff and community to develop culturally safe policies and procedures would help to ameliorate issues concerning cultural safety. Providing time for staff to actively engage in cultural protocols, ceremony and professional development at key times throughout the year would enable Indigenous employees to continue to develop personal empowerment and liberation.

\section{Community}

Indigenous Knowledge is living knowledge; it grows and evolves within living communities. To ensure relevancy and currency within the program, the college must be engaged with the Aboriginal community. According to a recent report of First Nation, Metis and Inuit education, "the experience of belonging and respect that Aboriginal students and families have a right to expect is premised on staff attitudes and understanding, as well as the inclusion of Aboriginal experiences and perspectives in the school curriculum" (People for Education, 2013, p. 5).

\section{Recruiting Aboriginal employees:}

Colleges and universities can ensure content is appropriate and valid by working with Aboriginal communities and hiring Aboriginal researchers, curriculum writers, faculty and by having oversight 
committees of Aboriginal experts. Stonechild (2009) reported that in a review of best practices in Aboriginal post- secondary education across Canada, "that whenever Aboriginals are given control over their own programs or institutions, there have been higher rates of success in Aboriginal enrolment and graduation...enrolment and retention strategies depend upon Aboriginals exerting control over their own education. A fundamental shift in the post-secondary system would depend on the initiation of increased Aboriginal control at the institutional level" (Stonechild, 2006, p. 119).

Aboriginal teachers bring with them a unique worldview and teaching disposition that Aboriginal learners can not only identify with, but are more readily to trust and establish reciprocal relationship with. Canadore reports a total "Aboriginal student enrolment of over 350 students each year" (Canadore College). This represents more than $16 \%$ of the total enrolment at the college, a significant representation for a small to medium sized college. Recruitment and hiring of Aboriginal faculty across programs would demonstrate the college's commitment to furthering Aboriginal education. "Effectively supporting new Aboriginal teachers in their first three years of practice assist in their retention in the profession and improves Aboriginal students success in public and First Nations schools across Ontario" (Cherubini, Niemczyk, Hodson, \& McGean, 2010, p. 547).

\section{Community involvement:}

There exists currently a process whereby the broader community is able to participate in forums that influence the college's overall strategic direction and programs which is a significant departure from earlier education models directed at Aboriginal communities. "The role of Aboriginal post-secondary education has evolved from a tool of assimilation to an instrument of empowerment" (Stonechild, 2006, p. 2). These processes include the Aboriginal Circle on Education which "provides expertise and acts as a resource to Canadore College to ensure access to culturally supportive education and training. The goal of ACE is to provide quality student support services and programs with stringent guidelines 
accountable to the grassroots within Canadore College's Framework for Education and Training Relationships with Aboriginal Nations and Aboriginal students" (Canadore College) and the Program Advisory Committees as described earlier. However, there is a need for a connection to community for other reasons that seem to fall outside of the existing processes. This includes an elder's council or an Indigenous Knowledge keeper's oversight council that would advise the college and validate IK within the college. Wilson (2008) describes Western Knowledge as separating science from so called art and religion, whereas Indigenous Knowledge integrates these knowledges and recognizes the relational nature of acquiring knowledge. "One major difference between those dominant paradigms and an Indigenous paradigm is that those dominant paradigms build on the fundamental belief that knowledge is an individual entity... knowledge is something that is gained, and therefore, knowledge may be owned by an individual. An Indigenous paradigm comes from the fundamental belief that knowledge is relationship...is shared with all of creation, the cosmos, with animals, plants, the earth..." (Wilson, 2008, p. 56) and that Indigenous Knowledge is shared by the collective people, Nations and at the same time, is something that is very personal. Recognizing and honouring the rightful place of ownership, control, access and possession of IK to Indigenous partners is essential, in addition to a shared leadership position of advancing Indigenous education within the College.

\section{Program resources:}

Funding to support capital and operational expenses were cited as major challenges in

introducing ceremony and cultural space within the program. Land based activities, it was shared, would reinforce student learning and help to mitigate the personal struggles students experience when dealing with program content on intergenerational trauma. Although idealistically, a cultural space located on campus in a natural setting would best serve Indigenous based programs, the college could work in partnership with a First Nation or Aboriginal organization to establish a cultural teaching lodge. The 
capital and operational expenses could be cost shared, making the venture more affordable and would speak to the collaborative nature of such partnerships. The construction of the traditional teaching lodges, incorporated into the learning outcomes of the Indigenous based content of the program better prepares learners in the practical application of IK in their work.

\section{Community collaboration:}

Applied knowledge and skills based learning - upon graduation, students must be confident in the knowledge and they have acquired throughout the program which includes a mix of both western and Anishinabe practices including the ability to create case notes, write treatment plans, develop and deliver prevention, treatment and aftercare programs within community based settings. Ensuring the relevancy and currency of such skill sets requires community collaboration and partnerships with agencies and treatment centres. "Students should be given many different experiences with Indigenous peoples in different communities to help them understand the unique realities and diversity of each community" (King \& King, 2014, p. 419), while in the program. Program Advisory Committees are one conduit to achieving more meaningful community based partnerships. Additionally, the curriculum can allow for field practicum and visits to the field to demonstrate at a practical level how approaches are being delivered in an agency setting. King and King (2014) posit that "training should also include opportunities to interact with and even shadow traditional healers and elders. Each bring different skills and techniques, but generally they approach wellness in a wholistic manner that focuses on spiritual as well as mental and physical health. These experiences help students to understand the important role traditional healing can play. It is important that trainees develop their practice in a way that provides systemic support for traditional knowledge and Indigenous medicines in the development of individualized treatment plans" (King \& King, 2014, p. 419). 


\section{$\underline{\text { Nation }}$}

The accreditation of the program through the First Nations Wellness and Addictions Counsellors Certification Board ensures that the college is continuing to meet regulated criterion within the program curriculum with respect to mental health and addictions counselling. However, the community's concern regarding the compromised position of the Anishinabe based teaching can be addressed by the inclusion of an elder's oversight council. "Traditionally, Elders help their communities in a variety of ways; they provide cultural teachings, share knowledge of the language and of the medicines, and offer spiritual teachings and wisdom. This role is evolving. Elders are being sought for guidance and advice not only in Aboriginal communities, but by non-Aboriginal communities as well" (Manitowabi, 2014, p. 87). This council of elders would ensure that the college is also meeting its commitment to providing Indigenous based learning and provide them an active role in validating local IK and its systems within the college environment.

\section{Program review and assessments:}

Additionally, the inclusion of Indigenous assessment tools developed by Indigenous experts in educational pedagogy and Anishinabe epistemology should be an inclusive practice in the college's regular program reviews, evaluation and quality assurance processes and other fact finding assessments of the college's programs. The inclusion of such metrics, demonstrates the college's shared commitment with the Indigenous community to ensure that Indigenous programs are as academically rigorous as their mainstream counterparts, and that the proverbial bar is set high enough to rise to the challenges identified throughout this study to prepare competent Indigenous healing and wellness practitioners for a dynamic career in this field. The academic standards and pedagogical assessments should be developed in collaboration with mainstream faculty to allow for an intellectual exchange. Collaboration increases exposure to and opportunity for faculty and other staff to build relationships and 
realize expanded potential not otherwise currently being employed. It is essential, that Indigenous based programs continue to be accountable to the Indigenous community and through this mechanism, that Indigenous communities have local control to steer its continued evolution. This would include an assessment of the programs current structure, delivery modality and whether or not they work to support Indigenous empowerment. The current college process does not engage with the local Indigenous community in the systematic review of its Indigenous programs, despite the fact that the college currently lacks formal positions that identify Indigenous content expertise.

Employing Indigenous scholars to develop assessment tools to work collaboratively with the institutional research arm, acknowledges expertise within the Indigenous academy. This process also presents opportunity to build professional capacity within the institution and with its Indigenous partners through participatory action research models and in-service learning opportunities with the wider community. 


\subsection{Conclusion:}

The Indigenous Wellness and Addictions Prevention program is unique and presents great opportunities for a community college to engage with the Indigenous community on many levels. The fact that the program aspires to maintain as its core principles an Anishinabe based foundation and education, the opportunities to develop bi-cultural and collaborative teaching and learning models is exciting. Although the program, not unlike many other Indigenous based programs found throughout the province, is challenged with human and financial resources, the prospects to develop Indigenous based assessment rubrics measured against Anishinabe knowledge is transformative.

While this formative evaluation identified a rich qualitative study and raised considerations in the discourse of academic rigour, it would serve this program, as well as other Indigenous based programs' best interests, to develop standardized metrics that would establish baseline data in terms of enrolment, factors leading to attrition, and characteristics of student success as defined by students. From a recruitment perspective in attracting Indigenous academics to teach within this and other Indigenous based programs, the college must articulate the specific competencies expected of faculty. Teaching faculty within the program must be adept at bridging the knowledge gap that exists between Western paradigms to IK. Moreover, teaching faculty must be supported by the college as they lead institutional research and development in this regard.

The issues raised in this research extend beyond the individual student. It identified systemic and structural challenges that continue to influence how Indigenous programs are supported, viewed and assessed within colleges in Ontario. While this study looked solely at one community college, it can be assumed that the experience of those in other colleges in Ontario is not much different. The dearth in available literature illustrates a need for further in-depth study with regard to how program assessment 
models can better evaluate how Indigenous programs meet academic rigour and Indigenous epistemologies.

There is a need to establish clear instructional design and pedagogy with respect to Indigenous based programs. We have heard throughout this research that faculty teaching styles, delivery of content and the subjective and relational nature of IK poses many considerations with respect to elements of instructional design, evaluation and assessment and indeed participation of learners within an Indigenous based program of instruction. Currently, college faculty employed across schools of study are recruited for their content expertise in their fields. Very few are trained in instructional design or program assessment outside of their practice. Therefore, it is critical that faculty are provided training to assist them as they design their courses of instruction, develop evaluation methodologies and engage with their learners in the classroom. Given that this program is based in Anishinabe ontology, training for this faculty and other faculty of Indigenous based programs, require a specialized training and supports that assists them in defining and assessing quality, rigour and mastered proficiency of its content.

Active and meaningful engagement with the local Indigenous community is paramount. A transformative education agenda challenges institutions and its partners to think outside of the box, to move beyond the comforts of the tried and true. Breaking new trails and setting higher goals and expectations and tracking milestones against them are what will ensure the agenda continues to move forward. Gone are the days where the college situates itself as the expert. "The coming together of Aboriginal and mainstream Western ways of dealing with addiction and mental health issues is important in the healing journey of our Aboriginal communities. It is important because we need to learn about our identity in order to heal and Aboriginal approaches to healing deal with identity" (CAMH, 2014, p. XV). Indigenous based programs have much to offer. Graduates of such programs come away 
with a bi-cultural lens in which to see and practice their work. When Indigenous programs are provided the opportunity and supports they require to demonstrate rigour against Indigenous identified milestones and are welcomed in to the fold within their institutions, they can be proclaimed Ontario college programs plus. 


\section{Bibliography:}

Aboriginal Healing Foundation. (2002). Mapping the Healing Journey: The final report of a First Nation Research Project on Healing in Canadian Aboriginal Communities. Ottawa, ON: Aboriginal Healing Foundation.

Aboriginal Healing Foundation. (2003). Aboriginal People Resiliance and the Residential School Legacy. Ottawa, ON: The Aboriginnal Healing Foundation Research Series.

Antone, R. A., Hill, D. L., \& Myers, B. A. (1986). The Power Within People. Brantford, ON: HURRYPRINT.

Antone, R., \& Hill, D. (1992). Ethnostress: The Disruption of the Aboriginal Spirit. Hagarsville, ON: Tribal Soveriegnty Associates.

Anuik, J., \& Gillies, C. L. (2012). Indigenous Knowledge in Post-Secondary Educators' Practice: Nourishing the Learning Spirit. Canadian Journal of Higher Education, 42(1), 63-79.

Assembly of First Nations, National Native Addictions Partnership Foundation and Health Canada. (2011). Honouring our Strengths: A Renewed Framework to Address Substance Abuse Issues Among First Nations Peoples in Canada. Ottawa, ON: Her Majesty the Queen in Right of Canada.

Ball, J. (2004, Summer/Fall). As if Indigenous KNowledge and Communities Mattered: Transformative Education in First Nations Communities in Canada. American Indian Quarterly, 28(3/4), 454-479.

Battiste, D. M. (2012). Indigenous Knowledge: Foundations for First Nations. Retrieved September 9, 2012, from University of Saskatchewan: iPortal Indigenous Studies Portal Research Tool: http://iportal.usask.ca

Belanger, Y. D. (2010). Ways of Knowing An Introduction to Native Studies in Canada. Toronto, ON: Nelson Education Ltd.

Benton-Banai, E. (2010). The Mishomis Book, 2nd Edition. Minneapolis, MN: University Of Minnesota Press.

Blackburn, B. R., \& Williamson, R. (2013, March/April). 4 Steps to Increasing Rigour in the Classroom. Leadership, pp. 8-9.

Bojuwoye, O., \& Sodi, T. (2010). Challenges and opportunities to integrating traditional healing into counselling and psychotherapy. Counselling Psychology Quarterly, 23(No. 3), 283-296.

CAMH. (2014). Journey to Healing Aboriginal Peoples with Adiction and Mental Health Issues. (P. Menzies, \& L. F. Lavallee, Eds.) Toronto.

Canada, P. H. (n.d.). Canadian Best Practices Portal. Retrieved 06 07, 2014, from Government of Canada: http://cbpp-pcpe.phac-aspc.gc.ca/public-health-topics/social-determinants-of-health/

Canadian Council of Provincial Child and Youth Advocates. (2010). Position Paper: Aboriginal Children and Youth in Canada: Canada Must Do Better. Retrieved 06 24, 2014, from New Brunswick, Canada: http://www.gnb.ca/0073/PDF/positionpaper-e.pdf 
Canadore Colege. (2014). Indigenous Wellness and Addictions Prevention. Retrieved 06 01, 2014, from Canadore College: http://www.canadorecollege.ca/programs-courses/indigenous-wellness-and-addictionsprevention

Canadore College. (1999). IWAP Program Proposal. North Bay, ON: Unpublished.

Canadore College. (2001). AETS Program Proposal. North Bay, ON: Unpublished.

Canadore College. (2012). Indigenous Wellness \& Addictions Prevention Program. North Bay: Canadore College.Unpublished

Canadore College. (2014). Indigenous Wellness and Addictions Prevention Program. Retrieved 06 24, 2014, from Canadore College: http://www.canadorecollege.ca/programs-courses/indigenous-wellness-and-addictionsprevention

Canadore College. (2014). Program Review Policy. Retrieved 07 11, 2014, from Canadore College: http://www.canadorecollege.ca/sites/default/files/images/Policies\%20and\%20Procedures/A19Program\%20Review\%20Policy-14.pdf

Canadore College. (n.d.). First Peoples' Centre. Retrieved 06 27, 2014, from Canadore College : http://www.canadorecollege.ca/FPC

Canadore College. (n.d.). The Skilled Solution. Retrieved 06 26, 2014, from Canadore College: http://www.canadorecollege.ca/sites/default/files/images/Downloads/canadore\%20skilled\%20solution\%2 02017.pdf

Cherubini, L., Niemczyk, E., Hodson, J., \& McGean, S. (2010, October). A grounded theory of new Aboriginal teachers' perceptions: the cultural attributions of Medicine Wheel Teachings. Teachers and Teaching: theory and practice, 16(5), 545-557.

Chiefs of Ontario. (2013). Retrieved September 5, 2013, from Chiefs of Ontario: http://www.chiefs-ofontario.org/landing-page/education

Chilisa, B. (2012). Indigenous Research Methodologies. Los Angelas: SAGE Publications Inc.

Colleges Ontario. (2008). Improving College System Pathways. Toronto, ON: Colleges Ontario.

Colleges Ontario. (2013). Aboriginal Studies Programs in Ontario. Retrieved September 29, 2013, from Ontario Colleges: http://www.ontariocolleges.ca

Coyhis, D., \& Simonelli, R. (2008). The Native American Healing Experience. Substance Use \& Misuse, 19271949.

Dirkx, J. M. (1998). Transformative Learning Theory in the Practice of Adult Education: An Overview. PAACE Journal of Lifelong Learning, Vol. 7, 1-14.

Fanon, F. (2008). Black Skin White Mask. London: Get Political London: Pluto. 
First Nations Wellness/Addictions Counsellors Certification Board. (n.d.). First Nations Wellness/Addictions Counsellors Certification Board. Retrieved 06 01, 2014, from http://fnwaccb.ca/certification/

Great Schools Partnership. (2014). Forthcoming Terms. Retrieved 07 04, 2014, from The Glossary of Education Reform: http://edglossary.org/rigour/

Haig-Brown, C., Hodgson-Smith, K. L., Regnier, R., \& Archibald, J.-A. (1997). Making the Spirit Dance Within Joe Duquette High School and an Aboriginal Community. Toronto: James Lorimer and Company Ltd.

Hart, M. A. (1999). Seeking Mino-pimatasiwin (the Good Life): An Aboriginal Approach to Social Work Practice. Native Social Work Journal, 91-112.

Hart, M. A. (2002). Seeking Mino-Pimitaisiwin. Winnipeg : Fernwood Publishing.

Hart, M. A. (2010). Indigenous Worldviews, Knowledge, and Research: The Development of an Indigenous Research Paradigm. Journal of Indigenous Voices in Social Work, 1-16.

Hart, M. A. (2014). Indigenous Ways of Helping, P. Menzies, \& L. F. Lavallee (Eds.), Journey to Healing Aboriginal People with Addictions and Mental Health Issues (pp. 73-86). Toronto: CAMH Publications.

Health Canada. (1998). National Native Alcohol and Drug Abuse Program General Review 1998. Retrieved 06 25, 2014, from Health Canada: http://www.hc-sc.gc.ca/fniah-spnia/pubs/substan/_ads/1998_rpt-nnadappnlaada/index-eng.php\#a3_3_5_1

Health Canada. (n.d.). National Native Alcohol and Drug Awareness Program. Retrieved 03 15, 2014, from Health Canada: http://www.hc-sc.gc.ca/fniah-spnia/substan/ads/nnadap-pnlaada-eng.php

Jacobs, J., \& Colvin, R. L. (June 2009). Rigour: its all the rage but what does it mean? Understanding and Reporting on Academic Rigour: A Hichenger Institute Primer for Journalists, 1-5.

King, A., \& King, M. (2014). Improving the Health of Indigenous People through Health Practitioner Training. In CAMH, P. Menzies, \& L. F. Lavallee (Eds.), Journey to Healing Aboriginal People with Addiction and Mental Health Issues (pp. 413-424). Toronto: CAMH.

Kovach, M. (2012). Indigenous Methodologies. Toronto: University of Toronto Press Inc 2009.

Lambe, J. (2003, Winter/Spring 2003). Indigenous Education, Mainstream Education and Native Studies Some Considerations When Incorporating Indigenous Pegagogy into Native Studies. American Indian Quarterly, 27(1 \& 2), 308-324.

Laurentian University. (n.d.). Academic Programs Naive Human Services. Retrieved October 1, 2013, from Laurentian University: http://www.laurentian.ca/content/program/native-human-services/overview

Lavallee, L. F. (2009). Practical Application of an Indigenous Research Framework and Two Qualitative Indigenous Research Methods: Sharing Circles and Anishinaabe Symbol-Based Reflection. International Journal of Qualitaive Methods, Pp. 21-40.

Macdonald, R. (2006, February ). The use of evaluation to improve practice in learning and teaching. Innovations in Education \& Teaching International, 43(1), 3-13. 
Manitowabi, S. (2014). The Role of Elders in the Community. In P. Menzies, \& L. F. Lavallee (Eds.), Journey to Healing Aboriginal People with Mental Health and Addictions Issues (pp. 87-100). Toronto: CAMH.

Marlow, C. R., \& Boone, S. (2005). Research Methods for Generalist Social Work. Belmont, CA: Brooks/Cole.

Mendelson, M. (2006). Aboriginal Peoples and Postsecondary Education in Canada. Ottawa, ON: Caledon Institute of Public Policy.

Ministry of Training, Colleges and Universities. (n.d.). Ministry of Training, Colleges and Universities. Retrieved September 28, 2013, from http://www.tcu.gov.on.ca/pepg/publications/GovAccount_Directive2010.pdf

Nabigon, H., \& Mawhiney, A. (n.d.). Aboriginal Theory A Cree Medicine Wheel Guide for Healing First Nations.

National Aboriginal Health Association. (2014). NAHO Publications. Retrieved 06 07, 2014, from National Aboriginal Health Organization (NAHO):

http://www.naho.ca/documents/naho/publications/determinants.pdf

Oldford, S., \& Ungerleider, C. (2010). Aboriginal Self-Identification and Student Data in Ontario's

Postsecondary System: Challenges and Opportunities. Toronto: Higher Education Quality Council of Ontario.

People for Education. (2013). First Nation, Metis and Inuit Education: Overcoming gaps in provincially funded schools. Toronto, ON: People for Education.

Popovic, T. (2012). First Nation, Metis, Inuit Students in Ontarios Post Secondary Education System Policy Paper. Toronto, ON: College Student Alliance.

R.A. Malatest \& Associates Ltd. (2004). Aboriginal Peoples and Post-Secondary Education What Educators Have Learned. Montreal, QC: Canada Millenium Scholarship Foundation.

Reading, C. L., \& Wien, F. (2009). Health Inequalities and Social Determinants of Aboriginal Peoples' Health. Prince George, B.C.: National Collaborating Centre for Aboriginal Health .

Regan, P. (2005, January 20). University of Victoria Research. Retrieved October 1, 2013, from University of Victoria:

http://web.uvic.ca/igov/research/pdfs/A\%20Transformative\%20Framework\%20for\%20Decolonizing\%20 Canada.pdf

Rybak, C., \& Decker-Fitts, A. (2009, September). Theory and Practice Understanding Native American Healing Practices. Counselling Psychology Quarterly, 22(3), 333-342.

Simpson, L. R. (2004, Summer/Fall). Anticolonial Strategies for the Recovery and Maintenance of Indigenous Knowledge. American Indian Quarterly, $28(3$ \& 4), 373-384.

Statistics Canada. (2013, 11 25). The Education and Employment Experiences of First Nations People Living Off Reserve, Inuit, and Métis: Selected Findings from the 2012 Aboriginal Peoples Survey. Retrieved 07 16, 2014, from Government of Canada: http://www.statcan.gc.ca/pub/89-653-x/89-653-x2013001-eng.htm 
Stonechild, B. (2006). The New Buffalo: The Struggle for Aboriginal Post-Secondary Education in Canada. Winnipeg, MN: University of Manitoba Press.

Truth and Reconciliation Commission of Canada. (n.d.). Truth and Reconciliation of Canada: For the child taken and the parent left behind. Retrieved 10 01, 2013, from Truth and Reconciliation Commission of Canada: http://www.trc.ca

Verwood, R., Mitchell, A., \& Machado, J. (2011). Supporting Indigenous Students through a Culturally Relevant Assessment Model Based on the Medicine Wheel. Canadian Journal of Native Education, 34(1), 49-66.

Wabano, M. (2012). Indigenous Wellness and Addictions Program Review. North Bay, ON: Unpublished.

Weissman, J., Bulakowski, C., \& Jumisko, M. K. (1997). Using Research to Evaluate Developmental Education Programs and Policies. New Directions for Community Colleges, 1997(100), 73-80.

Wilfred Laurier University. (n.d.). MSW Field of Study . Retrieved October 1, 2013, from Wilfred Laurier University: http://www.wlu.ca

Wilson, S. (2008). Research is Ceremony. Winnipeg: Fernwood Publishing. 


\section{List of Appendices:}

Appendix 1: Medicine Wheel as a Framework

Appendix 2: Self, Family, Community, Nation

Appendix 3: Salient Themes on the Medicine Wheel

Appendix 4: Interview Protocol for Sharing Circle

Appendix 5: Interview Protocol for key Participants Interviews 
Appendix 1: Medicine Wheel as a Framework

Medicine Wheel as Framework

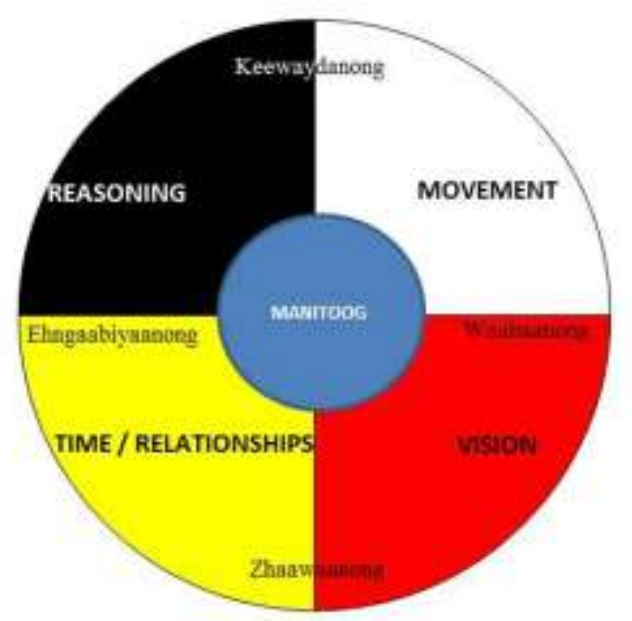


Appendix 2: Self, Family, Community, Nation

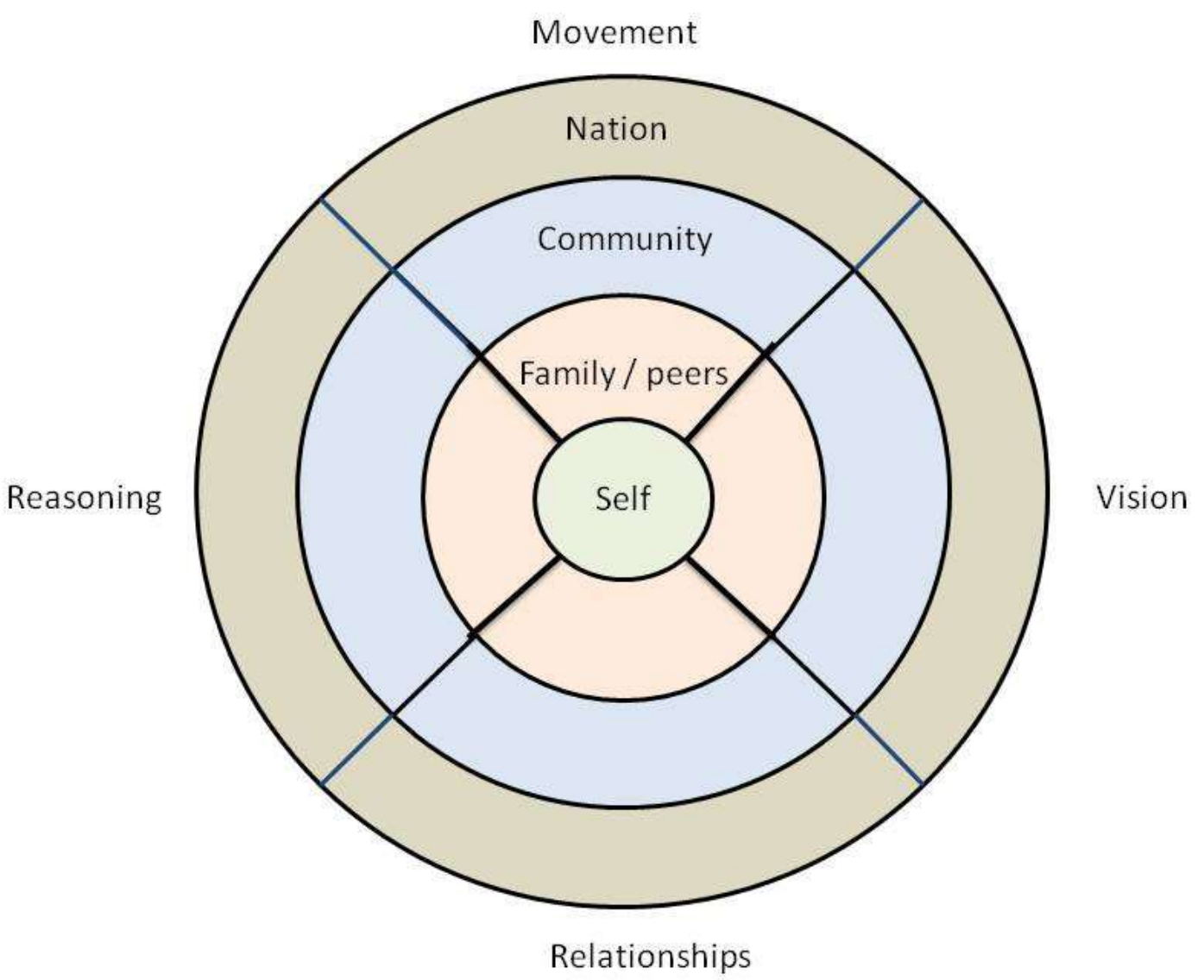




\section{Salient Themes on Medicine Wheel Framework}

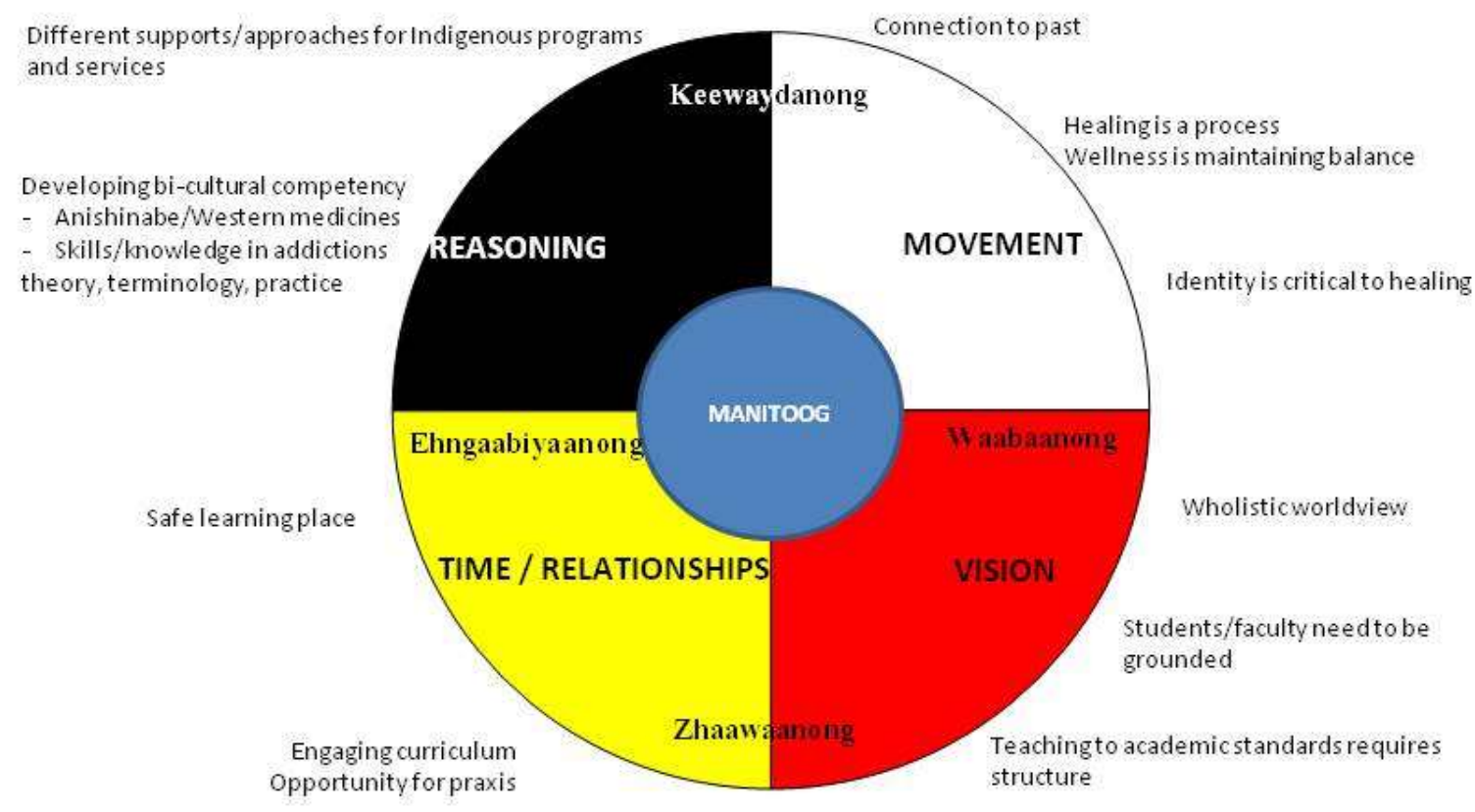




\section{Appendix 4: Interview Protocol for Sharing Circle PAST AND CURRENT IWAP STUDENTS}

\section{Opening Statement:}

This Sharing Circle is being held with past and current students of the Indigenous Wellness and Addictions Prevention program at Canadore College. The purpose of this Sharing Circle is to help inform a research project being undertaken by myself, Mary Wabano the primary investigator, for the evaluation of the Indigenous Wellness and Addictions Prevention program at Canadore College. This research project will also fulfill the requirements of the Masters of Social Work program at Carleton University where I am a full time student. The researcher is committed to and is bound by sound research ethics to ensure your safety throughout this study. The First Peoples' Centre has Counselors and an Elder in Residence available to meet with you individually during or following the focus group sessions should you deem you require support, this includes any referrals to other services in the community.

\section{Key Research Question:}

How can the Indigenous Wellness and Addictions Prevention program best provide an academically rigorous program rooted in Anishinabe knowledge and teaching?

\section{Sharing Circle Questions:}

- What is your understanding of healing? How would you describe wellness?

- How will or has this program prepared you to work within Indigenous healing and wellness models?

- How can Indigenous based programs maintain their Indigenous foundations while meeting academic standards?

- What are some challenges you see in having an Indigenous based program in a community college like Canadore? (Policy considerations, funding challenges, operational considerations, program design, and faculty recruitment/retention).

- How would you improve this program? 


\section{Appendix 5: Interview Protocol for Key Participants Interview}

\section{IWAP PROGRAM ADVISORY COMMITTEE MEMBERS, FACULTY, ADMINISTRATORS AND ABORGINAL PROGAM PERSONNEL}

\section{Opening Statement:}

Key Participants interviews are being held with individuals who work within Ontario colleges/universities at various capacities, it also includes members of the IWAP program advisory committee. The purpose of the key Participants interviews is to help inform a research project being undertaken by myself, Mary Wabano the primary investigator, for the qualitative evaluation of the Indigenous Wellness and Addictions Prevention program at Canadore College. This research project will also fulfill the requirements of the Masters of Social Work program at Carleton University where I am a full time student.

The primary focus of this research is to assess how the Indigenous Wellness and Addictions Prevention program can prepare graduates in addictions services while maintaining its Indigenous foundation and meeting rigorous academic standards. The Indigenous Wellness and Addictions Prevention program is a culture based 2 year college diploma program which provides training to participants who wish to acquire the knowledge and skills to work with both Aboriginal and non-Aboriginal clients within a cultural paradigm.

\section{Key Research Question:}

How can the Indigenous Wellness and Addictions Prevention program best provide an academically rigorous program rooted in Anishinabe knowledge and teaching?

\section{Key Participants interview questions:}

1. What is your understanding of healing? How would you describe wellness?

2. From that basis, describe how colleges and/or universities can prepare its graduates for work in this field?

3. Institutions of higher learning have some rigid academic standards, in your opinion, describe how Indigenous based programs can maintain their Indigenous foundations while meeting these academic standards?

4. What are some challenges you see in having an Indigenous based program in a community college like Canadore? You can include policy considerations, funding challenges, operational considerations, program design, and faculty recruitment/retention.

5. There are always ways in which to improve curriculum, reposition standards, overall program quality and ultimately student success, how would you improve this program or Indigenous programs in general to address either one or all of those areas?

6. Is there anything else that you would like to add to our conversation?

Miigwetch for your honesty, time and commitment to Indigenous education. 


\section{Glossary of Terms:}

Aboriginal - the descendants of the original inhabitants of North America. The Canadian Constitution recognizes three groups of Aboriginal people (Indians, Metis and Inuit). These are three separate peoples with unique heritages, languages, cultural practices and spiritual beliefs.

Anishinabe, Anishinabeg, Anishinabek - an Ojibwe translation to refer to the original people of the Americas otherwise known as Turtle Island

Assemma (traditional tobacco), is the first sacred medicine of the Anishinabeg. Assemma is offered to the Spirit when asking for something (help, guidance, etc.,). Between individuals, the gift of tobacco has responsibility to what is being asked and a responsibility to respond to the request, there is a reciprocal responsibility to the gift of tobacco.

Buhn (suffix) acknowledges the passing from the physical world to the spiritual world (passing on)

Circle (Sharing Circle, Healing Circle) - individuals gather, sit in a circle, usually facilitated by one individual; it is opened with prayer and smudge to center all participants in a good way; each individual in the circle has an opportunity to speak uninterrupted when the talking stick or feather is received by them. When the talking stick / feather is moving, all attention is paid to the individual holding the talking stick / feather. In circle, there is no beginning/end, everyone is at the same level, is equal.

Eagle Fan - a sacred item belonging to a person's sacred bundle, used in healing ceremonies, it represents connection to the Spirit, truth, humility, respect, bravery, honesty and love.

Engaagiyanong - refers to the western direction where we exit this physical realm.

FNMI (acronym) used to refer to First Nation, Metis, and Inuit people

Keewaydinong - refers to the northern direction

Indian(s) - persons identified under the Indian Act defines eligibility for Indian Status (i.e. Registered Indians) the Indian register is the official record identifying all Status Indians in Canada (https://www.aadnc-aandc.gc.ca/DAM/DAM-INTER-HQ/STAGING/textetext/br_is_eligb_1315710514986_eng.pdf

Native - with capital "N" refers to the original inhabitants, used interchangeably throughout document with Aboriginal, Indigenous, Anishinabe, First Peoples'

Manitoog - the Spirits

Mino-Bmaadziwin - Good life

Smudge - with the use of burning traditional medicines the smoke from the medicines is used to clear our mind, body and spirit to make way for good medicine to come, to gather our self in a good way (medicines include sage, cedar, and sweetgrass).

Spirit - refers to other than human beings, a higher power, Creator

Waabaanong - refers to the eastern direction where the sun rises and life begins 
Wholistic - refers to the whole, a whole item or whole body of a person or thing. The word defines the consideration of the entire structure or makeup, which includes the body, mind and the spirit in the case of a human being

Zhaawaanong - refers to the southern direction 